\title{
Medidas de óxido nítrico no ar exalado de pacientes com história prévia de broncoespasmo no período intra- operatório
}

Tese apresentada à Faculdade de Medicina da Universidade de São Paulo para obtenção do título de Doutor em Ciências.

Área de concentração: Fisiopatologia Experimental

Orientador: Dr. Joaquim Edson Vieira Co-orientador: Dr Fábio Machado Santana 


\section{Medidas de óxido nítrico no ar exalado de pacientes com história prévia de broncoespasmo no período intra- operatório}

Tese apresentada à Faculdade de Medicina da Universidade de São Paulo para obtenção do título de Doutor em Ciências.

Área de concentração: Fisiopatologia Experimental

Orientador: Dr. Joaquim Edson Vieira Co-orientador: Dr Fábio Machado Santana

São Paulo

2008 
FICHA CATALOGRÁFICA NO VERSO DA PG DE ROSTO 
Dedicatória 


\section{DEDICATÓRIA}

Ao meu esposo, amado e amigo Maurício Romanholo por ter me dado força, nesta grande realização e por agüentar pacientemente meus momentos de

estresse.

A minha mãe Maria do Socorro, aos meus avós, João e Francisca (in memorian), exemplos de dedicação, caráter, dignidade e honestidade.

Aos meus irmãos, José e Cristovam pelos seus exemplos de vida.

Aos meus sobrinhos Felipe e Luiza sensação de continuidade.

Ao pequenino que vem vindo, meu filho Pedro. 
Agradecimentos 


\section{AGRADECIMENTOS}

Agradeço a Deus, que tornou possível todas estas coisas.

Joaquim Edson Vieira

Professor no sentido mais literal desta palavra, que consegue ao mesmo tempo ser orientador e amigo, paciente com minhas dificuldades e com competência e coerência suficientes para me mostrar os caminhos a seguir nesta tarefa de fazer pesquisa.

Fabio Machado Santana

Co-orientador, minha admiração e gratidão são palavras pequenas para demonstrar a importância da sua participação na minha vida profissional.

Mílton de Arruda Martins

Exemplo de profissional a ser seguido e respeitado. Conviver e trabalhar ao seu lado nos faz mais seguros como pesquisadores e como pessoas. Ensinanos que, mais importante que falar é imprescindível que saibamos escutar.

Maria do Patrocínio Tenório Nunes

Minha amiga e chefe que sempre acreditou em mim, por ter me ajudado a entrar no "mundo da pesquisa". 


\section{Maria Lúcia Bueno Garcia}

Amiga que esteve sempre disposta a esclarecer minhas dúvidas e responder meus questionamentos.

Francine Maria de Almeida e Silvia Maria Albani

Amigas que com tamanha amabilidade e dedicação muito ajudaram fazer deste projeto uma realidade, superaram todas as minhas expectativas.

Iolanda de Fátima Lopes Calvo Tibério

Sua atenção e carinho foram e são essenciais na minha caminhada.

Adriana Salles Leme, Carla M. Prado, Cristina Helena F. Fonseca Guedes, Deborah de Camargo Hizume, Edna Ap. Leick Maldonado, Fernanda Deggobi Tenório Quirino dos Santos Lopes, Fernanda Magalhães Arantes Costa, Rodolfo de Paula Vieira e Serafim Fidalgo.

Amigos e companheiros de pesquisa, que além do carinho, estiveram sempre dispostos a esclarecer minhas dúvidas e contornar minhas dificuldades.

Adenir Perini, Adriana Pires, Dolores Helena Rivero, Eliane Tigre Heloisa Bueno, Jôse Mara Brito, Mariângela Macchione e Miriam Lemos, Regiani Carvalho de Oliveira e Rogério Pazetti.

Que bom poder contar com a amizade de vocês, sempre! É este carinho que me faz ter a certeza que tudo aquilo que construímos, não conseguimos sozinhos. 
Rosana Aparcida R. da Paz

Sempre me ajudando com questões administrativas.

\section{Maria Rivani Cavalcante}

Amiga fiel e dedicada, que com paciência e disposição inabaláveis conseguiu sempre uma palavra de consolo e um gesto de carinho para aplacar meu cansaço.

Ao Corpo Administrativo da Clínica Geral e Enfermagem do AGD

À retaguarda sempre fiel e solícita, meus sinceros agradecimentos. $\mathrm{O}$ apoio que recebi de todos estes profissionais foi decisivo no meu dia a dia.

Aos Colegas do Laboratório de Poluição Atmosférica (LIM 05)

Amigos e companheiros, que no decorrer deste período só fizeram aumentar minha convicção de que sem a amizade tudo o que conseguimos se torna pequeno e sem sentido.

Aos Pacientes

Meu muito obrigada. 
Epígrafe 


\section{A VERDADEIRA FELICIDADE}

Felizes são aqueles que não se não se deixam levar pelos conselhos dos maus, que não seguem o exemplo dos que não querem saber de Deus e que não se juntam com os que zombam de tudo o que é sagrado!

Pelo contrário, o prazer deles está na lei do Senhor, e nessa lei eles meditam dia e noite.

Essas pessoas são como árvores que crescem na beira de um riacho; elas dão frutas no tempo certo, e as suas folhas não murcham.

Assim também tudo o que essas pessoas fazem dá certo.

Pois o senhor dirige a abençoa a vida daqueles que lhe obedecem... (Salmos 1:1-3, 6) 
Esta dissertação está de acordo com:

Referências: adaptado de International Committee of Medical Journals Editors (Vancouver)

Universidade de São Paulo. Faculdade de Medicina. Serviço de Biblioteca e Documentação. Guia de apresentação de dissertações, teses e monografias. Elaborado por Anneliese Carneiro da Cunha, Maria Julia de A. L. Freddi, Maria F. Crestana, Marinalva de Souza Aragão, Suely Campos Cardoso, Valéria Vilhena. São Paulo: Serviço de Biblioteca e Documentação; 2005.

Abreviaturas dos títulos dos periódicos de acordo com List of Journals Indexed in Index Medicus. 


\title{
SUMÁRIO
}

\author{
LISTA DE FIGURAS \\ LISTA DE TABELAS \\ RESUMO \\ SUMMARY
}

$\begin{array}{ll}\text { 1. INTRODUÇÃO } & \text { Página } 1\end{array}$

1.1. Complicações Pulmonares no Perioperatório Página 2

1.1.1. Epidemiologia Página 2

1.1.2. Implicações do Procedimento Cirúrgico na Fisiologia Página 3 Pulmonar

1.2. Fatores de Risco Associados à Complicações Pulmonares Página 4 Perioperatórias

1.2.1. Fatores de Risco Clínico Relacionados ao Paciente Página 4

1.2.2. Fatores de Risco Relacionados ao Procedimento Página 8 Cirúrgico

1.3. Boncoespasmo no Perioperatório Página 9

1.3.1. Aspectos Epidemiológicos Página 9

1.3.2. Fatores Desencadeantes de Broncoespasmo Página 10

1.3.3. Fisiopatologia do Broncoespasmo Página 12

1.3.4. Diagnóstico e Tratamento do BCE Página 14

1.4. Óxido Nítrico (NO) Página 19 
4. RESULTADOS

6. CONCLUSÕES

\section{APÊNDICE}




\section{LISTA DE FIGURAS}

Figura 1 Volumes e Capacidades Pulmonares da Espirometria

Figura 2. Esquema Simplificado do Metabolismo da L-Arginina

Figura 3 Resumo do Protocolo em Estudo

Figura 4. Coleta de Óxido Nítrico no Ar Exalado

Figura 5 Aparelho para Registro de Óxido Nítrico

Figura 6 Espirômetro KOKO

Figura 7. Capacidade Vital Forçada Pré Broncodilatador

Figura 8 Capacidade Vital Forçada Pós Broncodilatador

Figura 9. Volume Expiratório Forçado no Primeiro Segundo

Pré Broncodilatador

Figura 10. Volume Expiratório Forçado no Primeiro Segundo

Pós Broncodilatador

Figura 11 Razão da Porcentagem do Volume Expiratório Forçado

e a Capacidade Vital Forçada em Relação ao Predito

Figura 12 Razão da Porcentagem do Volume Expiratório Forçado

e a Capacidade Vital Forçada Medida Pós Broncodilatador

Figura 13 Fluxo Expiratório Forçado Pré Broncodilatador

Figura 14. Fluxo Expiratório Forçado Medido Pós Broncodilatador

Figura 15 Porcentagem de Eosinófilos
Página 57

Página 16

Página 21

Página 36

Página 40

Página 40

Página 41

Página 51

Página 52

Página 53

Página 54

Página 55

Página 56

Página 58

Página 59 
Figura 16. Porcentagem de Neutrófilos

Página 60

Figura 17 Porcentagem de Linfócitos

Página 61

Figura 18 Porcentagem de Macrófagos

Página 62

Figura 19 Dosagem de Imunoglobulina E Sérica Total

Página 63

Figura 20. Óxido Nítrico no Ar Exalado

Página 64 


\section{LISTA DE TABELAS}

Tabela 1 Critérios para Aceitação dos Indivíduos no Estudo

Tabela 2 Características dos Pacientes

Tabela 3 Critérios para Aceitação da Amostra

Tabela 4 Dados Espirométricos dos Pacientes

Tabela 5 Marcadores Inflamatórios

Tabela 6 Prick Test
Página 34

Página 37

Página 43

Página 65

Página 66

Página 67 
Resumo 
Saraiva-Romanholo, BM. Medidas de óxido nítrico no ar exalado de pacientes com história prévia de broncoespasmo no período intraoperatório [Tese]. São Paulo: Faculdade de Medicina, Universidade de São Paulo; 2007.

INTRODUÇÃO: Pacientes com vias aéres hiperresponsivas têm uma resposta exarcebada das vias aéreas a vários estímulos. Nestes pacientes, a simples intubação é a causa mais freqüente do broncoespasmo, levando a complicações no peri-operatório. O óxido nítrico está envolvido na regulação da função fisiológica bem como em doenças das vias aéreas e nos últimos anos seu papel vem sendo constantemente estudado na modulação da broncoconstrição. OBJETIVO: Estudar a possibilidade da medida de óxido nítrico exalado (NOex) ser um marcador de episódios de broncoespasmo no intra-operatório. MÉTODOS: 146.358 fichas anestésicas foram analisadas no período de 1999/2004. Ocorreram registros de broncoespasmos em 863 pacientes neste período. Destas, nove sujeitos foram identificados como não asmáticos (grupo broncoespasmo), 12 sujeitos foram diagnosticados como asmáticos (grupo asma) e 10 indivíduos sem história prévia de doença foram selecionados aleatoriamente como grupo controle. Todos os sujeitos foram submetidos à medida de óxido nítrico exalado (partes/bilhão), espirometria e coleta de escarro induzido com salina hipertônica. Os dados foram comparados utilizando ANOVA seguido do teste de Tukey e Kruskal-Wallis seguido do teste de Dunn's. 
RESULTADOS: Os grupos broncoespasmo e controle apresentaram espirometria normal, com medidas estatísticamente diferentes do grupo asma ( $p<0,05)$. As porcentagens de eosinófilos (mediana) no escarro induzido foram maiores no grupo asma [2,5 $(0,4-6,8)]$, menores no grupo broncoespasmo [0,5 (0-1,3), e grupo controle [0,0 (0)]. A medida de óxido nítrico exalado foi maior no grupo dos asmáticos $[81,5 \quad(57,6-86,8)]$ em relação aos controles $[18,7(16,0-24,7)](p=0,001)$. Não houve diferença entre grupos broncoespasmo e asma, ambos significantemente diferentes do grupo controle $(p<0,05)$. CONCLUSÃO: Pacientes não asmáticos que apresentaram broncoespasmo no intra-operatório durante a anestesia e manipulação da traquéia, possuem níveis de óxido nítrico no ar expirado exalado elevado.

Descritores: óxido nítrico, espasmo brônquio, anestesia, escarro/citologia, asma. 
Summary 
Saraiva-Romanholo, BM. Exhaled nitric oxide measure from patients with previous history of intraoperative bronchospasm. [thesis]. São Paulo: School of Medicine, University of São Paulo; 2007.

INTRODUCTION: Airways of patients with bronchial hyperreactivity are characterized by exaggerated bronchoconstriction in response to a variety of stimuli. Henceforth, bronchospasm may occur during induction of anaesthesia. Nitric Oxide is part of either physiologic or pathophysiologic airway regulation and its role has been investigated as a bronchoconstrictior modulator. OBJECTIVE: to address the possibility of exhaled nitric oxide measurement (NOex) as a marker of intraoperative bronchospasm. METHODS: 146.358 anesthesia registered forms were revised (period: 1999/2004). Bronchospasm occurrence appeared registered in 863. From those, nine were identified as non-asthmatics patients (Bronchospasm group). Also, 12 asthmatics constituted one additional group (Asthma group) and 10 subjects with no previous airway disease or symptoms were randomly selected as control group. All subjects were submitted to exhaled nitric oxide measurements (parts/billion), spirometry and induced sputum. The data were compared by ANOVA followed by the Tukey test and KruskalWallis followed by Dunn's test. RESULTS: Both bronchospasm and control groups had normal lung function test, different from asthma group $(p<0.05)$. The percentage of eosinophils (median) in induced sputum was higher for asthma [2.5 (0.4-6.8)] lower for bronchospasm [0.5 (0-1.3)] and control group [0.0 (0)]. Exhaled Nitric Oxide was higher for asthmatic patients [81.5 (57.6- 
86.8)], compared to control group [18.7 (16.0-24.7)] $(p=0.001)$. There was no difference between bronchospasm and asthma groups both different from control $(p<0.05)$. CONCLUSION: non-asthmatics patients with intraoperative bronchospasm detected during anesthesia after airway manipulation showed higher nitric oxide expired levels.

Descriptors: nitric oxide, bronchial spasm, anesthesia, sputum/cytology, asthma. 
1-Introducão 


\subsection{COMPLICAÇÕES PULMONARES NO PERIOPERATÓRIO}

\subsubsection{EPIDEMIOLOGIA}

As complicações perioperatórias pulmonares são parte importante da avaliação do risco cirúrgico, sendo estas complicações tão ou mais freqüentes que as complicações cardíacas (Lawrence et al., 1995).

As cirurgias torácicas e abdominais altas estão associadas a alterações da função pulmonar no período pós-operatório, o que aumenta a incidência de complicações pulmonares (CPP) neste período (Chiavegato et al., 2000). A incidência de CPP nas cirurgias abdominais altas varia de 5 a 80\%. (Williams-Russo et al., 1992; Pereira et al., 1999; Kanat et al., 2007). Além disso, estas complicações são responsáveis por aumento no tempo de internação hospitalar em média de uma a duas semanas (Lawrence et al., 1996).

Neste interim, deve-se ter em mente a potencial morbimortalidade destas complicações, que pode chegar a 50\% (Kroenke et al., 1992; Smetana, 1999).

A verdadeira incidência e a verdadeira morbimortalidade das complicações pulmonares perioperatórias são de difícil identificação. 
Enquanto os profissionais envolvidos na avaliação do risco cirúrgico podem usufruir de longas e extensivas pesquisas no campo da avaliação do risco de complicações cardiovasculares, a disponibilidade de dados no campo da avaliação do risco de complicações pulmonares é muito limitada. Isto se deve ao fato de que as complicações cardíacas têm sido mais rigorosamente e extensivamente estudadas se comparadas com as complicações pulmonares. Além disso, estas últimas têm sido estudadas freqüentemente em estudos retrospectivos, usando apenas análises univariadas, com muitas falhas metodológicas. A falta de uniformidade na definição de complicação perioperatória pulmonar é outro grande obstáculo, devido à grande variedade (Bluman et al., 1998; Warner, 2000).

Os estudos mais recentes tendem a usar como definição de complicações pulmonares perioperatórias pneumonia, falência respiratória com necessidade de ventilação mecânica prolongada, broncoespasmo, atelectasias e exacerbação de doença pulmonar de base, complicações essas que provavelmente terão implicação na morbimortalidade e no tempo de permanência hospitalar (Lawrence et al., 1996; Warner, 2000).

\subsubsection{IMPLICAÇÕES DO PROCEDIMENTO CIRÚRGICO NA}

\section{FISIOLOGIA PULMONAR}

As alterações na fisiologia pulmonar durante o ato cirúrgico ocorrem em todos os pacientes e são devidas: 
- Ao ato cirúrgico propriamente dito,

- À anestesia,

- Ao uso de bandagens compressivas,

- Medicações pós-operatórias,

- Imobilização na posição supina.

Esses fatores contribuem para alterações nos volumes pulmonares, troca gasosa e nos mecanismos de defesa pulmonar (Tisi, 1979; Bacuzzi et al., 2004).

\subsection{FATORES DE RISCO ASSOCIADOS À COMPLICAÇÕES PULMONARES PERIOPERATÓRIAS}

1.2.1. FATORES DE RISCO CLÍNICO RELACIONADOS AO

\section{PACIENTE}

\section{Tabagismo}

O tabagismo é um fator de risco para complicações pulmonares pósoperatórias, aumentando o risco inclusive naqueles pacientes já portadores de doença pulmonar crônica. O tabagismo causa um aumento na secreção traqueobrônquica, alteração no epitélio brônquico e diminuição da atividade 
mucociliar. Além disso, o tabagismo está associado a uma diminuição da fagocitose e da atividade bactericida dos macrófagos pulmonares (Bluman et al.,1998; Kotani et al., 2000).

Estudos prospectivos mostraram um aumento de complicações pulmonares em pacientes tabagistas submetidos a revascularização miocárdica, com relação aos não tabagistas, além de demonstrarem que pacientes que deixaram de fumar até 8 semanas antes do procedimento não possuíam diminuição na incidência de complicações. O grupo que deixou o tabagismo menos de 8 semanas antes do procedimento, teve mais complicações pulmonares que os pacientes que não cessaram o tabagismo. Já o grupo de pacientes que cessaram o fumo 6 meses antes do procedimento cirúrgico apresentaram o mesmo comportamento do grupo que nunca fumou. (Bluman et al., 1998; Warner et al., 1989).

\section{Estado geral de saúde}

Índices usados para avaliação geral de risco perioperatório ou para avaliação de risco cardiológico conseguem ser preditores de risco de complicações pulmonares. O índice cardíaco de Goldman, que inclui variáveis clínicas e laboratoriais, é preditor de complicações pulmonares além de complicações cardíacas (Goldman et al., 1977; Wong et al., 1995).

A classificação da American Society of Anesthesiologists (ASA) é um forte preditor de complicações pulmonares perioperatórias, provavelmente 
por incluir fatores gerais pulmonares e não pulmonares (Garibaldi et al., 1981).

\section{Idade}

Os pacientes idosos apresentam uma diminuição da capacidade pulmonar total e da complacência pulmonar, contudo estas alterações não são importantes do ponto de vista fisiopatológico. Existe ainda a diminuição do volume corrente e da capacidade vital forçada, e o aumento da pressão de fechamento (Fernandes e Ruiz-Neto, 2002).

Apesar destas alterações fisiológicas da idade, esta não parece ser um fator importante no desenvolvimento de complicações pulmonares quando comparada a outros fatores de risco (Wong et al., 1995).

\section{Obesidade}

A obesidade leva a uma diminuição da complacência pulmonar, da capacidade vital, da capacidade inspiratória, da reserva expiratória, e da capacidade pulmonar total. Além disso, leva a um distúrbio de ventilaçãoperfusão, resultando em shunts anatômicos (Phillips et al., 1994).

Contudo, não existem dados na literatura que suportem a obesidade como um determinante isolado do risco de complicações pulmonares perioperatórias (Phillips et al., 1994; Moulton et al., 1996). 


\section{Doença pulmonar obstrutiva crônica}

Pacientes portadores de doença pulmonar obstrutiva crônica possuem um risco aumentado de complicações pulmonares perioperatórias, tendo um risco relativo que pode variar de 2,7 a 4,7, dependendo da definição da complicação e da severidade da doença pulmonar. Esses pacientes devem estar no seu melhor estado funcional possível no ato da intervenção cirúrgica (Smetana, 1999; Warner, 2000).

\section{Asma}

Os pacientes asmáticos assintomáticos possuem um risco aumentado, mas ainda assim baixo, de complicações perioperatórias pulmonares. Um estudo retrospectivo encontrou uma incidência de broncoespasmo no pós-operatório de pacientes asmáticos de apenas $1,7 \%$ (Warner et al., 1996).

O paciente asmático também deve ser submetido ao procedimento cirúrgico apenas quando este estiver no melhor de seu estado funcional. Para atingir este melhor estado funcional, pode-se fazer 0 uso de corticoterapia sistêmica se necessário. O uso de corticóides sistêmicos no período perioperatório, mantém uma baixa taxa de broncoespasmo no pósoperatório, sem aumentar a taxa de complicações infecciosas (Kabalin et al., 1995). 


\subsubsection{FATORES DE RISCO RELACIONADOS AO}

\section{PROCEDIMENTO CIRÚRGICO}

\section{Sítio cirúrgico}

O sítio cirúrgico é a principal variável relacionada com o aumento do risco de complicações pulmonares, e esse risco parece ser maior quando a incisão se aproxima do diafragma. As cirurgias torácicas e abdominais altas possuem o maior risco de complicações pulmonares perioperatórias (Brooks-Brunn, 1997).

As cirurgias não torácicas e não abdominais possuem um baixo risco de complicações (Brooks-Brunn, 1997). O risco é muito menor para pacientes submetidos a procedimentos laparoscópicos (Phillips et al., 1994).

\section{Tempo de duração da cirurgia}

O tempo de duração da cirurgia está diretamente ligado ao desenvolvimento de complicações pulmonares perioperatórias. Quanto maior o tempo de cirurgia, maior a incidência de complicações, sendo que o risco aumenta a partir de 2 horas de cirurgia e aumenta muito após 3 horas de cirurgia (Kroenke et al., 1992). 


\section{Tipo de anestesia}

Alguns estudos têm descrito um menor risco de complicações pulmonares com anestesia epidural ou espinhal quando comparadas com a anestesia geral. Contudo os resultados são controversos e provenientes de estudos retrospectivos. Nenhum estudo mostrou um aumento do risco em pacientes submetidos à anestesia espinhal. Nos pacientes com risco aumentado para complicações pulmonares, deve-se considerar o uso de anestesia espinhal se possível (Christopherson et al., 1993).

\subsection{BONCOESPASMO NO PERIOPERATÓRIO}

\subsubsection{ASPECTOS EPIDEMIOLÓGICOS}

No perioperatório a incidência de complicações pulmonares situa-se em torno de $25 \%$. Dentre as complicações mais freqüentes, encontramos o broncoespasmo (BCE) (Pereira, 1994), que deve ser considerado como uma complicação de potencial risco para a vida levando alguns pacientes a óbito principalmente com o avançar da idade (Zaugg e Lucchinetti, 2000). Isso tem motivado guidelines de avaliação pré-operatória pulmonar, porém ainda há poucos estudos sobre BCE no intra-operatório.

A incidência de broncoespasmo no intra-operatório pode variar da mesma forma que os estudos populacionais de prevalência de asma. Olsson (1987) relataram a incidência de broncoespasmo como complicação em 
0,17\% em 136.929 procedimentos anestésicos. No entanto, para população portadora de doenças obstrutivas, tal número situou-se em 2,19\% (Olsson, 1987).

Em um estudo restrospectivo foram analisados 15.965 procedimentos anestésicos, dos quais 42 pacientes apresentaram episódios de broncoespasmos classificados como graves e $94 \%$ destes ocorreram após anestesia geral com intubação traqueal (Litvan, 1998 apud Telles Filho, 2005)

Uma recente pesquisa realizada na Austrália, onde foram avaliados 4.000 casos, observaram-se 103 incidências de broncoespasmo, das quais 22 foram relacionadas com alergia ou anafilaxia. Em todos os casos sempre havia relatos de alguns sinais comuns adicionados à falta de ar, como, por exemplo, queda da complacência e saturação de oxigênio (Westhorpe et al., 2005)

\subsubsection{FATORES DESENCADEANTES DE BRONCOESPASMO}

Os estímulos que podem ocasionar episódios de broncoespasmo podem ser químicos, mecânicos ou de origem neurogênica (Pailo e Bernardelli, 2001).

Sabe-se que, em pacientes com vias aéreas hiperresponsivas, a simples intubação consiste no mais vigoroso estímulo para o aparecimento 
do broncoespasmo, por causar inrritação da vias aéreas levando à complicações no perioperatório (Pizov et al., 1995; Warner et al., 1996; Warner et al., 1999). No entanto foi demostrado que uma boa parte das ocorrências de broncoespasmo podem ser também ocasionadas devido à indução ou mesmo manutenção anestésica (Westhorpe et al., 2005). Entretanto, quando a intubação é imprescindível o uso de alguns agentes anestésicos inalatórios podem algumas vezes reduzir o risco de broncoespasmo para o paciente (Hirshman et al., 1982). Ainda que agentes anestésicos de uso intravenoso possam ser utilizados, tem-se discutido qual seria mais eficiente. Alguns agentes de indução intravenosa têm sido muito utilizados para diminuir o risco de bronchospasmo na indução anestésica e na intubação traqueal (Wu et al., 1996; Corssen et al.,1972).

Foi demostrado que a Ketamina é superior ao tiopental na prevenção do aumento de resistência nas vias aéreas em modelo experimental (Hirshman et al., 1979), sendo mais indicada para indução e manutenção durante a anestesia em pacientes de alto risco de desenvolver BCE. (Kingston e Hirshman, 1984). Brown e Wagner (1999) observaram que a Ketamina quando comparada ao anestésico tiopental foi mais eficaz na prevenção da constrição das vias aéreas e o mecanismo dessa broncoproteção pode ter ocorrido através do relaxamento direto da musculatura lisa brônquica ou pela inibição de mediadores neuronais. 
Outros anestésicos como o midazolam e o propofol também apresentaram um efeito significante no relaxamento da musculatura lisa das vias aéreas e isso foi mais evidente em vias aéreas distais. (Cheng et al., 1996).

Pizov et al. (1995) demonstraram que até $45 \%$ de pacientes asmáticos apresentaram sibilância à indução da anestesia, enquanto $16 \%$ de não-asmáticos tiveram o mesmo quadro. A causa desse broncoespasmo foi aparentemente relacionada à droga de escolha, sendo menor a incidência de sibilos quando do uso de propofol.

Agentes anestésicos inalatórios possuem efeitos broncodilatador diminuindo a responsividade e atenuando o broncoespasmo (Burburan et al., 2007). Portanto tem-se recomendado para técnicas de anestesia geral em pacientes que apresentam doenças de vias aéreas obstrutivas o uso de agentes voláteis tais como halotano e isoflurano, sendo menos recomendado o Desflurane, por causar aumento de secreção, tosse, espasmo na laringe, inclusive broncoespasmo (Goff et al., 2000).

\subsubsection{FISIOPATOLOGIA DO BRONCOESPASMO}

Boncoespasmo é uma contração espasmódica da musculatura lisa brônquica (DeCS, 2007) e pode ser causado por vários estímulos. Consiste em um aumento acima do normal da contração dos músculos bronquiais resultando em um estreitamento agudo e obstrução de vias aéreas, esta 
contração do brônquio faz com que ocorra uma diminuição em seu diâmetro, isso ocorre logo após um determinado estímulo (West, 1996a; Maitra e Kumar, 2003).

Hiperresponsividade brônquica é um termo usado para descrever vias aéreas que se estreitam com muita facilidade em resposta ao contado com estímulos físicos, a exposição à agonista constritor, estimulantes famacológicos e fatores emocionais (Blease et al., 2000; Fredberg, 2004; GINA, 2005), em outros termos, uma das carcterísticas da hiperresponsividade brônquica é o broncoespasmo.

Em uma via aérea hiperresponsiva, junto ao broncoespasmo, podem ocorrer alterações na mucosa, com a presença de edema e produção excessiva de rolhas de muco espesso pelas glândulas do epitélio brônquico, onde uma simples tosse não é capaz de expectorá-lo, obstruindo o fluxo de ar tanto inspiratório como expiratório (Burburan et al., 2007; O’ Byrne, 2003). Quando isso ocorre é necessário uso de pressões mais freqüentes para empurrar o ar, que é uma forma do organismo conseguir oxigênio (Guyton, 2002). Assim a respiração durante o broncoespasmo exige muito mais esforço que uma respiração normal (Burburan et al., 2007).

Quando broncoconstritores de ação direta são utilizados, a hiperresponsividade brônquica pode ser vista tanto por uma resposta mais precoce, observada por meio de baixas concentrações de agonistas 
necessárias para iniciar uma resposta de broncoconstrição, como pode ser observada a hiperreatividade que é a magnitude dessa broncoconstrição induzida (O' Byrne, 2003; Fredberg, 2004), estes fatores resultam em obstrução do lumem das vias aéreas.

\subsubsection{DIAGNÓSTICO E TRATAMENTO DO BCE}

A musculatura brônquica é reconhecida como o principal efetor do estreitamento agudo de vias aéreas (Fredberg, 2004). O broncoespasmo pode ocorrer em pacientes com via aérea normal, ou hiperresponsiva (Shnider e Papper, 1961).

O BCE pode estar presente em doenças, como asma, infecções respiratórias, doenças pulmonares crônicas e choque anafilático (Pereira et al., 1996; Maitra e Kumar, 2003). As manifestações clínicas podem ser observadas pelos sintomas de dispnéia, sibilos, cianose e tosse, além de alterações das propriedades mecânicas pulmonares (Pailo e Bernadelli, 2001; Maitra e Kumar, 2003).

Dentre os tratamentos utilizados para reverter o quadro de broncoespasmo, o mais comum é o uso de agonista do receptor B2adrenérgico (Pailo e Bernadelli, 2001). No Brasil, temos à disposição de médicos e pacientes os seguintes sais: salbutamol, fenoterol, terbutalina, bambuterol, salmeterol e formoterol. Em uma pesquisa realizada em São Paulo observou-se que para reversão desse quadro durante anestesia e 
pós-operatório, as condutas tomadas pelos anestesistas são bastante variadas. Essa diversidade de medicações registradas sugere a necessidade de maior divulgação de cuidados no período pré-operatório, incluindo a avaliação do quadro clínico da asma para sua classificação (Menezes e Vieira, 2002).

A obstrução em pacientes com doenças obstrutivas crônicas pode ser mensurada por meio da mecânica respiratória que avalia o grau de obstrução das vias aéreas, complacência do tecido pulmonar e restrição da parede torácica.

A melhor forma de prevenir complicações de doenças pulmonares é o melhor controle possível dessas moléstias, e optimização da função pulmonar no pré-operatório. Atualmente para se avaliar a obstrução a espirometria é o teste padrão-ouro por ser a forma mais reprodutível, padronizada e objetiva de se medir a limitação do fluxo aéreo (GOLD, 2006). A quantificação do grau dessa obstrução, pode se feito por meios de aparelhos espirométricos portáteis que são muito práticos.

A espirometria pode ser o primeiro teste indicado na presença de doença obstutiva crônica, no entanto, este exame sozinho não define completamente a extensão ou a gravidade da doença, pois não fornece uma história pulmonar prévia, por ser uma medida pontual (West, 1996b). 
Os aparelhos de espirometria medem fluxos e volumes durante uma manobra inspiratória forçada seguida de uma expiração forçada (Stelmach et al., 2005).

A figura 1 abaixo é uma representação esquemática dos volumes e capacidades pulmonares da espirometria

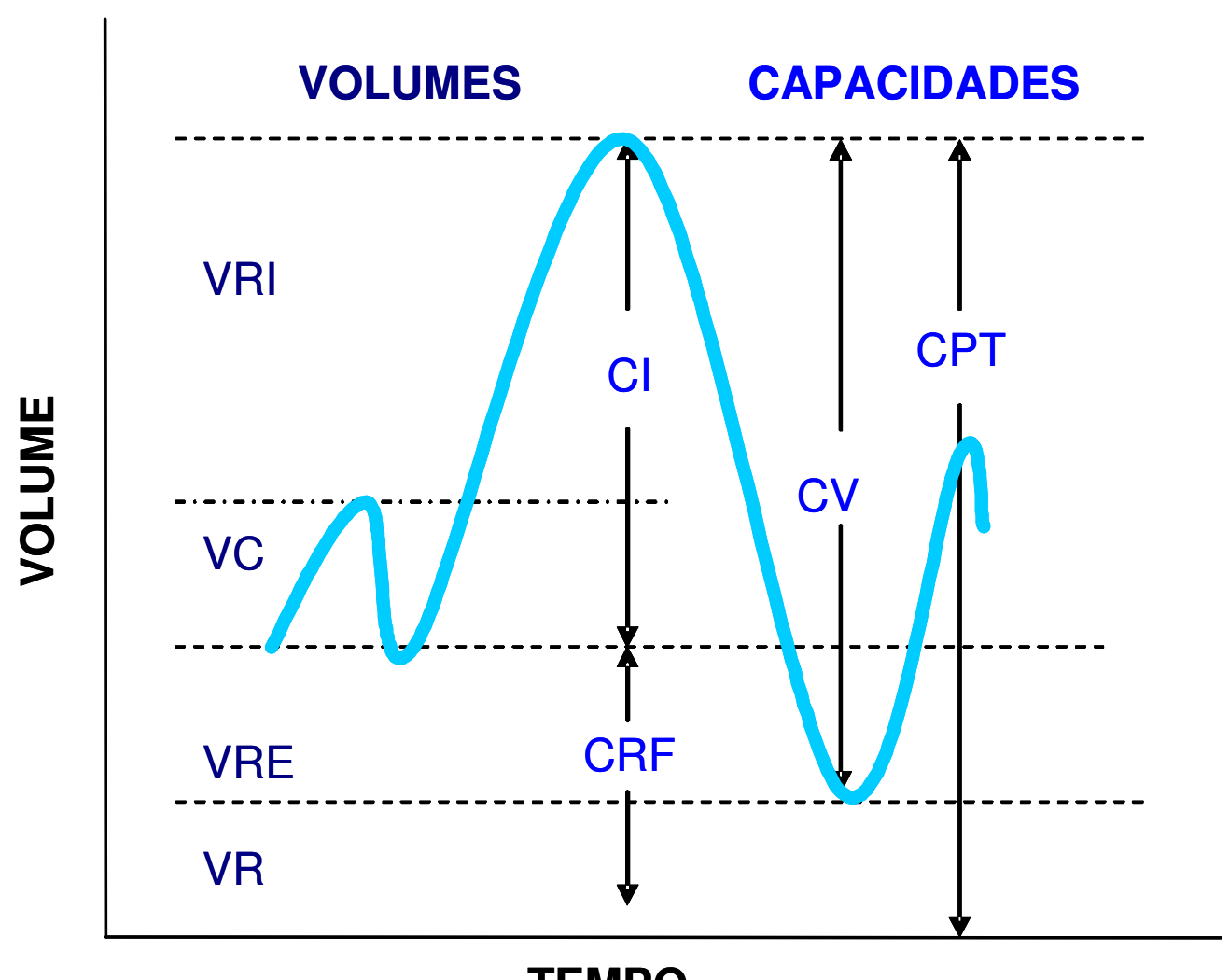

\section{TEMPO}

Figura 1. Volumes e capacidades pulmonares no exame de espirometria. $\mathrm{VC}=$ volume corrente. $\mathrm{VRI}=$ volume de reserva inspiratória. $\mathrm{VRE}=$ volume de reserva expiratória. $\mathrm{VR}$ volume residual. $\mathrm{Cl}=$ capacidade inspiratória (volume de reserva inspiratória + volume corrente). $\mathrm{CRF}=$ capacidade de reserva funcional (volume de reserva expiratória + volume residual). $\mathrm{CV}=$ capacidade vital (volume corrente + volume de reserva inspiratória + volume de reserva expiratória). CPT= capacidade pulmonar total (soma de todos os volumes). 
Para estabelecer o diagnóstico nestes pacientes a espirometria pode ser complementada por um teste de broncoprovocação Este teste caracteriza-se por quantificar a reatividade brônquica (obstrução), utilizandose agonistas pulmonares como histamina e/ou metacolina, ou salina hipertônica ou hipotônica e mesmo ar frio ou exercício físico (Celli, 2000).

Nos últimos anos tem-se buscado outros parâmetros além dos métodos funcionais para avaliação da doença obstutiva crônica. Para tanto, tem-se empregado técnicas invasivas como a biópsia brônquica e o lavado bronco-alveolar que são utilizados para analisar os padrões de resposta celular relacionados à gravidade clínica, expressão de células inflamatórias, produção de citocinas e de mediadores da resposta inflamatória mediada por eosinófilos e neutrófilos (Pizzichini et al.,1998; Woerly et al., 2004). Contudo estes procedimentos não podem ser aplicados para monitorização rotineira do processo inflamatório.

Atualmente, dispõem-se da análise do escarro induzido e da medida do óxido nítrico no ar exalado, que são considerados métodos não invasivos, ou relativamente não invasivo (Kanazawa et al., 1997; Pizzichini et al., 1998; Hunter et al., 1999).

A análise de escarro de pacientes com vias aéreas inflamadas em crise ou fora dela, tem sido empregada na tentativa de melhor compreender o mecanismo fisiopatológico da doença. 
Nos últimos anos muitos pesquisadores optaram pela indução do escarro por meio de solução hipertônica para estudos citológicos de pacientes asmáticos devido à escassez de secreção espontânea que a maioria dos pacientes estáveis apresenta. Pin et al. (1992), foram bem sucedidos no estudo de células inflamatórias em amostra de escarro induzido por salina hipertônica em indivíduos asmáticos e não asmáticos.

A salina hipertônica é uma substância que pode causar irritações, provocando tosse, fornecendo assim evidências de que este aerosol estimula inervações excitatórias das fibras não adrenérgicas e não colinégicas (NANC) (Eschenbacher et al., 1984).

Recentemente foi demostrado que a porcentagem de eosinófilos no escarro induzido constitui o marcador inflamatório mais acurado para diferenciar indivíduos saudáveis de pacientes asmáticos, e a análise deste escarro pode ser simplificada realizando-se um simples esfregaço no lugar da técnica de citocentrifugação (Saraiva-Romanholo et al., 2003).

Num estudo realizado em crianças e adolecentes com asma estável Paro-Heitor et al (2008) mostraram que o exame do escarro particularmente induzido com salina hipertônica é um método de difícil realização na avaliação rotineira destes pacientes. 
O escarro induzido tem como desvantagem a demanda de tempo na coleta e processamento, necessita de um período de intervalo prolongado entre uma coleta e outra, além de necessitar da presença de médicos ou para-médicos durante a indução com $\mathrm{NaCl}$ à $3 \%$ e de pessoal técnico especializado para o processamento da amostra.

\section{4. ÓXIDO NÍTRICO (NO)}

\subsubsection{CARACTERÍSTICAS, SÍNTESE E METABOLISMO}

\section{DO NO}

O óxido nítrico é uma molécula gasosa simples, composta por um único átomo de nitrogênio e um de oxigênio, porém é um agente químico altamente reativo.

Até os anos 80, o NO era considerado apenas um "vilão" encontrado no ar atmosférico em pequenas quantidades e considerado um dos responsáveis pela destruição da camada de ozônio, causando desta forma a chuva ácida (Culotta e Koshland, 1992).

Em 1980 foi comprovado que células endoteliais são capazes de liberarem uma substância vasodilatadora dependente do endotélio (fator de relaxamento derivado do endotélio - EDRF). A presença dessas células mediava o relaxamento arterial induzido pela acetilcolina (Furchgott e 
Zawaszdki, 1980). Alguns anos mais tarde, em 1987, constatou-se que era o NO responsável pela atividade biológica do EDRF (Ignarro et al., 1987; Palmer et al., 1987).

Assim, o NO passou a ser reconhecido e considerado como uma molécula essencial na fisiologia de diversos órgãos do corpo humano regulação do tônus vascular, função plaquetária, ação bactericida e moduladora do sistema imunológico (Hibbs et al., 1987; Marletta et al.,1988).

Esta molécula possui meia-vida curta quando diluído, com menos de 10 segundos, devido à sua rápida oxidação (Ignarro, 2002).

O NO ainda pode exercer efeitos fisiológicos, operando como mensageiro e estimulando a síntese de GMP cíclico e promovendo o relaxamento da musculatura lisa brônquica. (Bredt e Snyder, 1989; Ashutosh, 2000).

O óxido nítrico é sintetizado quando um grupo molecular guanidino de aminoácido L-arginina, que é catalisado pela ação enzimática das enzimas óxido nítrico sintases (NOS) (Ignarro, 2002) formando o óxido nítrico e Lcitrulina (Culotta e Koshland, 1992).

A L-arginina é um aminoácido semi-essencial para o organismo. Contudo, é sintetizado em quantidades insuficientes para suprir todas as 
necessidades. Proteínas ingeridas são degradadas, até arginina, que podem ser diretamente absorvidas e utilizadas no ciclo da uréia e no tecido hepático. Por fim a arginina pode modificar-se no epitélio intestinal em ornitina e assim ser convertida em citrulina. Esta última por sua vez é capaz de ser transformada em arginina no ciclo renal ou ser diretamente convertida nas células endoteliais e nos macrófagos em L- arginina (Konturek e Konturek, 1995; Flora-Filho e Zilberstein, 2000).

A L-arginina produzida é transportada para o interior das células por um sistema de transporte aminoácido catiônico e pode ser metabolizada por dois grupos distintos de enzimas, as óxido nítrico sintases, e a arginase (Ricciardolo et al., 2004), como demostrando na figura 2 abaixo.

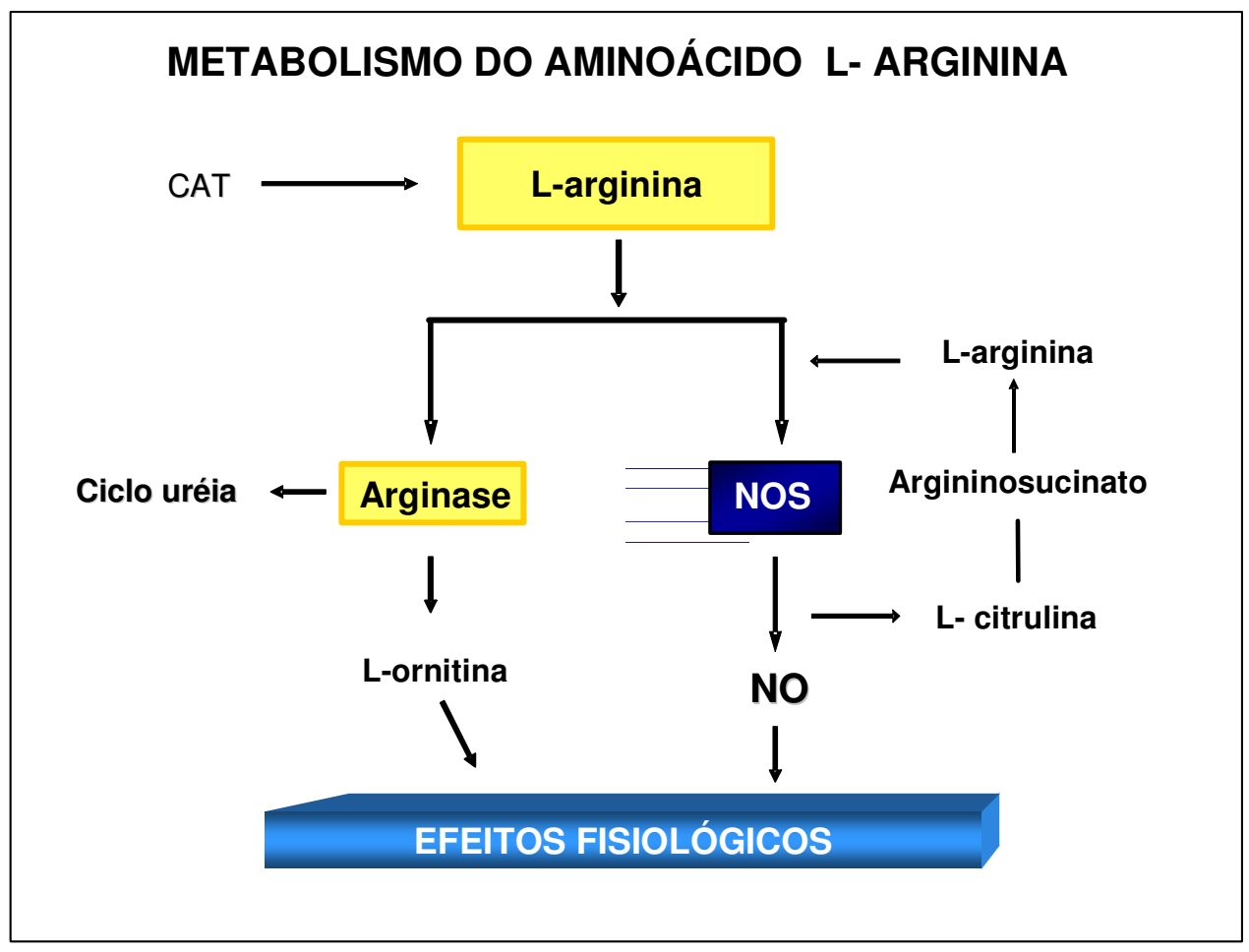

Figura 2. Esquema simplificado do metabolismo da L-arginina. (Fonte: Modificado de Ricciardolo et al., 2004). 
As principais isoformas das enzimas óxido nítrico sintases (NOS) são a isoforma neuronal (nNOS ou NOS1), a isoforma induzida (iNOS ou NOS2) e a isoforma endotelial (eNOS ou NOS3) sendo cada uma produto de genes distintos localizados em diferentes cromossomos humanos, com diferenças em suas propriedades estruturais e bioquímicas. As três isoformas de NOS estão presentes em vias aéreas (Robbins et al.,1994; Shaul, 1994; FloraFilho e Zilberstein, 2000).

A Isoforma nNOS e a eNOS são ativadas constitutivamente (cNOS), apresentam uma resposta rápida e produzem baixas concentrações de NO. São enzimas cálcio dependentes, ou seja é imprescindível determinado nível de $\mathrm{Ca}^{2}+$ intracelular para que ocorra a atividade enzimática, ocorrendo inativação dessas isoformas constitutivas (cNOS) com a diminuição do $\mathrm{Ca}^{2}+$ citoplasmático (Asano et al., 1994; Ricciardolo et al., 2004).

A nNOS localiza-se em terminações nervosas (neurônios e nervos) das vias aéreas de humanos e animais (Guembe e Villaro, 1999; Eynott et al., 2002). Nas fibras nervosas presentes na musculatura lisa das vias aéreas o NO é o principal mediador neuronal, atuando como neurotransmissor no sistema inibitório não adrenérgico não colinérgico (iNANC), agindo tanto em nível central como periférico, promovendo o relaxamento da musculatura lisa das vias aéreas (Imasaki et al., 2001). A expressão da nNOS também já foi encontrada em células epiteliais (Asano et al., 1994). O óxido nítrico derivado da nNOS produz um efeito benéfico em 
doenças pulmonares obstrutivas como asma, por causar a broncodilatação na musculatura lisa das vias aéreas desses pacientes (Barnes, 1996).

Embora inicialmente acreditava-se que a nNOS estava presente apenas nas terminações nervosas, estudos mais recentes já demonstraram a presença desta isoforma em diversos tipos celulares, incluindo células infamatórias presentes nas vias aéreas de modelos experimentais e humanos, tais como eosinófilos, linfócitos entre outras (Prado et al., 2008). Apesar de constitutiva, sua expressão é modulada pela presença da inflamação (Prado et al., 2006).

A óxido nítrico sintase endotelial tem este nome porque foi descoberta primeiramente em células endoteliais (Lamas et al., 1992). O NO é expresso constitutivamente no epitélio bronquial (Shaul et al., 1994) e em células epiteliais alveolares do tipo II humanas (Pechkovsky et al., 2002) é encontrado também vasos sanguíneos pulmonares (Shaul et al., 2002) e em todos tipos de artérias, particularmente na artéria radial. (Gaudino et al., 2003). O NO gerado por esta enzima é responsável por manter o tônus vascular baixo e prevenir a aderência leucocitária e de plaquetas na parede vascular (Ignarro, 2002). Contudo, pode levar a vasodilatação nas arteríolas, levando ao extravasamento do plasma e edema (Barnes, 1996).

A óxido nítrico sintase induzida é expressa a estímulos próinflamatórios, é independente de cálcio e produz localmente quantidades 
centenas de vezes maiores que as isoformas produzidas constitutivamente. Embora tenha sido inicialmente encontrada em macrófagos (Xie et al., 1992), sabe-se que esta isoforma pode ser induzida em diferentes células, tais como neutrófilos, linfócitos, eosinófilos, mastócitos e também células endoteliais (Nussler e Billiar, 1993). Tem sido relatada também nas vias aéreas, em células do músculo liso e em células epiteliais do trato respiratório (Eynott et al., 2002).

O NO produzido a partir da iNOS pode apresentar efeitos citostáticos e citotóxicos (Ricciardolo et al., 2004). O óxido nítrico possui ações pró e antioxidantes, dependendo do local onde ele irá atuar, e das suas concentrações. Em baixos níveis possui uma ação protetora e quando gerado em concentrações altas em condições patológicas, ele apresenta ações deletérias. (Joshi et al., 1999).

$\mathrm{O}$ efeito protetor do NO inclui neuromodulação, relaxamento do músculo liso e diminuição da hiperresponsividade brônquica causada por estímulos bronconstritores. Por outro lado, como efeitos deletérios do NO temos: atividades pró-inflamatórias, aumento de secreção nas vias aéreas, aumento de células inflamatórias, apoptose e necrose (Ricciardolo et al., 2004).

Vários autores demonstraram um aumento significativo da produção de óxido nítrico em desordens respiratórias (Kharitonov et al., 1995a; 
Kharitonov et al., 1995b; Maziak et al., 1998) e por isso o estudo do papel do NO é relevante em patogenias como asma, fibrose cística, e DPOC (Ricciardolo et al., 2004).

A presença do óxido nítrico no ar expirado em humanos e animais foi descrita pela primeira vez em 1991 (Gustafsson et al., 1991) em seguida surgiram uma série de estudos bem elaborados que comprovaram que a concentração de NO exalado está aumentada em pacientes asmáticos (Kharitonov et al.,1996; Ricciardolo et al., 2004), e também em modelos experimentais de inflamação crônica pulmonar (Alving et al.,1993; LeickMaldonado et al., 2004; Prado et al., 2005a e b).

Asmáticos tratados com corticoides inalatório apresentam níveis de óxido nítrico exalado (NOex) similares aos sujeitos saudáveis (Kharitonov et al., 1994), sendo a diminuição do NO observada logo após uma semana de tratamento com budesonida (Silkoff et al., 1998).

Contudo Langley et al. (2003), comparando pacientes asmáticos tratados com corticóide inalatório e pacientes asmáticos não tratados, não foram capazes de identificar diferenças significativas no NO exalado entre os grupos. Entretanto, neste estudo houve uma relação entre as medidas de óxido nítrico exalado e a hiperresponsividade brônquica (HRB) à metacolina $(\mathrm{MCH})$ e histamina destes pacientes. 
A relação entre óxido nítrico no ar expirado em pacientes e hiperresponsividade brônquica é bastante controversa na literatura, enquanto alguns autores demonstram haver correlação entre estes parâmetros (Jatakanon et al. 1998; Dupont et al. 1998; Nogami et al. 2003), outros afirmam que esta correlação não existe.

Van Rensen et al (1999); Van Den Berge et al (2001); Spallarossa et al. (2003) e também Del Giudice et al. (2004), estudando portadores de asma intermitente e leve não observaram esta correlação quando submeteram estes indivíduos à $\mathrm{PC}_{20}$ histamina, adenosina monofosfato e à metacolina, nesses estudos foram utilizados adultos, adolescentes e crianças.

É claro que devido a todo este entusiasmo por parte dos pesquisadores em estudar medidas de óxido nítrico exalado, surgiram alguns consensos, com algumas recomendações para a coleta e análises destas medidas, que devem ser rigorosamente seguidas (ERS,1997, 1997; ATS, 1999; ATS, 2006).

O NOex pode ser obtido por meio da medida online ou offline, (ATS, 1999; ATS, 2006). A principal recomendação que deve ser tomada é a padronização da taxa do fluxo expiratório que deve ser realizada, uma vez que esta influencia significativamente na concentração de NO exalado (ERS,1997; ATS, 2006). 


\subsection{JUSTIFICATIVA DO PROJETO}

Dada a prevalência crescente da asma e a bem documentada baixa aderência ao tratamento (Cerveri et al., 1999) é razoável aventar a hipótese dos anestesiologistas se depararem cada vez mais com episódios de broncoespasmo no período peri-operatório.

Nos últimos anos o papel do óxido nítrico vem sendo constantemente estudado na modulação da broncoconstrição (Persson et al., 1993). Como já foi citado anteriormente, vários estudos têm demonstrado que esta medida é uma ferramenta não invasiva e útil para estudar a inflamação de vias aéreas inferiores de seres humanos.

O NOex é um teste bem atrativo para a pesquisa por ser produzir resultados são imediatos, sendo ideal para aplicação clínica (ATS, 2006).

Em 2000 Dra. Adriana Sales Leme pesquisadora do laboratório em conjunto com o Dr Joaquim Edson Vieira implantaram no Laboratório de Terapêutica Experimental I um sistema para medir o óxido nítrico no ar exalado de pacientes e animais. Testando um dispositivo filtrante nacional para coleta do NO exalado em pacientes com intuito de tornar economicamente factível as futuras pesquisas no laboratório, indivíduos asmáticos e pessoas saudáveis sem história clínica de doença pulmonar participaram da coleta de NOex. Neste estudo, observaram que no grupo de 
asmáticos todas as pessoas apresentavam o óxido nítrico no ar exalado elevado, no entanto algumas pessoas saudáveis também apresentaram NO exalado elevado. Na ocasião, questionou-se se estes indivíduos do grupo controle com NO elevado sem história de doença poderiam ter o mesmo comportamento daquelas que durante a indução de uma anestesia geral e mediante uma intubação traquel apresentam broncoespasmo sem história prévia de doença respiratória. 
2-Objetivo 
Esta investigação tem por objetivo estudar medidas de óxido nítrico exalado como possível marcador de episódios de broncoespasmo, no intraoperatório. 
3-Metodologia 


\subsection{PACIENTES E MÉTODOS}

Este estudo foi aprovado pela Comissão de Ética para Análise de Projetos de Pesquisa do Hospital das Clínicas. Todos os participantes concordaram e assinaram um termo de consentimento livre e esclarecido de acordo com as normas da lei 196/96 (anexo A).

\subsubsection{SUJEITOS}

Foi identificada uma polulação de pacientes com história de broncoespasmo durante a intubação traqueal no intra-operatório, selecionados a partir do levantamento de registros de casos obtidos junto à Divisão de Anestesia do ICHC-FMUSP, nos anos de 1999 a 2004 (figura 3).

Os pacientes com história documentada de broncoespasmo no intraoperatório foram contatados e convidados para comparecer ao hospital para uma consulta médica para participar do protocolo de estudo.

Após a avaliação clínica e preenchimento da ficha de registro de casos (CRF) (anexo B), foi possível classificá-los em asmáticos (12 pessoas) ou não-asmáticos (9 pessoas), porém, todos com história de broncoespasmo. Dentre as fichas dos pacientes em que não havia registros 
de história de broncoespasmo foi possível selecionar, aleatoriamente, 10 indívíduos para o grupo controle, que foram expostos ao protocolo da mesma forma que os demais indivíduos que tiveram BCE.

\subsubsection{DESENHO DO ESTUDO}

Os sujeitos foram contatados e convidados por telefone para comparecer ao ambulatório em duas visitas para consulta médica e realização dos exames do protocolo (figura 3).

O médico preencheu a CRF com as respostas de todos os sujeitos (anexo B) para melhor investigar a história clínica desses indivíduos como: alergia, história de uso de cigarro e asma. Nenhum sujeito apresentava doença cardíaca, diabete, hipertensão, insuficiencia renal, creatinina elevada, AVC, alteração no eletroencefalograma, DPOC, câncer ou cirurgias de emergência, e não havia gestantes nos grupos estudados.

Foram permitidos participar do protocolo pacientes que foram submetidos, há um ano ou dois, às cirurgias do tipo: otorrino, hérnia de hiato, oftalmo, ginecologia, cirurgia abdominal, buco-maxilo, urologia ou cirurgia plástica. Todos os sujeitos alocados no estudo atenderam aos critérios de inclusão detalhados na tabela 1. 
Tabela 1. Critérios para aceitação dos indivíduos no estudo.

CRITÉRIOS DE INCLUSÃo

CRITÉRIOS DE EXCLUSÃO

\begin{tabular}{ll}
\hline Adultos com idade entre17a 60 & Crianças $\leq 16$ anos e Adultos $>60$ \\
anos & anos \\
Ausência de infecção das vias & Presença de infecção das vias \\
aérea há pelo menos 30 dias & aéreas há menos de 30 dias \\
(critérios clínicos) & (critérios clínicos) \\
Ausência de doenças associadas & Doenças associadas que \\
que comprometessem a avaliação & comprometessem a avaliação \\
pulmonar & pulmonar \\
Presença de broncoespasmo & Asma descompensada \\
descrito no intra-operatório & Gestantes \\
\hline
\end{tabular}

Todos os pacientes com história de asma foram classificados pelo médico de acordo com os critérios adotados pela Iniciativa Global para Asma de 2002 (GINA, 2002), que foram: história de episódios de tosse e/ou chiado e/ou dispnéia diurnos ou noturnos, intermitentes/ ou frequentes e de curta duração há pelo menos um ano. Utilizou-se o critério da GINA (2002) também para classificar os indivíduos asmáticos quanto à gravidade da asma. Todos os participantes do estudo realizaram prova de função 
pulmonar de acordo com os critérios da American Thoracic Society (ATS, 1995).

Desta forma participaram do protocolo os seguintes grupos.

1. Grupo Controle: pacientes sem broncoespasmo no intra-operatório e sem doença pulmonar clínica registrados em ficha anestésica.

2. Grupo Broncoespasmo: indivíduos com broncoespasmo registrado em ficha anestésica, que foram separados em dois grupos.

- Grupo Asma: pacientes com broncoespasmo no intra-operatório e com doença pulmonar clínica.

- Grupo Broncoespasmo: indivíduos com BCE registrado em ficha anestésica, e sem doença pulmonar clínica registrada em ficha anestésica.

Os sujeitos inclusos no estudo foram encaminhados para a realização dos seguintes exames laboratoriais (figura 3)

1. Medidas do óxido nítrico exalado (NOex)

2. Espirometria

3. Escarro induzido

4. Sangue periférico

5.Teste alérgico cutâneo

6. Raio x 
Figura 3. Resumo do protocolo em estudo.

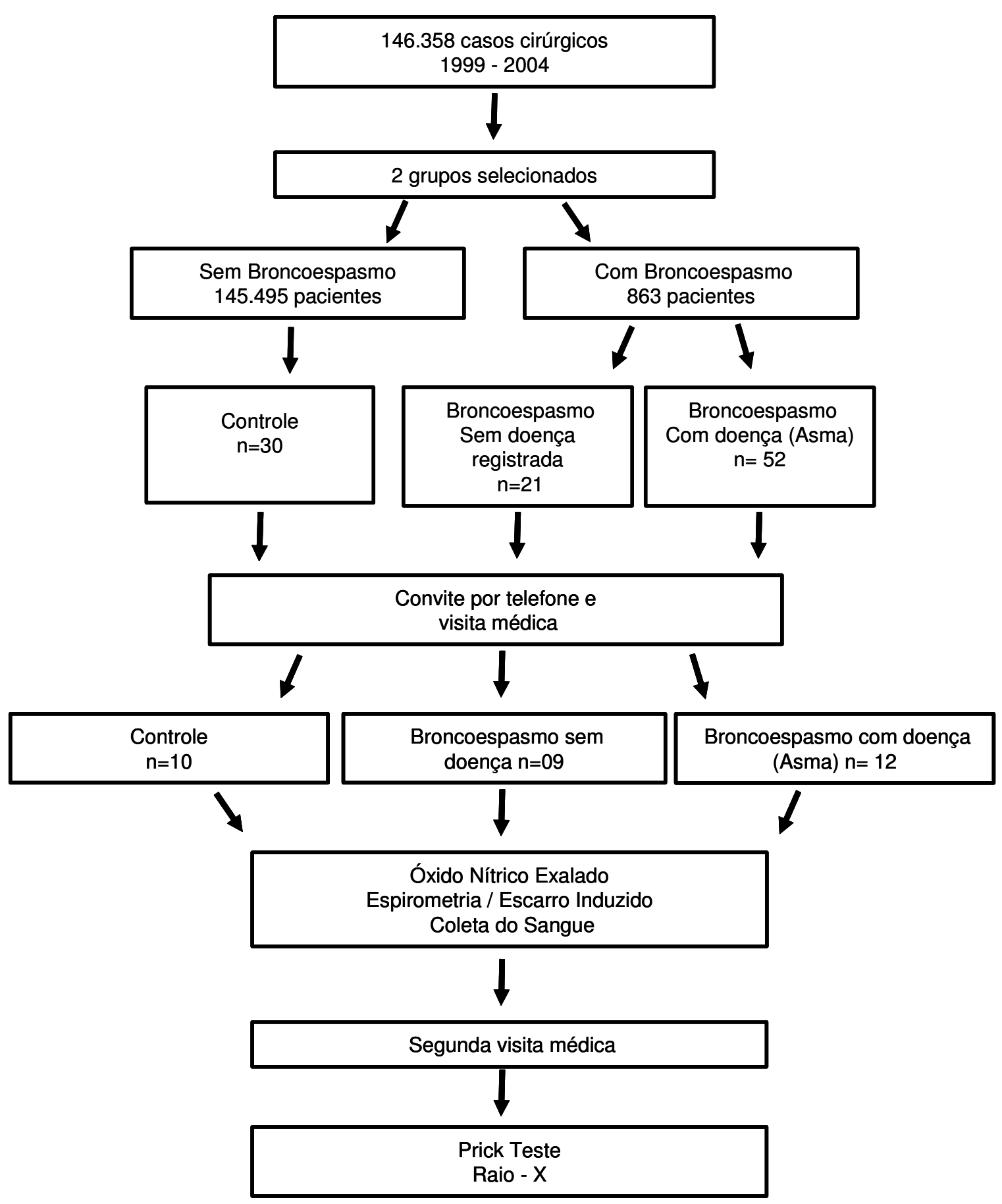


Todos os asmáticos estudados tinham asma e de acordo com a gravidade eram pacientes com asma intermitente, persistente leve e persistente moderada. Todos os participantes do estudo não apresentavam sintomas de infecção de vias aéreas superiores há pelo menos trinta 30 dias. As características dos sujeitos encontram-se resumidas na tabela 2.

Tabela 2. Características dos Pacientes.

\begin{tabular}{|c|c|c|c|}
\hline Grupo & $\begin{array}{l}\text { Controle } \\
(n=10)\end{array}$ & $\begin{array}{c}\text { Broncoespasmo } \\
(n=09)\end{array}$ & $\begin{array}{l}\text { Asma } \\
(n=12)\end{array}$ \\
\hline Idade (anos) & $(39-51)$ & $(17-60)$ & $(19-53)$ \\
\hline Média $\pm d p$ & $41,90 \pm 3,54$ & $37,22 \pm 15,37$ & $30,33 \pm 11,04$ \\
\hline Feminino & 8 & 6 & 8 \\
\hline \multicolumn{4}{|l|}{ Sexo } \\
\hline Masculino & 2 & 3 & 4 \\
\hline Fumantes & 0 & 1 & 1 \\
\hline Ex-fumantes & 2 & 0 & 2 \\
\hline História de rinite & 0 & 0 & 10 \\
\hline História de dermatite & 0 & 1 & 1 \\
\hline História de sinusite & 0 & 0 & 7 \\
\hline Uso de $\beta_{2}$-Agonista & 0 & 0 & 8 \\
\hline Uso de Corticosteroide & 0 & 0 & 5 \\
\hline Refluxo gastroesofágico & 0 & 0 & 2 \\
\hline
\end{tabular}

Questionário Médico, Idade apresentada em Média+Desvio Padrão. 


\subsubsection{PROCEDIMENTOS REALIZADOS}

\subsubsection{1.ÓXIDO NÍTRICO (NO)}

A coleta do óxido nítrico exalado foi realizada offline e antes de qualquer procedimento e imediatamente antes da prova de função pulmonar e foi solicitado que os pacientes viessem ao ambulatório em jejum de 8 horas antes do procedimento. No dia que antecedeu a coleta eles não deveriam ter comido alface e a partir da meia noite deste mesmo dia eles deveriam evitar a ingestão de produtos embutidos, chocolates e café (ATS, 1999).

O paciente foi instruído a respirar normalmente pela boca em um Kit de coleta da Sievers (Sievers Instruments Inc., Boulder, CO, USA) contendo um filtro bacterial $0.3 \mu \mathrm{m}$ HEPA (TROX Technik Ltda, SP, Brasil) por 3 segundos; em seguida foi instruído a inspirar até a capacidade pulmonar total neste sistema de coleta. Então foi aberta a válvula do sistema de coleta para o balão e, imediatamente, exalado o ar por aproximadamente 4 segundos. Em seguida, a válvula foi fechada mantendo uma pressão de 12 cm de água garantindo um fluxo estável de 200 mL/s (ERS,1997; Leme et al., 2002). Vide figura 4.

Conectado a este Kit havia um filtro inspiratório para reduzir óxido nítrico do ar ambiente a concentrações muito baixas e dessa maneira evitar 
a contaminação do NO do espaço morto proveniente de via aérea superior. Foi, então, solicitado que os pacientes já com o bocal acoplado na boca realizassem no mínimo 2 ciclos respiratórios, antes de iniciarem a coleta no balão (ATS, 1999).

Posteriormente, os balões foram selados e a concentração de óxido nítrico no ar exalado foi determinada até 4 horas após a coleta, por quimioluminescência em aparelho Sievers (modelo Sievers NOA 280) (American Thoracic Society, 1999), conforme apresentado na figura 5. A concentração média do NOex presente no balão foi registrada em partes por bilhão como um índice da concentração de NO exalado.

O analizador de óxido nítrico foi calibrado diariamente, utilizando-se um dispositivo que filtra o NO presente no ar ambiente e um gás de referência, com concentração conhecida de NO, (mistura padrão para calibração de $\mathrm{No}$ em NO 2 a 45ppb) (White Martins gases industriais AS, São Paulo SP, Brasil). A variabilidade entre os níveis de medida de NO dos três balões foi menos que 10\%. (ERS,1997; ATS, 1999; Leme et al., 2002). 
Figura 4. Coleta de óxido nítrico no ar exalado

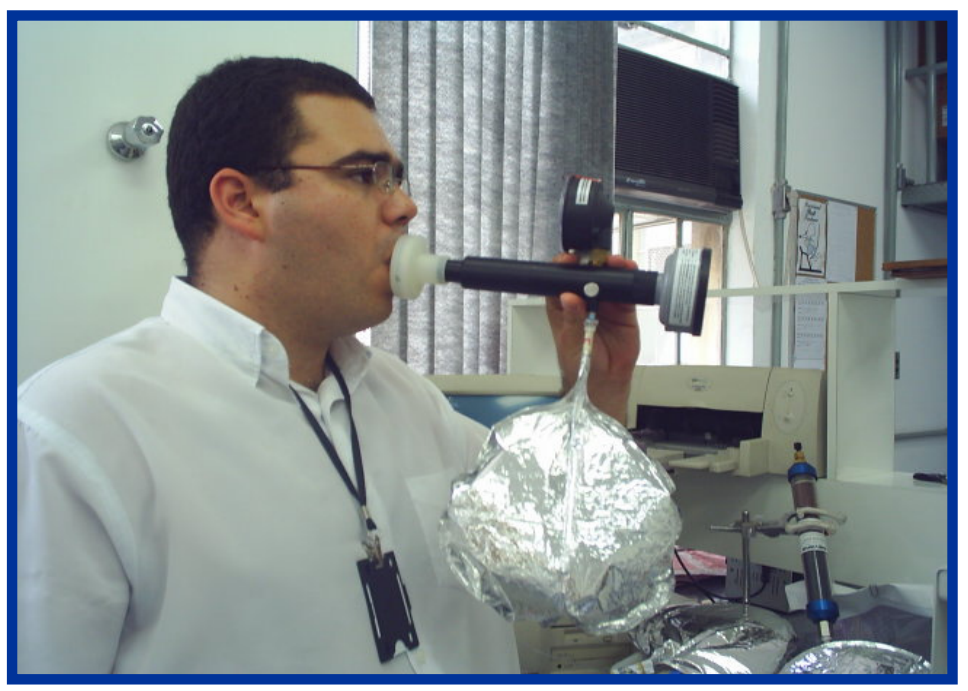

A concentração média de NO presente no balão foi registrada em partes por bilhão (ppb), como um índice de concentração de NO exalado.

Figura 5. Aparelho para registro de óxido nítrico

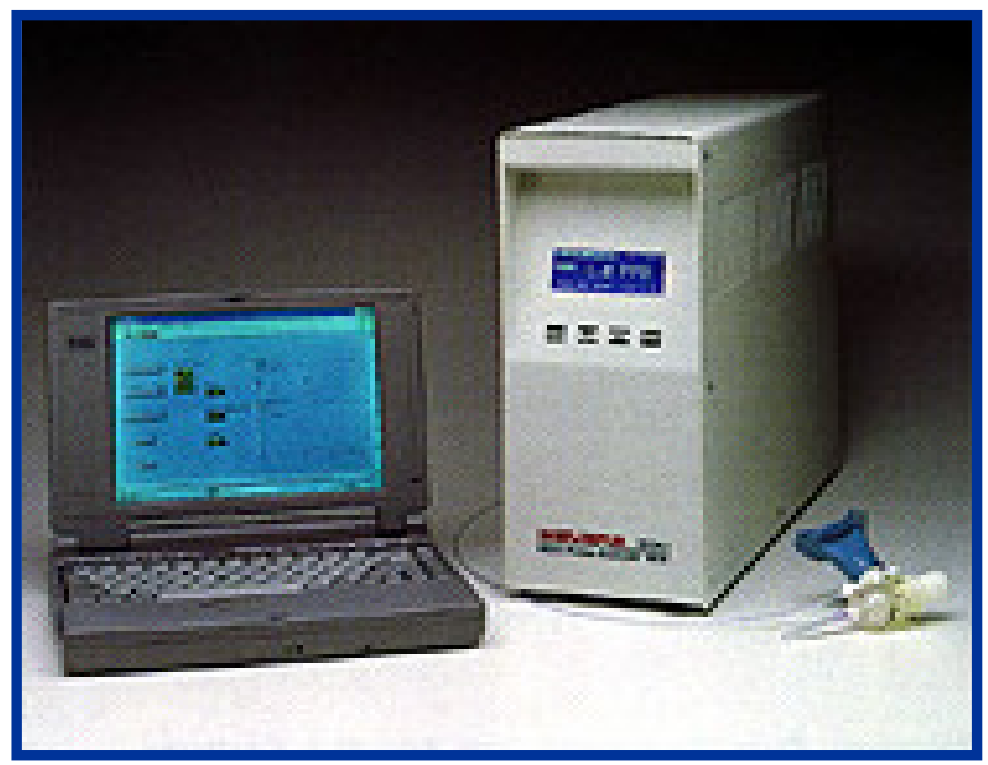

A concentração de NOex foi determinada por quimiluminescência com analisador Sievers NOA 280. 


\subsubsection{ESPIROMETRIA}

Logo após, realizaram uma prova de função pulmonar pré e pós broncodilatador de acordo com os critérios da American Thoracic Society (ATS, 1995) (figura 6), onde se considerou:

a) capacidade vital forçada (CVF);

b) volume expiratório forçado no primeiro segundo $\left(V_{E F}\right)$;

c) fluxo expiratório forçado (FEF25\%-75\%); e ainda

d) relação entre a porcentagem do volume expiratório forçado e a capacidade vital forçada $\left(\% \mathrm{VEF}_{1} / \mathrm{CVF}\right)$.

Figura 6. Espirômetro KOKO

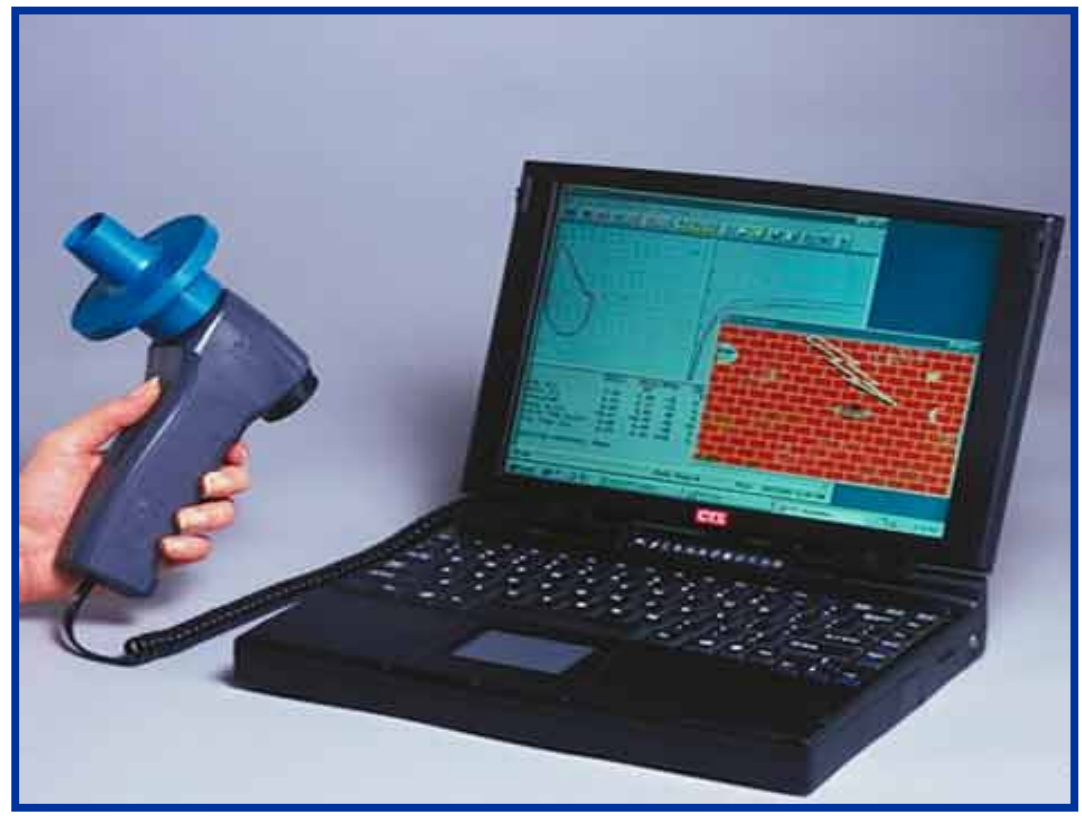

Aparelho portátil Koko (Pds Instrumentation Inc., Lousville, Estados Unidos da América) utilizado para realização da prova de função pulmonar. 


\subsubsection{ESCARRO INDUZIDO}

Após as medidas da espirometria os sujeitos foram submetidos à coleta de escarro induzido onde receberam até três inalações de salina hipertônica em concentração de $3 \%$, por 7 minutos. Utilizou-se um nebulizador ultrassônico DeVilbiss Ultraneb 99 (DeVilbiss Corp., Somerset, $\mathrm{PA}$, USA) com um débito de $2,4 \mathrm{~mL} / \mathrm{min}$, gerando partículas de $4,5 \mu \mathrm{m}$. Houve sempre a retaguarda de um médico e corpo de enfermagem para as eventuais intercorrências médicas durante o processo de indução. Todo o processo de indução foi feito dentro do Hospital das Clínicas da Faculdade de Medicina de São Paulo.

Após cada inalação, os pacientes enxaguaram a boca com água, assuaram o nariz e o escarro foi colhido em recipiente estéril próprio (Pizzichini et al., 1996). A amostra foi processada como descrita a seguir.

O escarro foi separado da saliva com ajuda de um microscópio invertido e dividido em duas porções. A primeira parte foi destinada à confecção de um esfregaço simples, onde o muco foi colocado sobre uma lâmina e distribuído por esta ("puxado") com o auxílio de outra lâmina (Saraiva-Romanholo et al., 2003). O esfregaço foi deixado para secar ao ar livre e corado com Diff Quick (Pizzichini et al., 1998).

A segunda porção do escarro foi tratada com o volume de ditiotreitol (DTT) igual a 1 vez o peso do escarro em mg. A solução foi diluída a $0,1 \%$ 
em PBS. O material foi homogeneizado e posto em banho-maria por 15 minutos e, em seguida, o número total de leucócitos na câmara de Neubauer foi contado (Palomino et al., 2005).

Consideram-se adequadas amostras obtidas após período mínimo de 14 minutos de inalação, com um tempo de processamento não superior a duas horas, com um volume de escarro coletado $\geq 1 \mathrm{~mL}$, com número de células escamosas $\leq 80 \%$ e onde foi possível contar, no mínimo 400 células inflamatórias. Vide tabela 3 abaixo.

\section{Tabela 3. Critérios para aceitação da amostra}

\section{ACEITAÇÃO DA AMOSTRA}

Tempo de inalação $\geq 14$ minutos.

Volume de escarro $\geq 1 \mathrm{~mL}$

Tempo de processamento da amostra 2 horas

Células escamosas $\leq 80 \%$ 400 células inflamatórias

A contagem diferencial foi realizada no microscópio óptico, no aumento de 1000x onde foram identificados eosinófilos, linfócitos, neutrófilos, macrófagos, células planas, células caliciformes e células ciliadas. 


\subsubsection{IMUNOGLOBULINA E SÉRICA TOTAL}

A $\lg E$ sérica total foi quantificada pelo método de nefelometria utilizando-se um kit Dade Berhing, em aparelho automatizado (Berhing Nephelometer Analyser) de acordo com a rotina do Laboratório Central do Hospital das Clínicas.

\subsubsection{TESTE ALÉRGICO CUTÂNEO}

Os testes cutâneos de hipersensibilidade imediata foram realizados pelo método de puntura de acordo com as normas do Sub-Comitê de Testes Cutâneos da EAACI (Dreborg, 1993) e foram realizados no ambulatório de Alergia-Imunologia do Hospital das Clínicas da FMUSP

Foram utilizados extratos comerciais de sete alérgenos: ácaros (Dermatophagoides pteronyssinus e Blomia tropicalis), cachorro (Canis familiaris), gato (Felis domesticus), barata (Periplaneta americana, Blatella germanica), fungos (Aspergillus fumigatus, Alternaria alternata, Penicillium notatum) e Pólens [(mistura): Dactylis glomerata, Festuca pratensis, Lolium perene, Poa pratensis e Pheum pratense]. Como controle negativo utilizouse solução salina e, como positivo, histamina. Todos os extratos foram adquiridos do laboratório IPI ASAC BRASIL.

Para a interpretação dos resultados, foi calculada a média aritmética, entre as medidas do maior diâmetro e seu respectivo diâmetro ortogonal, 
sendo consideradas positivas as pápulas maiores que três milímetros (Dreborg, 1993).

\subsubsection{ANÁLISE ESTATÍSTICA}

A análise estatística foi realizada utilizando o programa Sigma Stat (Sigma Stat for Windows). Análise descritiva foi empregada para o estudo da média e desvio padrão das características dos sujeitos.

A análise de variância, com teste de Kruskal-Wallis foi utilizada para analisar a citologia de escarro, óxido nítrico e $\lg E$ nos 3 grupos (controle, broncoespasmo e asma). A seguir, para se verificar onde estavam essas diferenças, utilizou-se o teste de Dunn.

O teste de Tukey foi utilizado para análises dos dados da função pulmonar (mediana e percentil 25-75). Foi considerado estatisticamente significante um $\mathrm{p}<0,05$ (Zar, 1984a; Zar, 1984b). 
4-Resultados 
Do período de 1999 a 2004 foram analisadas 146.358 fichas anestésicas e foram encontrados 863 relatos de broncoespasmo descritos no intra-operatório. Destes, 277 eram pacientes portadores de alguma doença sistêmica. Das fichas que remanesceram, 175 eram de pacientes com mais de 60 anos, 139 crianças com idade até 16 anos, e 39 pacientes foram identificados como fumantes. Desta forma todas estas fichas foram excluídas. Dentre as 233 fichas que apresentavam alguma descrição de pacientes com broncoespasmo induzido por intubação traqueal, 52 eram portadores de asma e 21 eram pacientes sem história documentada de asma e com broncoespasmo. Em 160 fichas restantes o broncoespasmo foi identificado, mas não foi possível contatá-los por telefone ou mesmo por correspondência.

Daqueles 52 asmáticos, treze foram contatados por telefone, doze foram aceitos e uma paciente declarou na véspera do exame estar grávida, portanto retirou-se o convite para participar do protocolo. Daquelas 21 fichas de pacientes com broncoespasmo sem história de asma, foi possível convidar por telefone 20 sujeitos, onde seis se recusaram a participar do protocolo, uma relatou por telefone sintomas de asma e outra relatou obesidade móbida, um não conseguiu fazer a espirometria corretamente, 
resultando em erro de técnica e dois foram diagnosticados na primeira visita ao médico, como portadores de DPOC leve, sendo excluídos do estudo. Os 9 pacientes que restaram não apresentavam nenhuma doença respiratória detectada na primeira visita ao médico.

Resumidamente, foram incluídos no protocolo 21 casos de broncoespasmo e dez controles, constituindo assim três grupos; asma - 12 pacientes, broncoespasmo - 9 pacientes e 10 como grupo controle (tabela 4 e figura 3).

Os dados da função pulmonar mostraram-se compatíveis para cada grupo estudado: Asma, broncoespasmo e controle. O grupo asma foi diferente do grupo controle e diferente do grupo broncoespasmo (figura 9). O grupo broncoespasmo e controle apresentaram dados espirométricos dentro dos padrões de normalidade (tabela 4 e figuras 7 a 14).

O escarro foi obtido em todas das induções. Utilizou-se neste trabalho as análises de uma amostra por sujeito da pesquisa. De todas as induções realizadas, nenhum indivíduo relatou desconforto respiratório (tosse, chiado e/ou falta de ar), para interromper o procedimento antes de completar os 14 minutos de inalação. 
As porcentagens de eosinófilos no escarro foram estatisticamente significantes somente quando comparados os asmáticos com os controles (tabela 5 e figura 15). Embora os eosinófilos do grupo broncoespasmo tenham se mostrado elevados, não foi encontrada diferença em relação ao grupo controle (tabela 5 e figura 15).

Todos os pacientes apresentaram uma porcentagem de neutrófilos levemente elevada, com excessão do grupo de asmáticos. No entanto, não houve diferença estatística entre os grupos. Quando o total de células foi analisado na câmera de Neubauer nenhuma diferença foi encontrada (tabela 5 e figura 16).

Os linfócitos no grupo broncoespasmo mostraram-se um pouco elevados, mas não houve diferença estatística em relação aos outros grupos (tabela 5 e figura 17).

Macrofágos foram as células predominantes no escarro induzido e portantos os três grupos apresentaram uma grande quantidade destes marcadores (tabela 5 e figura 18).

Com relação a dosagem de $\operatorname{lgE}$, no grupo broncoespasmo, mostrouse elevada em relação aos controles, contudo, sem diferença estatística. 0 grupo asma também apresentou IgE elevada e foi estatisticamente diferente 
do grupo controle (tabela 5 e figura 19). Dois pacientes do grupo asma não compareceram para coleta da imunoglobulina E sérica, desta forma foram analisados a $\lg \mathrm{E}$ de 10 sujeitos do grupo controle, 9 do grupo broncoespasmo e 10 do grupo asma.

O teste alérgico cutâneo mostrou-se positivo para uma variedade de alérgenos e levemente elevado nos asmáticos. No grupo controle um indíviduo não realizou este exame ficando este grupo com nove sujeitos. (tabela 6).

O óxido nítrico exalado mostrou-se elevado, tanto no grupo asma como no grupo que apresentou broncoespasmo no intra-operatório sem doença, sendo ambos estatisticamente diferentes em relação ao grupo controle $(p \leq 0,005)$. Vide tabela 5 e figura 20 .

Os gráficos apresentados em Box Plot são mais apropriados para representar dados que não atendem aos pré-requisitos de normalidade estatística. A barra (negra) representa a mediana, a base inferior da caixa está situada na altura do percentil $25 \%$ e a superior na do percentil $75 \%$. 0 intervalo interquartílico é a diferença entre o terceiro e o primeiro quartil. Do elemento mais alto que não seja um outlier traça-se uma linha até o centro da base superior da caixa (percentil 90\%) o mesmo ocorrendo com o mais baixo, definindo o percentil $10 \%$. 
Nas figuras abaixo a cor vermelha representa o grupo controle, a amarela o grupo broncoespasmo e a rosa o grupo asma.

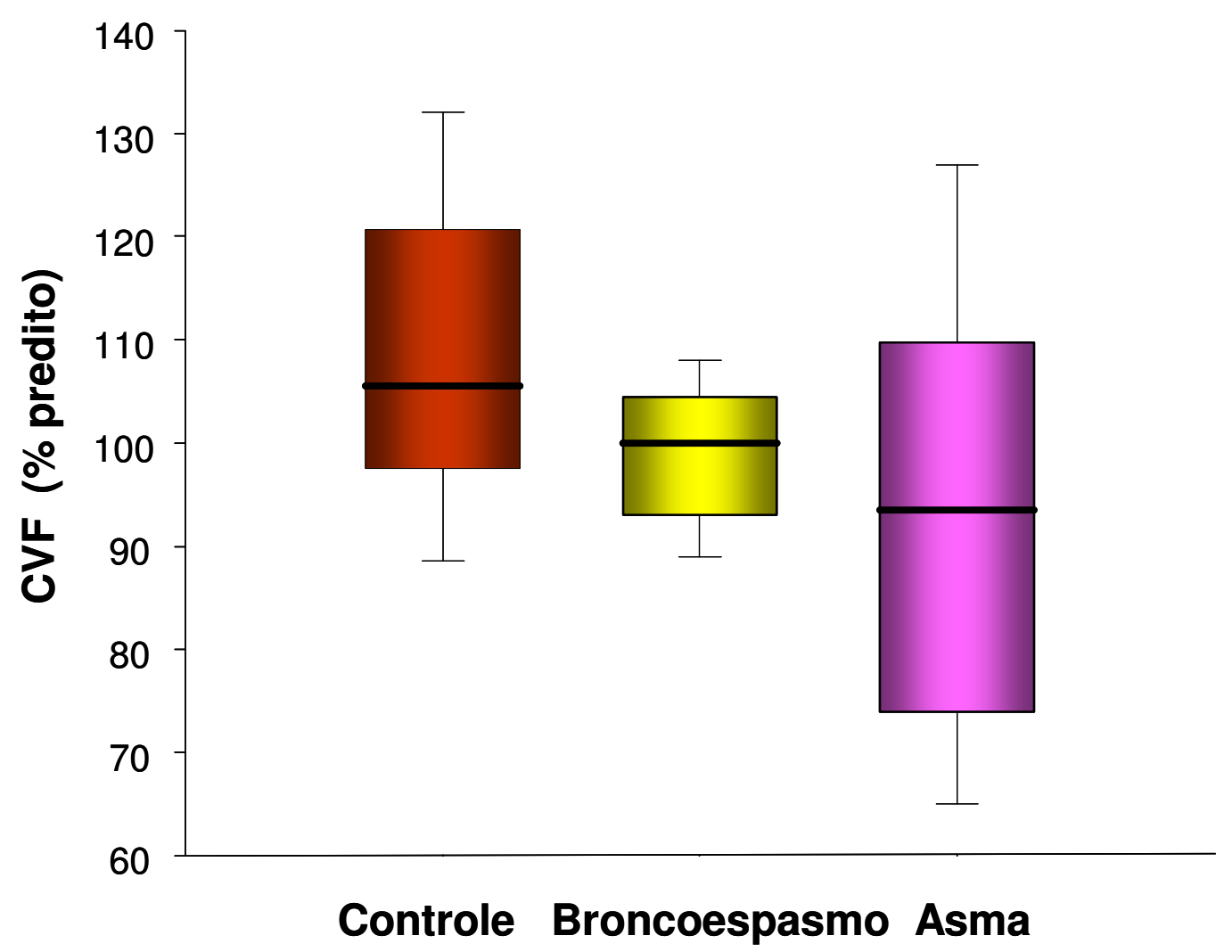

Figura 7. Box Plot ilustrando os dados da CVF- capacidade vital forçada pré broncodilatador, nos diferentes grupos estudados: controle, broncoespasmo e asma. Não houve diferença estatisticamente significativa entre os grupos. 


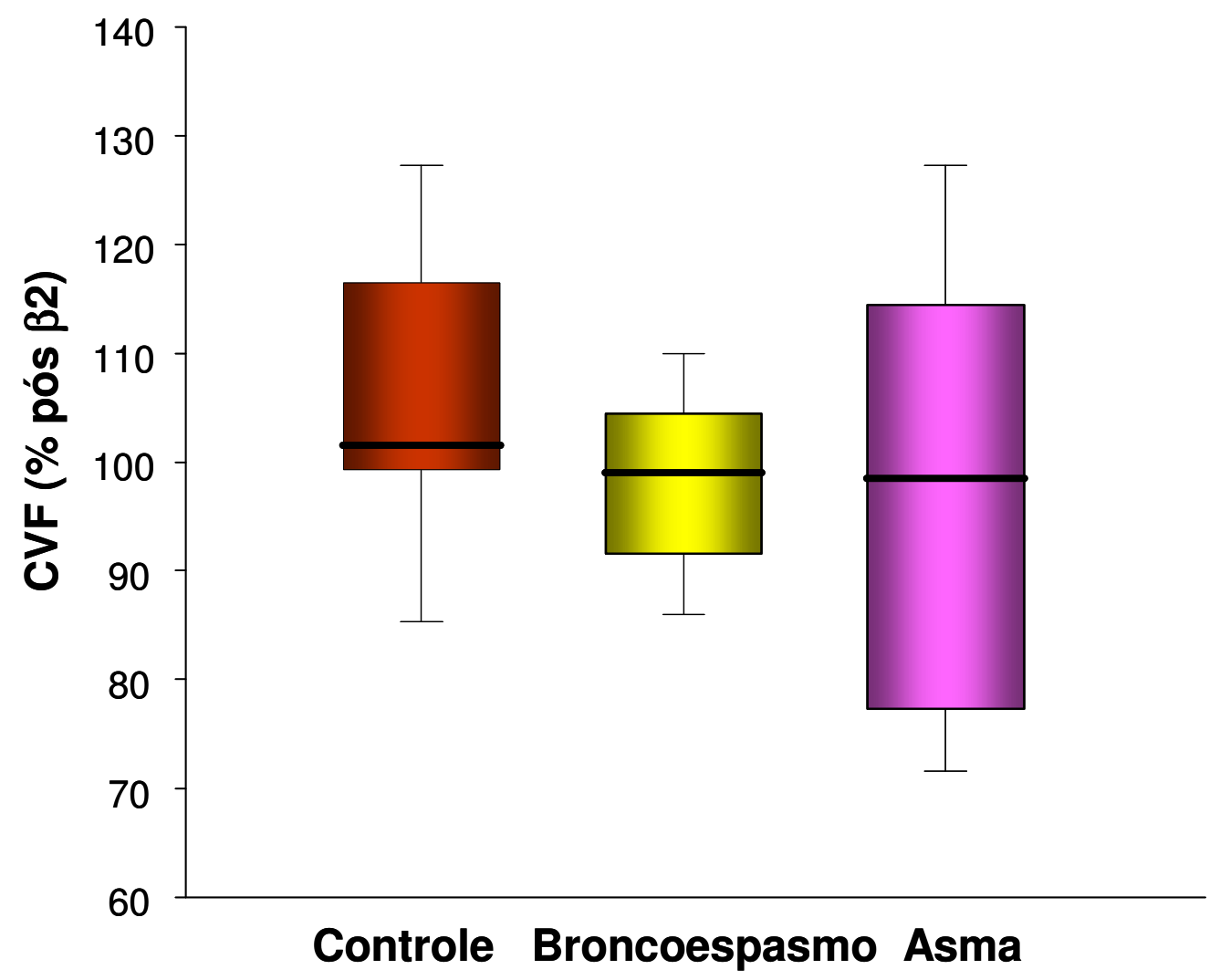

Figura 8. Box Plot ilustrando os dados da CVF- capacidade vital forçada pós broncodilatador, nos diferentes grupos estudados: controle, broncoespasmo e asma. Não houve diferença estatisticamente significativa entre os grupos. 


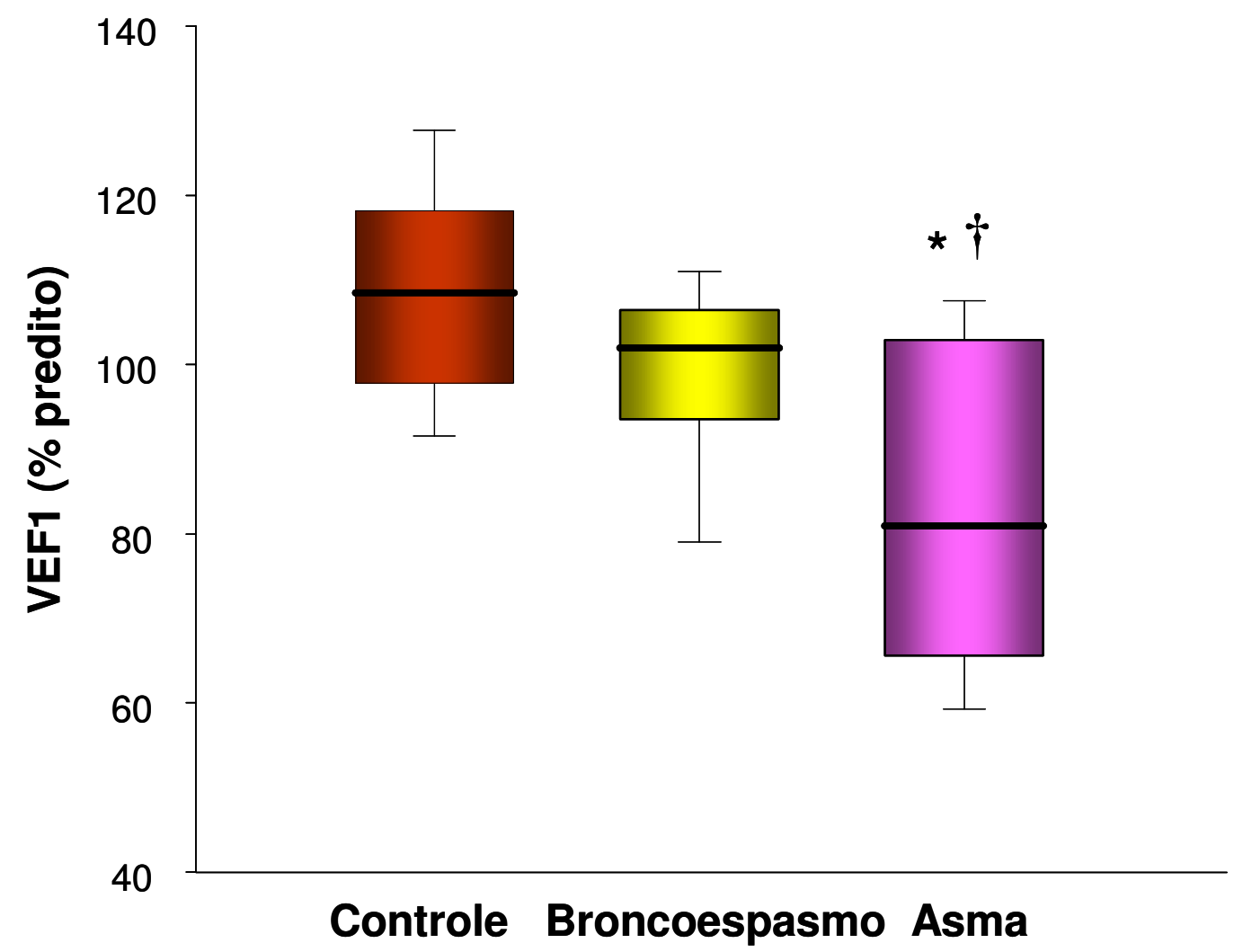

Figura 9. Box Plot ilustrando os dados do $\mathrm{VEF}_{1}$ - volume expiratório forçado no primeiro segundo pré broncodilatador, nos diferentes grupos estudados: controle, broncoespasmo e asma. Significantemente $\left({ }^{*}\right)$ em relação ao controle, $(\dagger)$ em relação ao grupo broncoespasmo. Valores individuais de $\mathrm{p}$ encontram-se na tabela 4. 


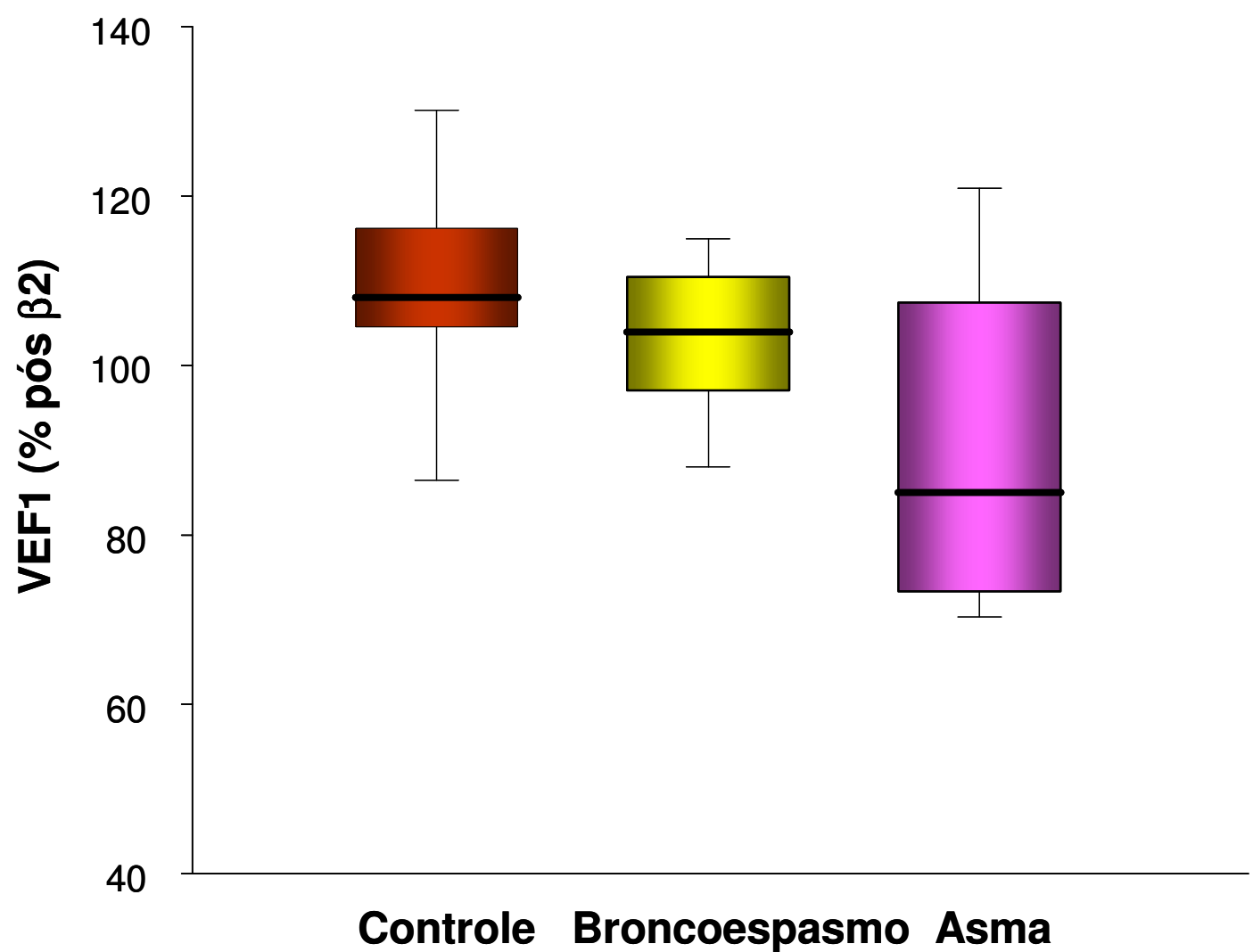

Figura 10. Box Plot ilustrando os dados do $\mathrm{VEF}_{1}$ - volume expiratório forçado no primeiro segundo pós broncodilatador, nos diferentes grupos estudados: controle, broncoespasmo e asma. Não houve diferença estatisticamente significativa entre os grupos. 


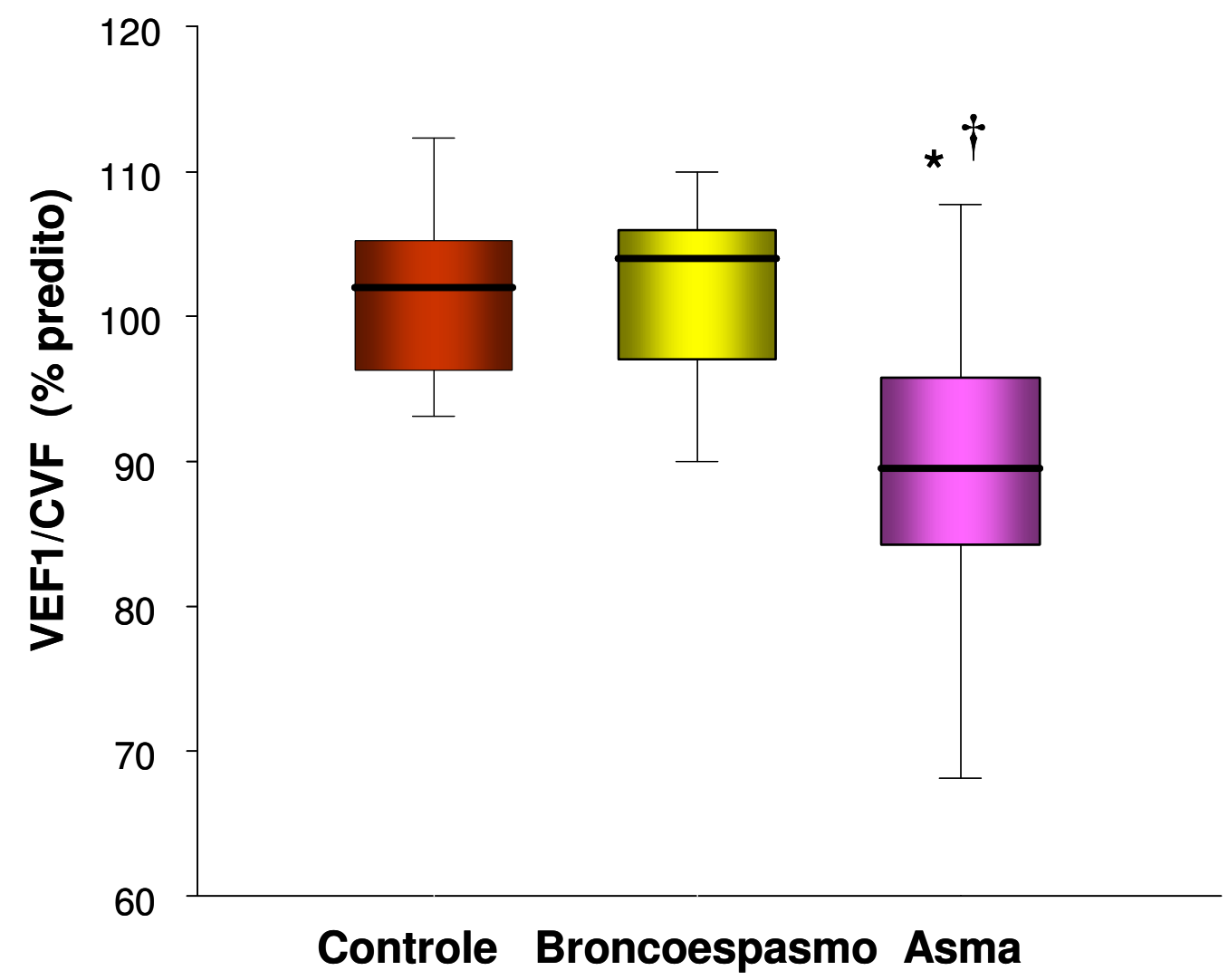

Figura 11. Box Plot ilustrando os dados da $\mathrm{VEF}_{1} / \mathrm{CVF}$ - razão da porcentagem do volume expiratório forçado e a capacidade vital forçada em relação ao predito, nos diferentes grupos estudados: controle, broncoespasmo e asma. Significantemente $\left(^{*}\right)$ em relação ao controle, $(\dagger)$ em relação ao grupo broncoespasmo. Valores individuais de p encontram-se na tabela 4. 


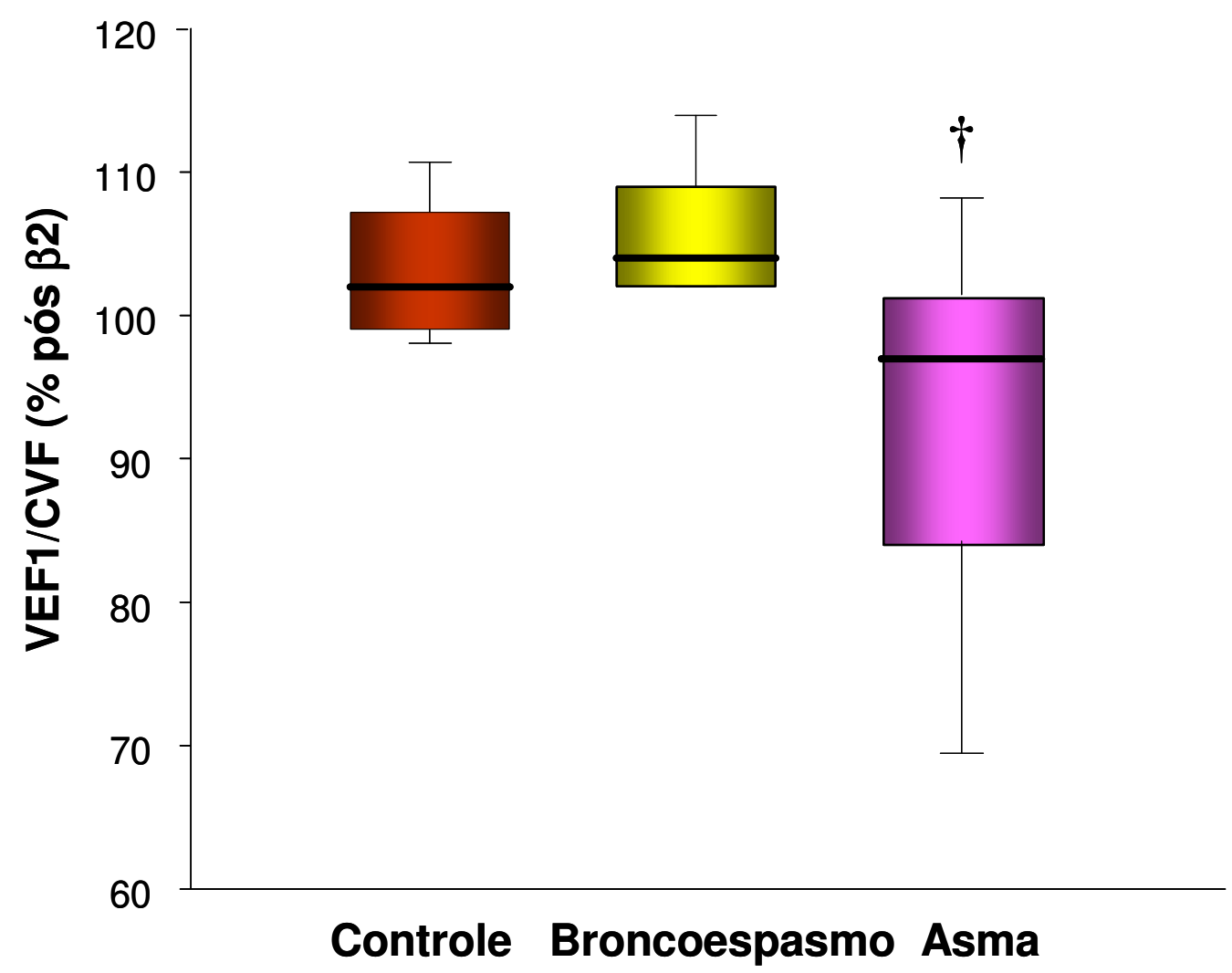

Figura 12. Box Plot ilustrando os dados da $\mathrm{VEF}_{1} / \mathrm{CVF}$ - razão da porcentagem do volume expiratório forçado e a capacidade vital forçada medida pós broncodilatado, nos diferentes grupos estudados: controle, broncoespasmo e asma. ( $\dagger$ ) em relação ao grupo broncoespasmo. Valor de p encontra-se na tabela 4. 


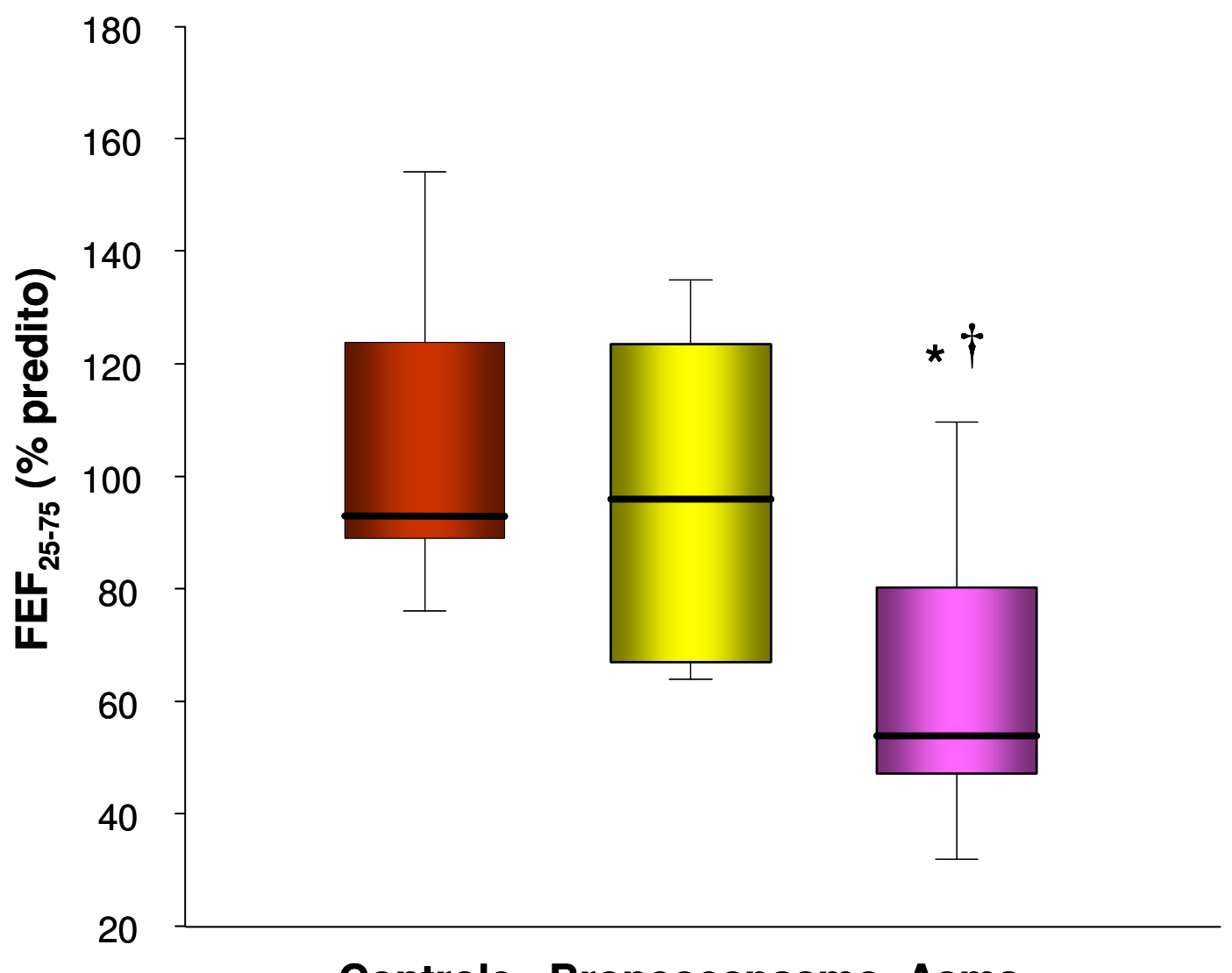

Controle Broncoespasmo Asma

Figura 13. Box Plot ilustrando os dados do $\mathrm{FEF}_{25-75}$ - fluxo expiratório forçado pré broncodilatador, nos diferentes grupos estudados: controle, broncoespasmo e asma. Significantemente $\left(^{*}\right)$ em relação ao controle, (†) em relação ao grupo broncoespasmo. Valores individuais de $p$ encontram-se na tabela 4. 


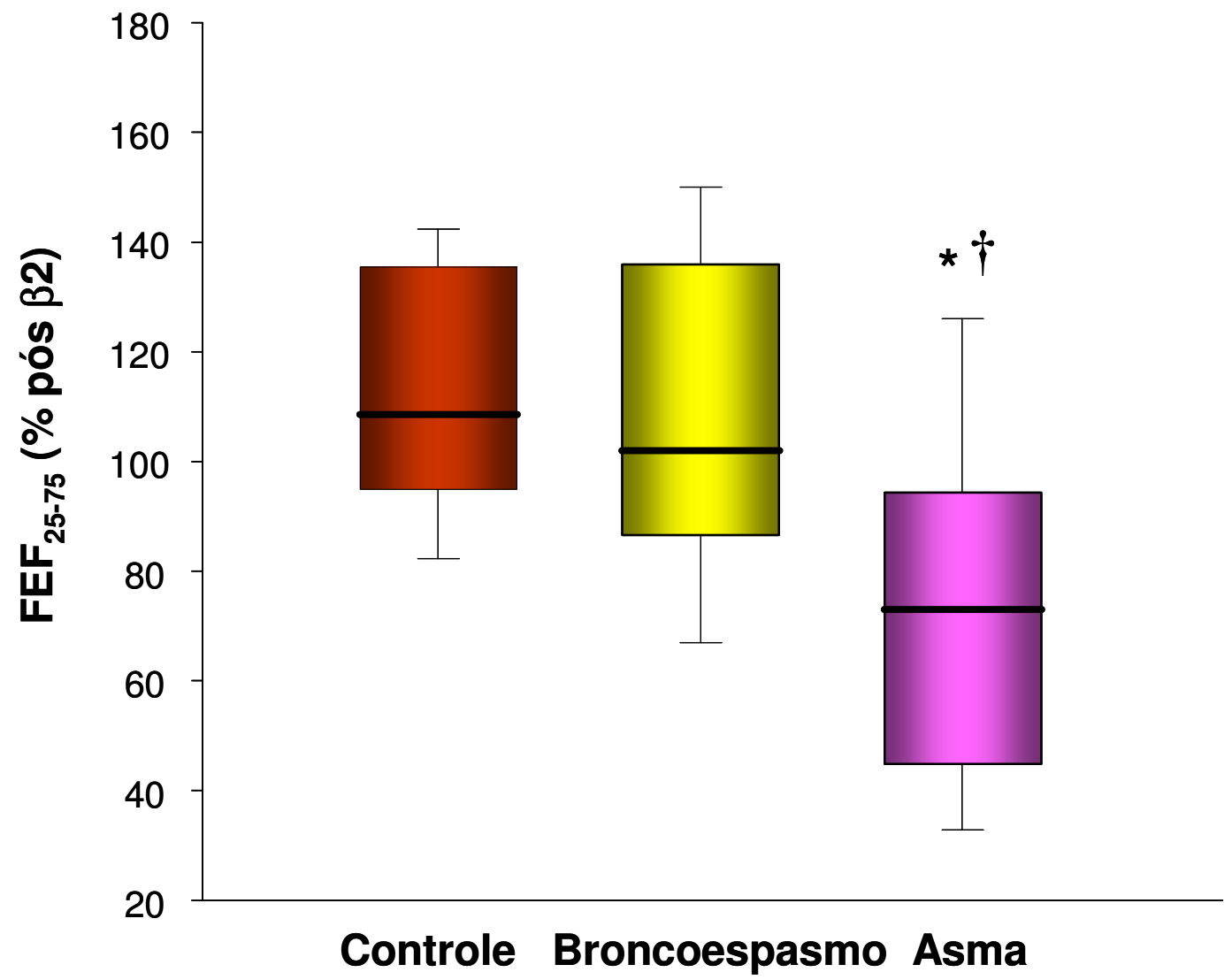

Figura 14. Box Plot ilustrando os dados do $\mathrm{FEF}_{25-75}$ - fluxo expiratório forçado medido pós broncodilatador, nos diferentes grupos estudados: controle, broncoespasmo e asma. Significantemente $\left({ }^{*}\right)$ em relação ao controle, $(\dagger)$ em relação ao grupo broncoespasmo. Valores individuais de $p$ encontram-se na tabela 4. 


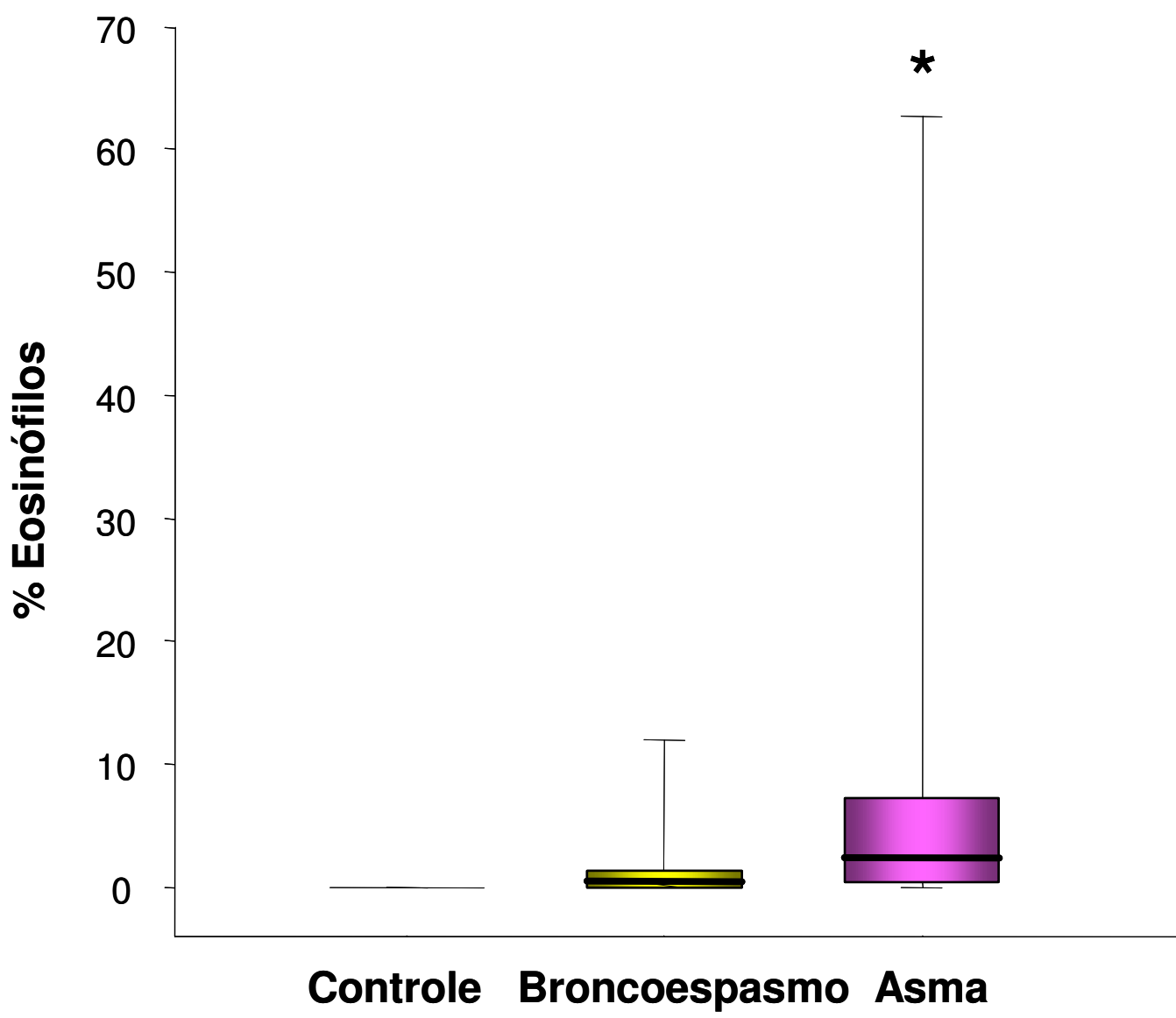

Figura 15. Box Plot ilustrando os dados de eosinófilos quantificados em escarro induzido nos diferentes grupos estudados: controle, broncoespasmo e asma. Significantemente $\left(^{*}\right)$ em relação ao controle. Valor de p encontra-se na tabela 5. 


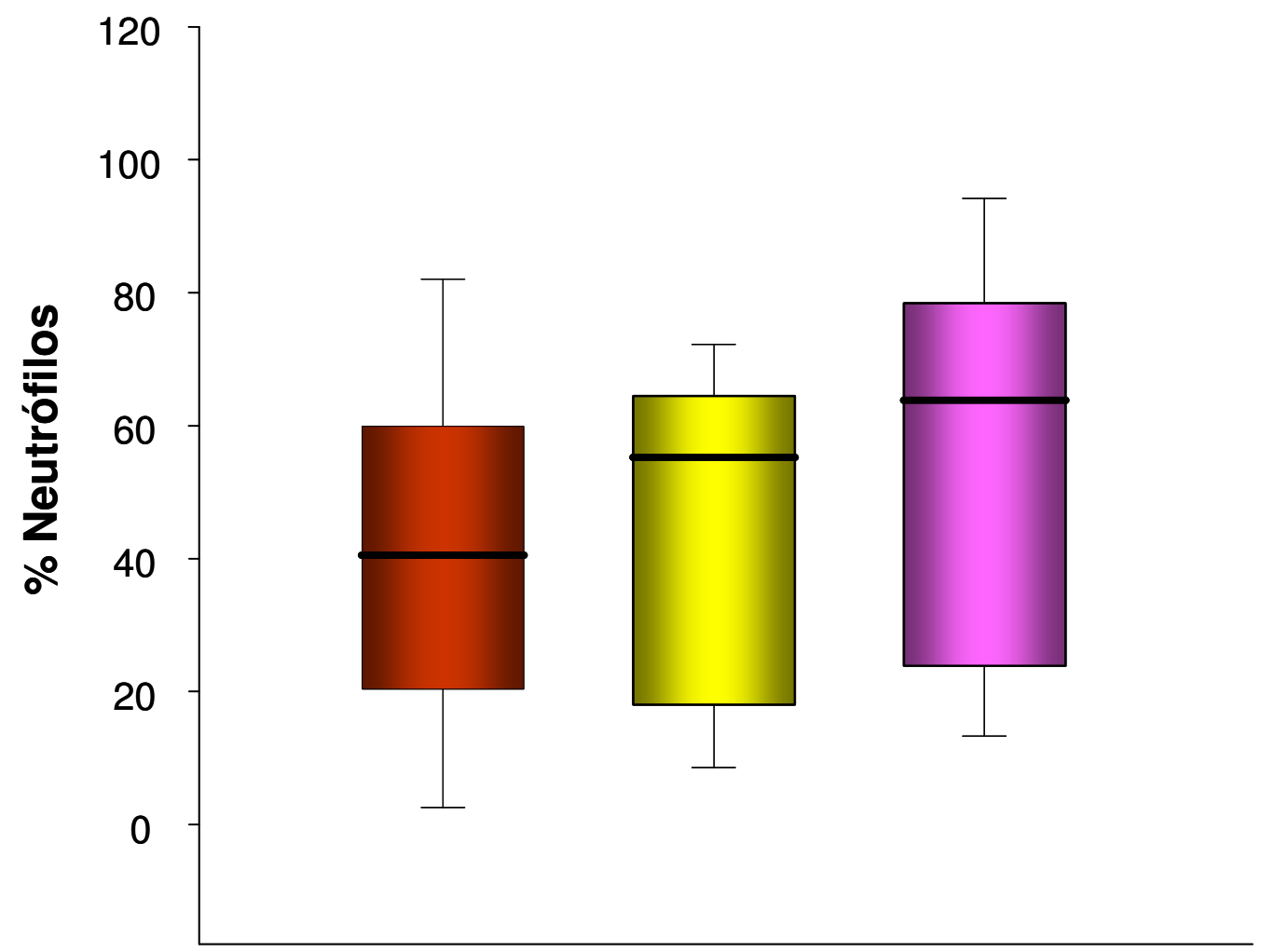

Controle Broncoespasmo Asma

Figura 16. Box Plot ilustrando os dados de neutrófilos quantificados em escarro induzido nos diferentes grupos estudados: controle, broncoespasmo e asma. Não houve diferença estatisticamente significativa entre os grupos. 


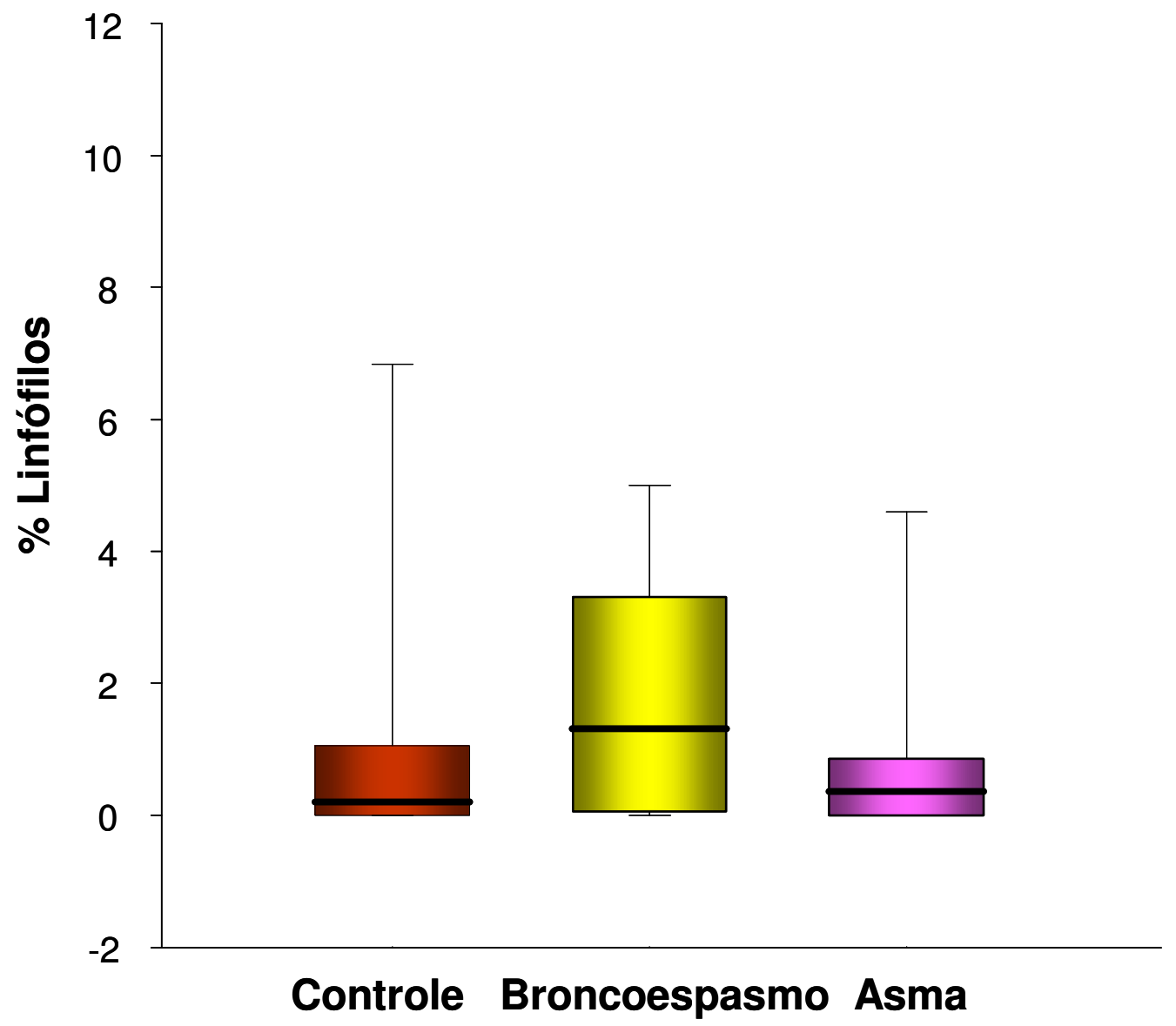

Figura 17. Box Plot ilustrando os dados de linfócitos quantificados em escarro induzido nos diferentes grupos estudados: controle, broncoespasmo e asma. Não houve diferença estatisticamente significativa entre os grupos. 


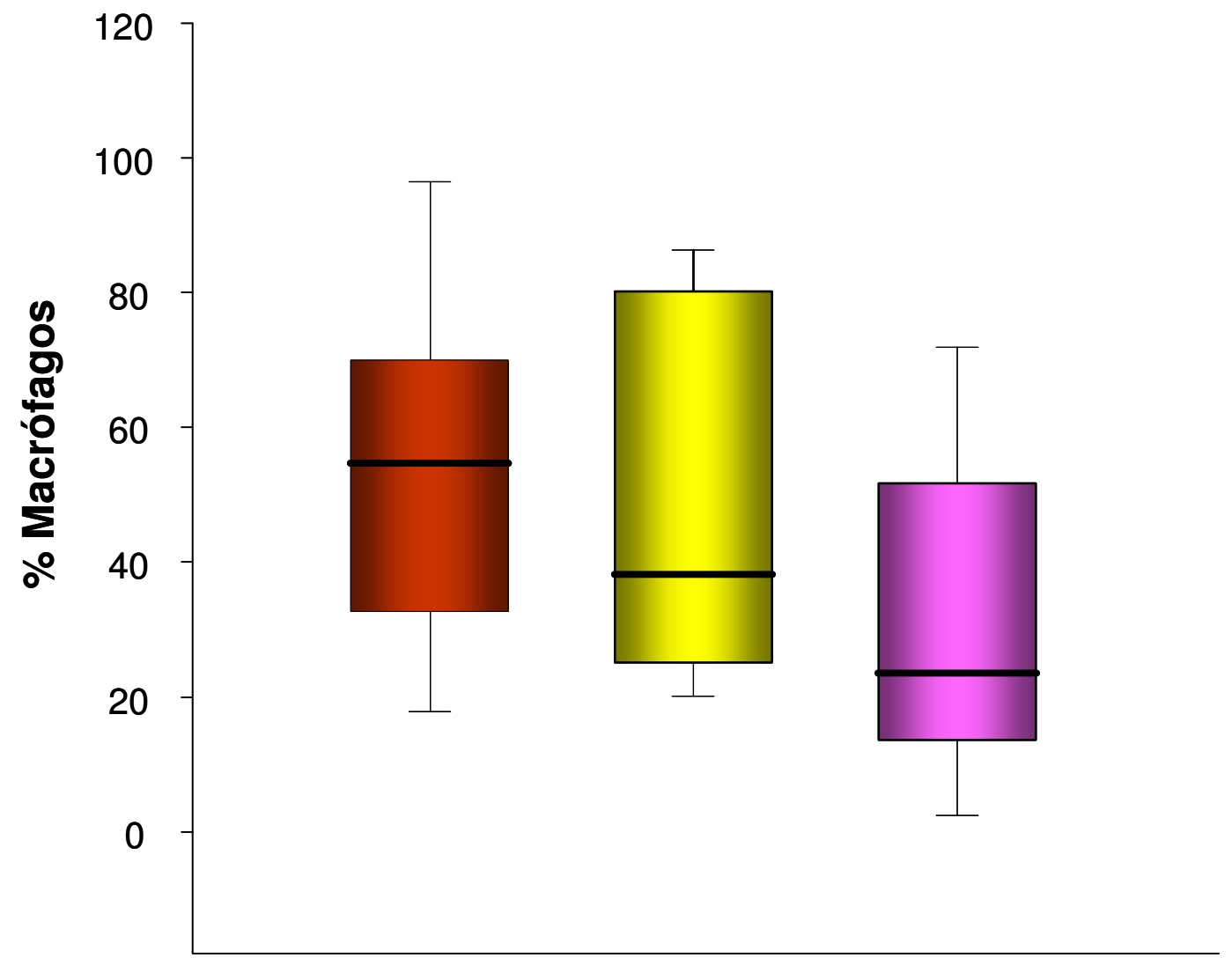

\section{Controle Broncoespasmo Asma}

Figura 18. Box Plot ilustrando os dados de macrófagos quantificados em escarro induzido nos diferentes grupos estudados: controle, broncoespasmo e asma. Não houve diferença estatisticamente significativa entre os grupos. 


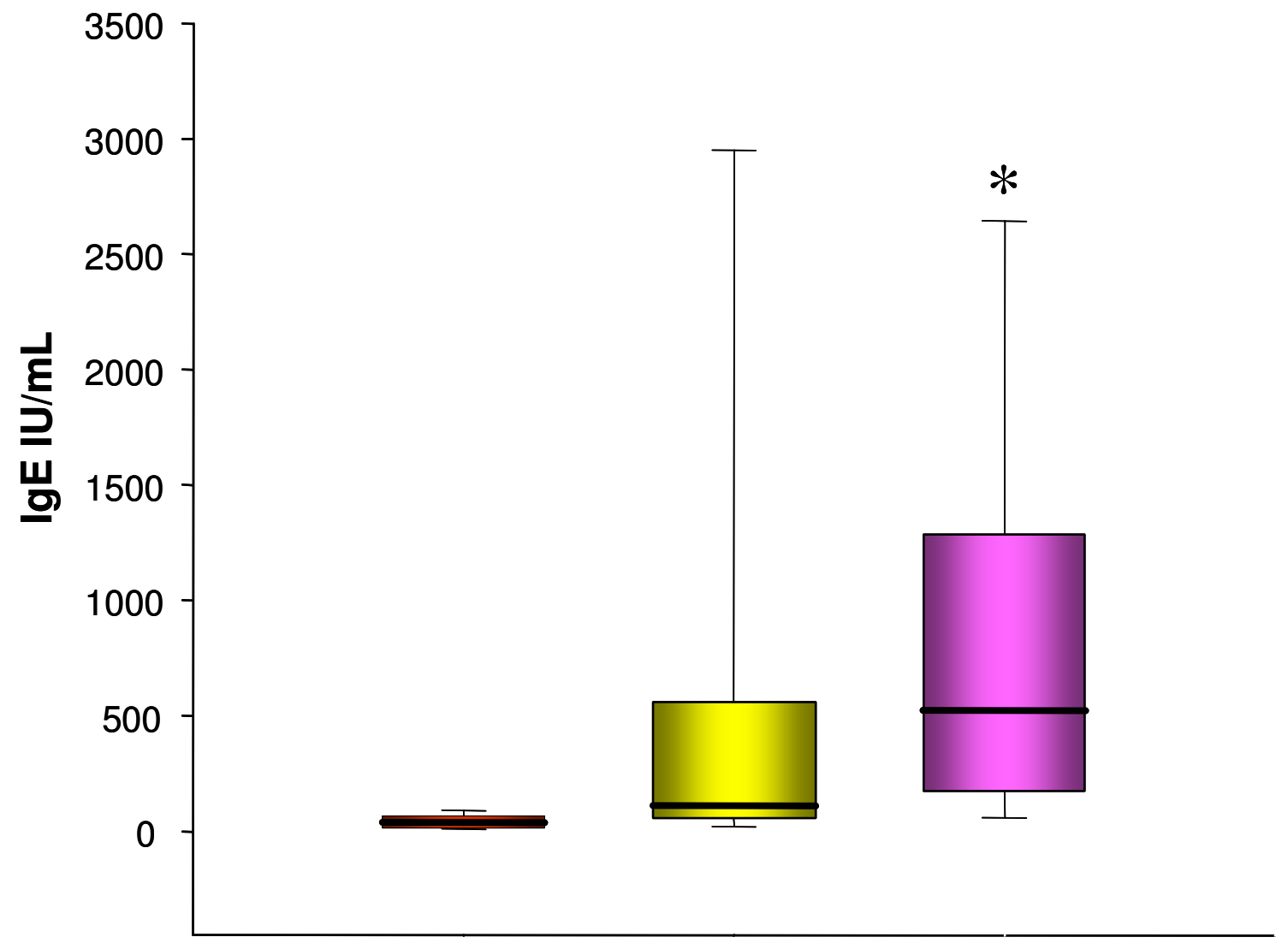

Controle Broncoespasmo Asma

Figura 19. Box Plot ilustrando os dados de IgE UL/mL imunoglobulina E quantificados no sangue periférico, nos diferentes grupos estudados: controle, broncoespasmo e asma. Significantemente $\left(^{*}\right)$ em relação ao controle. Valor de $\mathrm{p}$ encontra-se na tabela 5. 


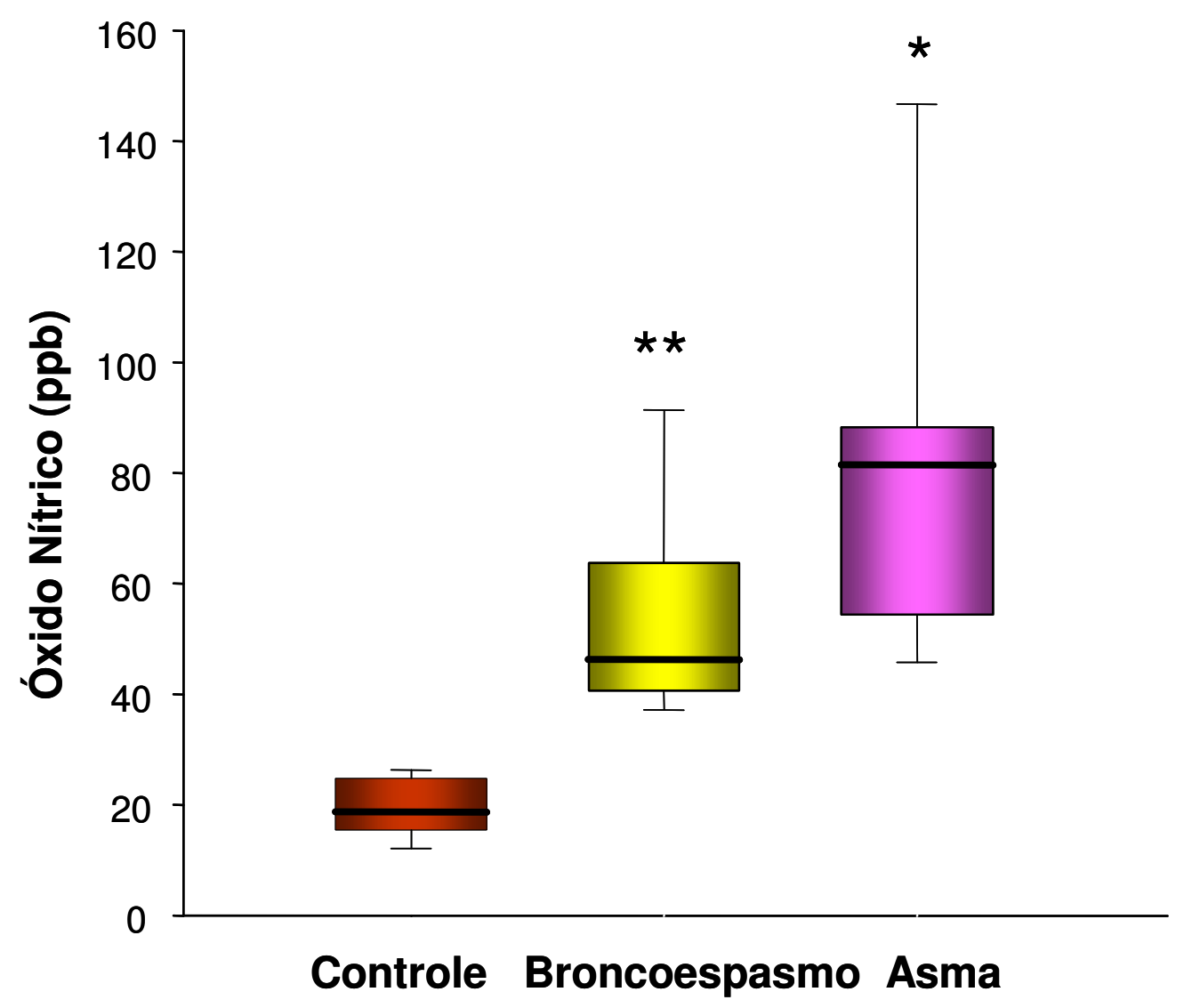

Figura 20. Box Plot ilustrando os dados de NOex (ppb), óxido nítrico quantificados no ar exalado, nos diferentes grupos estudados: controle, broncoespasmo e asma. Significantemente $\left({ }^{*}\right)$ asma em relação ao controle, $\left.{ }^{(* *}\right)$ broncoespasmo em relação ao controle. Valores individuais de $p$ encontram-se na tabela 5. 
Tabela 4. Dados Espirométricos dos Pacientes

\begin{tabular}{|c|c|c|c|c|}
\hline Grupo & $\begin{array}{c}\text { Controle } \\
\text { Mediana } \\
\text { [25\%-75\%] }\end{array}$ & $\begin{array}{c}\text { Broncospasmo } \\
\text { Mediana } \\
\text { [25\%-75\%] }\end{array}$ & $\begin{array}{c}\text { Asma } \\
\text { Mediana } \\
\text { [25\%-75\%] }\end{array}$ & $\mathbf{P}$ \\
\hline CVFpré (\%) & $\begin{array}{c}105,5 \\
{[99,0-120,0]}\end{array}$ & $\begin{array}{c}100,0 \\
{[93,0-104,2]}\end{array}$ & $\begin{array}{c}93,5 \\
{[79,0-108,5]}\end{array}$ & NS \\
\hline CVFpós (\%) & $\begin{array}{c}101,5 \\
{[100,0-115,0]}\end{array}$ & $\begin{array}{c}99,0 \\
{[92,7-104,2]}\end{array}$ & $\begin{array}{c}98,5 \\
{[80,5-113,0]}\end{array}$ & NS \\
\hline $\mathrm{VEF}_{1}$ pré (\%) & $\begin{array}{c}108,5 \\
{[98,0-116,0]}\end{array}$ & $\begin{array}{c}102,0 \\
{[95,2-105,7]}\end{array}$ & $\begin{array}{c}81,0 \\
{[67,0-102,0]^{\star} \dagger}\end{array}$ & $\begin{array}{l}{ }^{*} 0,0003 \\
+0,020\end{array}$ \\
\hline $\mathrm{VEF}_{1}$ pós (\%) & $\begin{array}{c}108,0 \\
{[106,0-114,0]}\end{array}$ & $\begin{array}{c}104,0 \\
{[97,0-110,2]}\end{array}$ & $\begin{array}{c}85,0 \\
{[73,5-107,0]}\end{array}$ & NS \\
\hline VEF $_{1} /$ CVFpré (\%) & $\begin{array}{c}102,0 \\
{[97,0-105,0]}\end{array}$ & $\begin{array}{c}104,0 \\
{[97,0-106,0]}\end{array}$ & $\begin{array}{c}89,5 \\
{[84,5-94,5]^{*} \dagger}\end{array}$ & $\dagger^{\star} 0,002$ \\
\hline $\begin{array}{c}\mathrm{VEF}_{1} / \mathrm{CVFpós} \\
(\%)\end{array}$ & $\begin{array}{c}102,0 \\
{[99,0-107,0]}\end{array}$ & $\begin{array}{c}104,0 \\
{[102,0-108,5]}\end{array}$ & $\begin{array}{c}97,0 \\
{[87,5-101,0] \dagger}\end{array}$ & $\dagger 0,005$ \\
\hline FEF $_{25-75}$ pré (\%) & $\begin{array}{c}93,0 \\
{[90,0-122,0]}\end{array}$ & $\begin{array}{c}96,0 \\
{[68,0-120,7]}\end{array}$ & $\begin{array}{c}54,0 \\
{[47,5-74,5]^{*} \dagger}\end{array}$ & $\begin{array}{l}{ }^{*} 0,001 \\
+0,01\end{array}$ \\
\hline $\mathrm{FEF}_{25-75}$ pós (\%) & $\begin{array}{c}108,5 \\
{[98,0-135,0]}\end{array}$ & $\begin{array}{c}102,0 \\
{[87,7-132,5]}\end{array}$ & $\begin{array}{c}73,0 \\
{[49,5-93,0]^{*} \dagger}\end{array}$ & $\begin{array}{l}{ }^{*} 0,003 \\
+0,001\end{array}$ \\
\hline
\end{tabular}

primeiro segundo, $\mathrm{VEF}_{1} / \mathrm{CVF}$ - razão da porcentagem do volume expiratório forçado e a capacidade vital forçada em relação ao predito, $\mathrm{FEF}_{25-75}$ - fluxo expiratório forçado. Pré - predito esperado para, sexo, idade e altura dos sujeitos, Pós - broncodilatador. "Quando comparado com o grupo controle; $†$ quando comparado com o grupo broncoespasmo; NS não significativo. 
Tabela 5. Marcadores Inflamatórios (mediana [25\%-75\%])

\begin{tabular}{|c|c|c|c|c|}
\hline Grupo & $\begin{array}{l}\text { Controle } \\
\text { Mediana } \\
\text { [25\%-75\%] }\end{array}$ & $\begin{array}{c}\text { Broncoespasmo } \\
\text { Mediana } \\
\text { [25\%-75\%] }\end{array}$ & $\begin{array}{c}\text { Asma } \\
\text { Mediana } \\
\text { [25\%-75\%] }\end{array}$ & $\mathbf{P}$ \\
\hline CTC/mL. $10^{6} \mathrm{EI}$ & $0,4[0,3-0,9]$ & $1,3[0,2-2,6]$ & $1,1[0,6-2,0]$ & NS \\
\hline EOS (\%)EI & $0[0-0]$ & $0,5[0-1,3]$ & $2,5[0,4-6,8]$ * & ${ }^{*} 0,002$ \\
\hline Neu (\%)EI & $40,4[24,4-57,0]$ & $55,2[21,9-63,9]$ & $63,8[25,1-78,1]$ & NS \\
\hline Linf (\%)EI & $0,2[0-0,5]$ & $1,3[0,1-3,2]$ & $0,4[0-0,8]$ & NS \\
\hline Macr (\%)EI & $54,6[33,2-65,0]$ & $38,2[25,0-77,1]$ & $23,5[14,5-48,2]$ & NS \\
\hline $\operatorname{lgE~UL/mL~}$ & $35,5[14,0-61,0]$ & $110,0[67,5-395,5]$ & $\begin{array}{c}523,0 \\
{[193,0-1220,0]^{*}}\end{array}$ & ${ }^{*} 0,001$ \\
\hline NOex (ppb) & $18,7[16,0-24,7]$ & $46,2[42,0-62,6]^{* *}$ & $81,5[57,6-86,8]^{\star}$ & $\begin{array}{l}{ }^{*} 0,001 \\
{ }^{* *} 0,005\end{array}$ \\
\hline
\end{tabular}

$\mathrm{CTC} / \mathrm{mL} \cdot 10^{6} \mathrm{El}$. Contagem global de células por mililitro de escarro induzido; EOS (\%) El porcentagen de eosinófilos no escarro induzido; Neu (\%) El porcentagen de neutrófilos no escarro induzido; Linf (\%) EI porcentagen de linfócitos no escarro induzido; Macr (\%) El porcentagen de macrófagos no escarro induzido; lgE $\mathrm{UL} / \mathrm{mL}$ imunoglobulina $\mathrm{E}$ no sangue periférico; NOex (ppb), óxido nítrico no ar exalado. *Grupo asma em relação ao controle. ${ }^{*}$ Grupo broncoespasmo em relação ao controle; NS não significativo. 
Tabela 6. Prick Test

\begin{tabular}{|c|c|c|c|}
\hline Grupo & $\begin{array}{c}\text { Controle (9) } \\
\text { Positivo(n) }\end{array}$ & $\begin{array}{c}\text { Broncoespasmo (9) } \\
\text { Positivo(n) }\end{array}$ & $\begin{array}{c}\text { Asma (12) } \\
\text { Positivo(n) }\end{array}$ \\
\hline Fungo & 1 & 1 & 3 \\
\hline Pólen & 2 & 1 & 10 \\
\hline Ácaro & 4 & 6 & 2 \\
\hline Gato & 2 & 2 & 3 \\
\hline Cachorro & 2 & 1 & 4 \\
\hline Barata & 5 & 1 & \\
\hline
\end{tabular}

Número de pacientes positivos para cada alérgeno nos diferentes grupos controle, broncoespasmo e asma. 


\section{5-Discussão}


O presente estudo demonstrou pela primeira vez que os níveis de óxido nítrico exalado apresentam-se aumentado em pacientes que apresentaram broncoespasmos devido à manipulação das vias aéreas durante a anestesia sem histórico de asma, reforçando alguns estudos que têm sugerido que a hiperresponsividade brônquica está associada aos níveis aumentados de óxido nítrico.

Vários estudos relatam convincentemente que o NO é um marcador inflamatório e ferramenta útil para mensurar a atividade inflamatória das vias aéreas de pacientes asmáticos (Van Den Toorn et al., 2000; Kharitonov et al., 1995c; Zitt, 2005) e é também um importante mediador de inúmeros processos fisiológicos que ocorrem no sistema respiratório, além de estar envolvido na fisiopatologia da asma (Kharitonov et al., 1995a; Barnes, 1996; Ricciardolo et al., 2004).

Apesar de várias pesquisas já terem demonstrado que o óxido nítrico no ar exalado é uma medida não invasiva, bastante útil para se estudar o grau de inflamação de vias aéreas (Barnes e Kharitonov,1996; Baraldi et al., 1997; Lanz et al., 1997), o presente estudo nos permitiu observar que o NO exalado pode também estar elevado em pacientes sem história de via aérea inflamada, mas que apresentam broncoespasmo quando submetidos à 
manipulação das vias aéreas. Entretanto, os dados da literatura são controversos e alguns estudos relatam não haver correlação entre o NO e a hiperresponsividade brônquica (Lim et al., 1999; Van Rensen et al., 1999; Van Den Berge, 2001).

Também deve ser notado que existem trabalhos que mostram não haver relação entre as concentrações de NO com a idade ou sexo em indivíduos adultos (Jilma et al., 1996). Entretanto, em crianças com idade entre 7 a 13 anos, Franklin et al. (1999) demonstraram aumento dos níveis de NO exalado relacionado com a idade. Por este motivo tomou-se o cuidado de recrutar para este estudo somente indivíduos com idade mínima de 17 anos e que durante a visita médica relataram nunca terem apresentado história de asma de acordo com a ATS (1999). Apesar do grupo de broncoespasmo ter um indivíduo com 60 anos de idade, a média da idade deste grupo foi menor que a dos indivíduos do grupo controle.

Os consensos que padronizaram as medidas de NO em animais e em humanos nos dão algumas diretrizes sobre a coleta de NO exalado, ressaltando que uma das principais recomendações é a atenção com a pressão e com o fluxo utilizados na coleta. Por esse motivo, no presente estudo, todos os pacientes sopraram no balão por meio de um bocal nacional mantendo uma pressão respiratória de $12 \mathrm{cmH}_{2} \mathrm{O}$, com um fluxo de $200 \mathrm{~mL} / \mathrm{s}$, de acordo os protocolos padronizados em nosso laboratório por Leme et al (2002). Nesse estudo, os autores testaram dois bocais sendo um 
nacional e um da Sievers e obtiveram semelhança nos dados de NO, onde a pressão de $12 \mathrm{cmH}_{2} \mathrm{O}$ e o fluxo de $200 \mathrm{~mL} / \mathrm{s}$ permaneceram dentro do recomendado pelo consenso da ERS (1997). Além disso, tomamos todos os cuidados para excluir qualquer contaminação proveniente de vias aéreas superiores seguindo os critérios dos consensos ERS (1997) e ATS (1999).

Com a informação de broncoespasmo e também sem outro registro na ficha de anestesia de que se tratasse de um paciente com doença respiratória, estes pacientes foram contatados, entre 1 a 2 anos após 0 registro de broncoespasmo durante anestesia geral com intubação orotraqueal.

Postulou-se uma hipótese de que poderiam ser estes pacientes portadores de hiperresponsividade brônquica. Nesta situação o NOex estaria elevado, não somente pela ocasião da intubação orotraqueal, mas possivelmente de forma constante, ou perene.

Muitos fatores contribuem para o aumento da resistência das vias aéreas, como o broncoespasmo, o qual é geralmente observado em pacientes com doença pulmonar obstrutiva crônica ou história pregressa de asma. O broncoespasmo durante a anestesia é uma complicação que pode se tornar muito grave e até levar à morte. Pode variar de um espasmo moderado com sibilos até casos mais graves nos quais a ventilação mecânica é praticamente impossível de ser utilizada. São fatores 
predisponentes: presença de sibilos pré-operatórios, utilização de agentes histamino-liberadores, intubação em plano superficial ou ainda broncoaspiração de conteúdo gástrico (Pailo e Bernardelli, 2001). A incidência de broncoespasmo no peri-operatório pode variar de $0,17 \%$ a 2,19\% em população com doença obstrutiva (Olsson, 1987). Pacientes com história de broncoespasmo durante a manipulação de vias aéreas podem ter tais episódios relacionados a um mal controle da doença inflamatória respiratória crônica (asma ou DPOC) ou mesmo mal diagnosticadas, e isso tem motivado cada vez mais o surgimento de guidelines de avaliação préoperatória pulmonar. Porém, ainda há poucos estudos sobre o broncoespasmo no intra-operatório e quando se conversa informalmente com médicos anestesistas, é provável que esta incidência possa ser bem maior do que a relatada na literatura. Isso porque o fenômeno é muitas vezes, rapidamente revertido no intra-operatório. Assim, a ocorrência de broncoespasmo neste estudo foi definida pelo registro de obstrução de vias aéreas ou sibilos, relatados pelos anestesistas nas fichas anestésicas dos pacientes. Entretanto, pode ser verificado, durante a consulta clínica, que alguns destes pacientes não tinham o conhecimento de alguma vez na vida terem apresentado sinais ou sintomas que pudessem ser associados a alguma doença respiratória.

A partir da primeira consulta realizada nos pacientes, ficou clara a existência de dois grupos distintos: pacientes asmáticos e pacientes sem nenhuma história de doença respiratória, mesmo tendo sofrido de 
broncoespasmo durante a manipulação de sua via aérea. Este grupo de pacientes com broncoespasmo e sem doença respiratória (grupo broncoespasmo) apresentou também $\lg \mathrm{E}$ aumentada e um pequeno aumento nas células inflamatórias do escarro colhido, embora ainda dentro dos padrões de normalidade. A espirometria destes sujeitos não revelou nenhuma alteração significante, tanto do ponto de vista clínico quanto do ponto de vista de comparação estatística. É interessante notar que estes resultados não permitem diagnosticá-los como pacientes asmáticos ou portadores de alguma doença respiratória. Mas o fato de terem as concentrações de óxido nítrico no ar exalado elevado faz com que eles fiquem situados entre aqueles com vias aéreas hiperresponsivas.

É do conhecimento clínico que a asma é uma doença inflamatoria crônica de vias aéreas, onde algumas células e elementos celulares têm sua participação. Muitos trabalhos têm revelado o exame do escarro induzido como um método seguro e eficaz para a avaliação da inflamação das vias aéreas podendo ser realizado em asmáticos (Berlyne et al., 2000; Gibson et al., 2000; Jatakanon et al., 1998; Paro-Heitor et al., 2007). Contudo Fahy et al. (2001) em um estudo multicêntrico realizado em asmáticos adultos relataram queda do PFE acima de $20 \%$ em aproximadamente $18 \%$ dos pacientes que participaram do estudo, sendo que em alguns pacientes os sintomas de sibilos ocorreram logo nos primeiros quatros minutos de indução, indicando que alguns pacientes podem apresentar broncoespasmo devido à inalação com salina hipertônica. Saraiva-Romanholo et al (2003) 
mostraram que o escarro induzido com salina hipertônica, processado seja pela técnica de citocentrifugação ou por meio da confecção de um esfregaço simples, é uma boa ferramenta para diferenciar asmáticos de pessoas saudáveis, tendo os eosinófilos como as células mais importantes para a diferenciação destes. Este estudo confirmou que o exame é um procedimento seguro e útil para se avaliar a inflamação em indivíduos com diagnósticos de asma, pois nenhum paciente relatou crise de sibilância ou qualquer desconforto respiratório.

Interessante notar que, apesar da presente investigação também indicar que os eosinófilos são importantes marcadores para identificar a inflamação de vias aéreas de pacientes com diagnóstico de asma, o escarro não foi sensível para detectar qualquer diferença entre os indivíduos supostos "hiperresponssivos", do grupo BCE, dos indivíduos do grupo controle. Ou seja os pacientes que tiveram broncoespasmo, se considerados como hiperresponssivos, não têm células inflamatórias detectadas no escarro, tais como os asmáticos. O teste do escarro induzido não foi sensível para detectar uma possível inflamação pulmonar nos pacientes do grupo broncoespasmo, haja vista que células inflamatórias não foram encontradas. Assim, é interessante notar que os resultados do escarro induzido se aproximam ou mesmo se assemelham aos dos pacientes do grupo controle, saudáveis. 
Lönnkvist et al. (2004), estudando crianças tratadas com corticóide comparadas com crianças que tiveram esta medicação suspensa, também aponta que o escarro não foi capaz de detectar diferença entre estes grupos, mas indicam a utilidade do NOex como auxiliar do controle clínico.

Sabe-se que a hiperresponsividade das vias aéreas é uma característica importante da asma e representa uma resposta aumentada dos brônquios a uma variedade de estímulos. Ichinose et al. (2000) estudaram asmáticos e relatam que o NO se correlaciona inversamente com a medida do $F E V_{1}$ em pacientes sem corticóides. Já a hiperresponsividade brônquica não se correlacionou nem com o NO exalado nem com a porcentagem de eosinófilos no escarro induzido. Ainda nesse estudo, os autores relataram haver uma correlação apenas entre a hiperresponsividade à metacolina e à espirometria, indicando que a hiperresponsividade basal de alguns pacientes não se relaciona com parâmetros inflamatórios (Ichinose et al., 2000).

Entretanto, uma vez que pessoas saudáveis apresentem broncoespasmo no período intra-operatório e possuam óxido nítrico elevado, como identificado neste estudo, é possível que aquela indicação possa ser contemplada, já que o achado tardio de NOex elevado coincide com registro clínico prévio de broncoespasmo - embora não tenha sido caracterizada a hiperresponsividade pelo teste $\mathrm{PC}_{20}$. Se o óxido nítrico no ar exalado pode ser considerado um método para predizer a hiperresponsividade brônquica 
em sujeitos não asmáticos, isso ainda deve ser o alvo de investigações mais aprofundadas (Del Giudice et al., 2004; Nogami et al., 2003). Embora médicos anestesiologistas possam tratar estes eventos de brocoespasmos com fármacos, estes pacientes ainda representam uma população de risco, principalmente porque há uma grande diversidade de tratamentos sendo utilizados por estes médicos para reverter o quadro de broncoespasmo, como mostrou a pesquisa de Menezes e Vieira (2002).

A asma pode ocorrer em qualquer idade, apesar da maioria dos casos começarem na infância e parecer estar ligada a um componente hereditário. Em muitos casos ocorre em indivíduos que já têm história de asma na família. Apesar de avanços ocorridos relacionados com a etiologia e patogenia da asma, ainda está distante a compreensão total do desenvolvimento dessa doença (GINA, 2005). O diagnóstico da asma em muitos casos nem sempre é realizado corretamente e geralmente é baseado em condições clínicas e funcionais (SBP e Tisiologia, 2001).

Nos pacientes avaliados neste estudo, a presença da $\lg E$ moderadamente aumentada, associada ao $\mathrm{NO}$ elevado e um modesto aumento do número de eosinófilos no escarro pode sugerir novas possibilidades para identificar pessoas com este perfil e identificar os mecanismos que desenvolvem a asma. A principal questão do por que destes pacientes, eventualmente hiperresponsivos com NOex elevado, não serem asmáticos poderia ser dirigida ao campo genético, com uma melhor 
compreensão da variabilidade genética que predispõe pessoas à asma. Pode ser especulativo, mas ainda assim interessante, considerar a suscetibilidade à asma determinada por expressão genética complexa e também vinculada à regulação de lgE e hiperresponsividade (Postma et al., 1995). Adicionalmente, a implementação da prova de broncoprovocação $\mathrm{PC}_{20}$ poderia enriquecer muito este estudo. Entretanto, considerou-se que este exame seria um risco desnecessário para os pacientes, uma vez que já apresentaram broncoespasmo e possuíam valores de óxido nítrico elevado, o que sugeriria uma predisposição à hiperresponsividade. A ausência deste teste certamente prejudica a sensibilidade da medida, porém, optou-se pela segurança dos pacientes. Seria razoável considerar o NO exalado como marcador que pode ser usado para detectar ocorrências de broncoespasmos, tendo como vantagem ser um exame de baixo risco em relação ao teste de broncoprovocação $\left(\mathrm{PC}_{20}\right)$ (Dupont et al., 1998; Langley et al., 2003; Nogami et al. 2003).

A inflamação de vias aéreas e a hiperresponsividade brônquica são as principais características da asma, no entanto esta relação ainda não está muito clara ou completamente elucidada. Brusasco et al. (1990) mostraram que a exposição de pacientes sensibilizados a alérgenos causa mudança na responsividade de suas vias aéreas, que é associoada com um influxo de células inflamatórias, particularmente eosinófilos. Entretanto, existem também muitos tabalhos que relatam não existir relação entre vias aéreas hiperresponsivas e inflamação (Pizzichini et al., 1996; Foresi et al. 1990). 
Crimi et al. (1998) estudando a inflamação de asmáticos por meio de três parâmentros - lavado brônquico alveolar (BAL) ou escarro induzido ou a biopsia, não encontraram significante relação entre 0 grau de hiperresponsividade das vias aéreas e a inflamação, recuperada por meio destes conhecidos métodos. No entanto, a proteína catiônica eosinofílica (ECP) se correlacionou com a porcentagem de eosinófilos no escarro e no BAL, mas não se correlacionou com a HRB. Recentemente foi demonstrado, em camundongos Balb/c sensibilizados, que menores doses de dexametasona são necessárias para inibir a presença de eosinófilos no lavado brônquico alveolar e no tecido do que aquelas utilizadas para inibir os efeitos da HRB, provavelmente por haver uma dissociação entre a presença dos eosinófilos e a hiperresponsividade brônquica (Birrell et al., 2003).

Estes dados da literatura podem sustentar a hipótese discutida neste trabalho de que pacientes hiperresponsivos não têm doença clínica respiratória, mas podem ter marcadores elevados, na perspectiva de se considerar o NOex como um destes marcadores. Seriam necessárias biópsias brônquicas para confirmar se tais pacientes com HRB teriam também tecidos com presença de células inflamatórias. No entanto, pode-se questionar em que medida tal detecção acrescentaria, já que a presença de HRB pode ser determinante para broncoespasmo e eventualmente independe da presença de inflamação. 
Considerando o NOex elevado como um marcador confiável para hiperresponsividade brônquica, sua detecção poderia instruir diagnóstico precoce ou de suspeita para broncoespasmo no intra-operatório, reduzindo seus riscos pelo tratamento pré-operatório ou por medidas de cautela na manipulação de vias aéreas no intra-operatório.

Desta forma, este trabalho mostrou que o óxido nítrico elevado, detectado no intra-operatório em sujeitos não asmáticos durante a anestesia e manipulação de vias aéreas, pode ser associado com broncoespasmo. A medida do NO exalado pode auxiliar no perioperatório no diagnóstico de pacientes hiperresponsivos e sem história prévia de vias aéreas inflamadas. 
6-Conclusões 
1. Em um estudo controlado o NO exalado mostrou-se elevado em uma população de pacientes sem história clínica de doença respiratória.

2. Pacientes não asmáticos que apresentaram broncoespasmo no intra-operatório, apresentam níveis de NO exalado maiores do que os que não apresentam broncoespasmo no intra-operatório.

3. A espirometria, o $\lg E$ e os eosinófilos no escarro induzido não foram capazes de diferenciar os grupos broncoespasmo e controle. 
7-ANEXOS 
Anexo A. Ficha de Registro de Casos

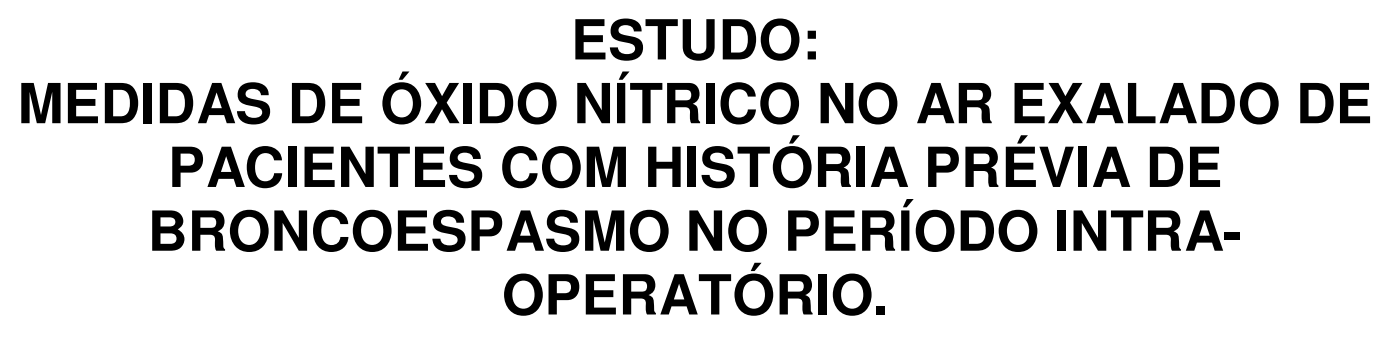

CASE REPORT FORM

CASO $\mathrm{N}^{\circ}=$ 


\section{IDENTIFICAÇÃO}

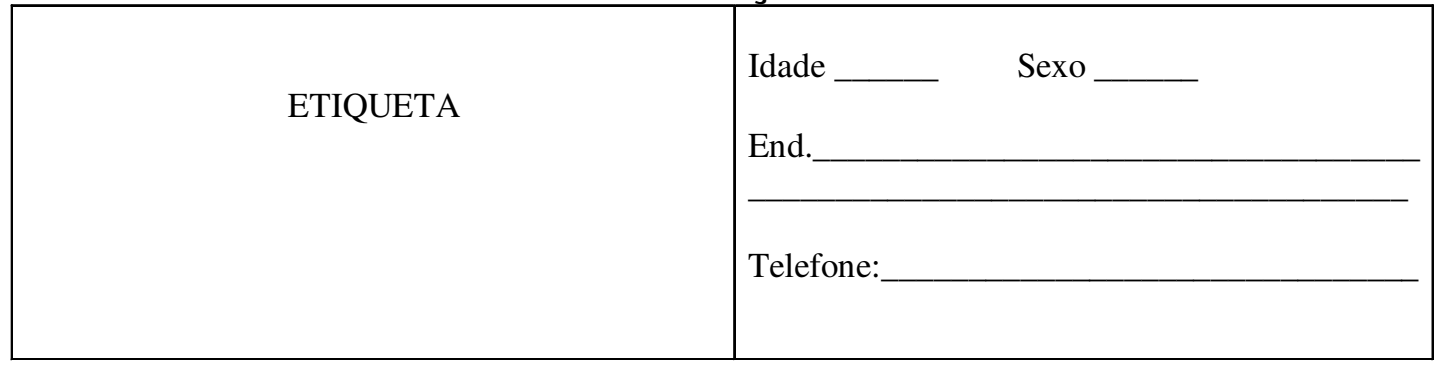

\section{Grupos de pacientes}

1. Pacientes com broncoespasmo no intra-operatório e sem evidência de doença pulmonar pela história clínica e espirometria ( )

2. Pacientes com broncoespasmo no intra-operatório e com evidência de doença pulmonar pela história clínica, ou espirometria ( )

3. Pacientes sem broncoespasmo no intra-operatório e sem evidência de doença pulmonar pela história clínica e espirometria ( )

Índice de Detsky

classe 1

classe 2

classe 3

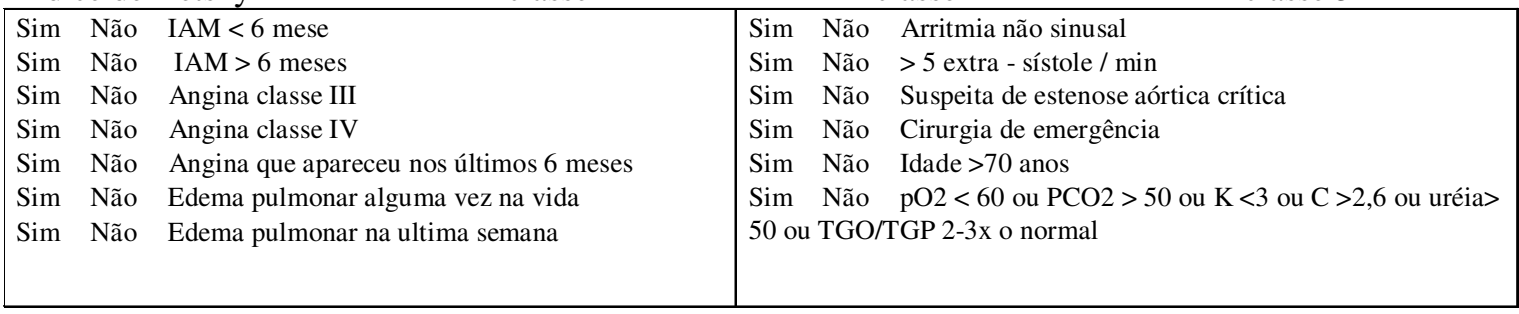

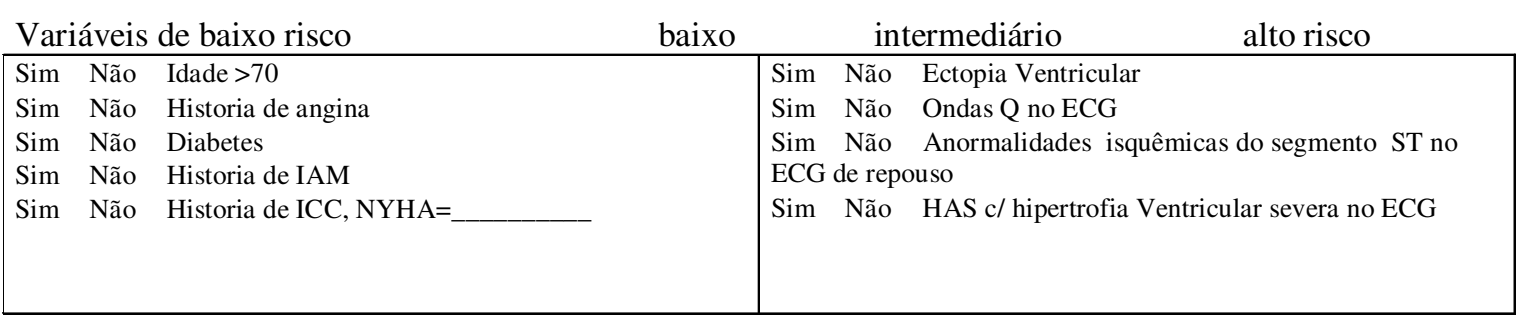

Antecedentes

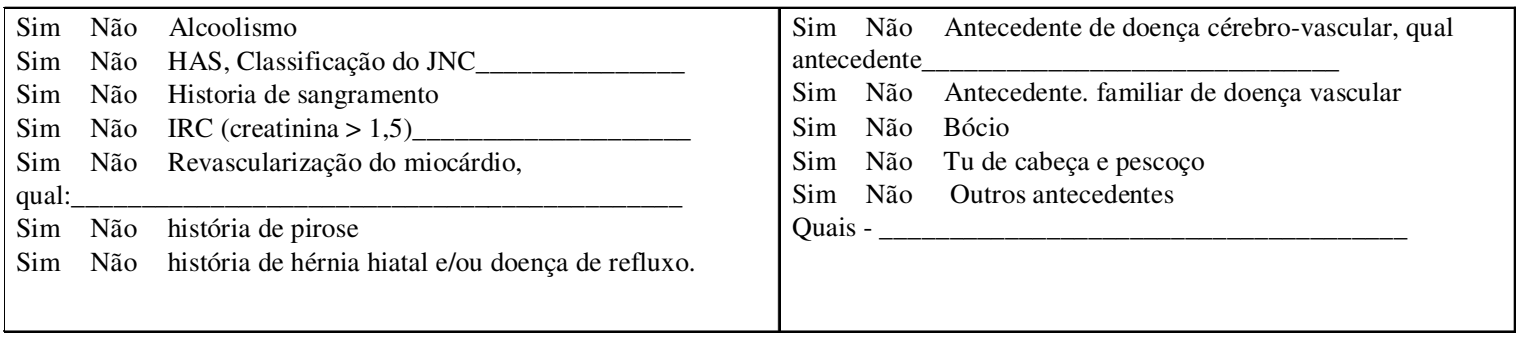


Tipo de Cirurgia - Anestesia peridural Geral Local Raquianestesia Balanceada

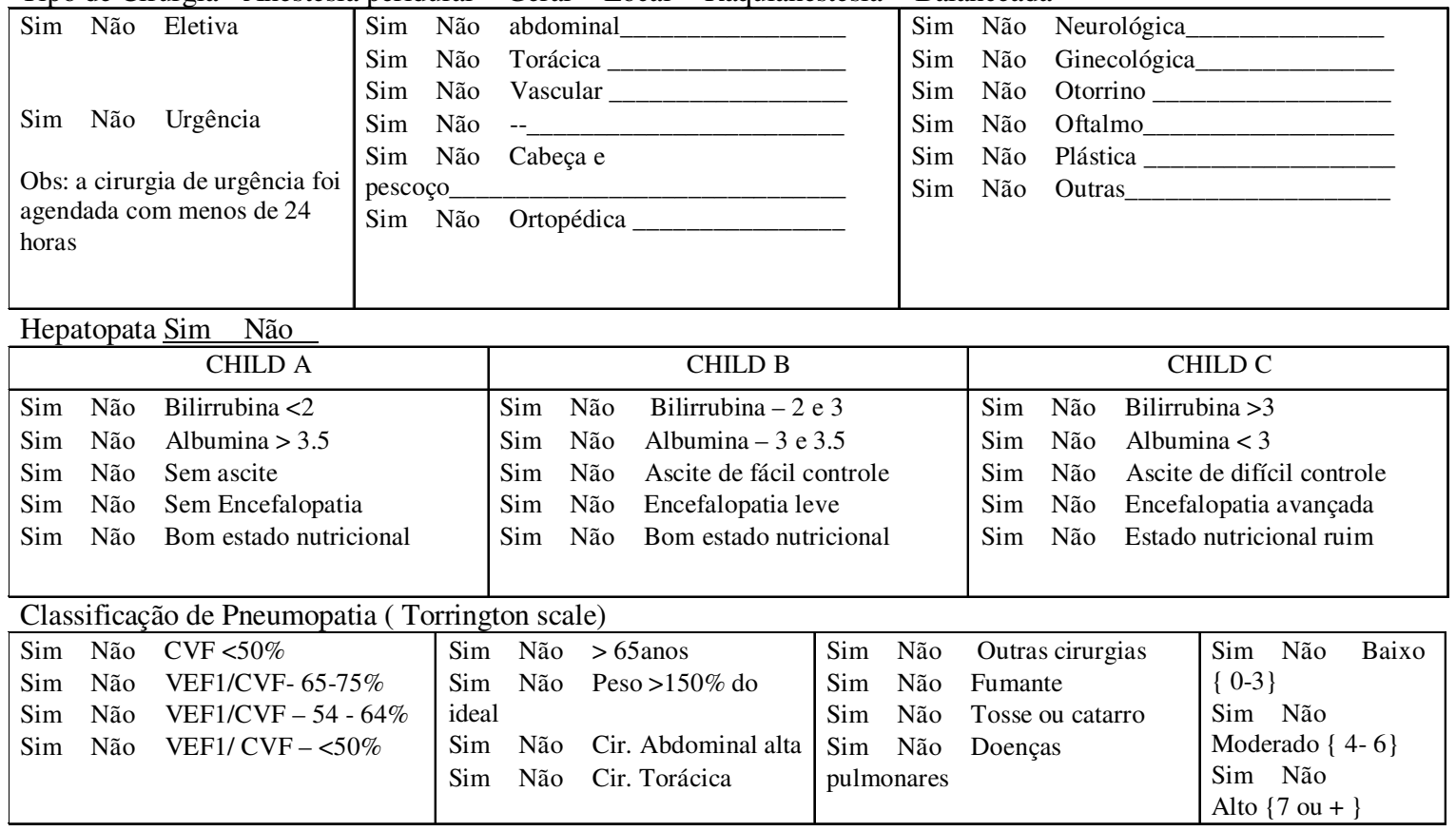

Antecedentes de Doença Pulmonar ou Alérgica

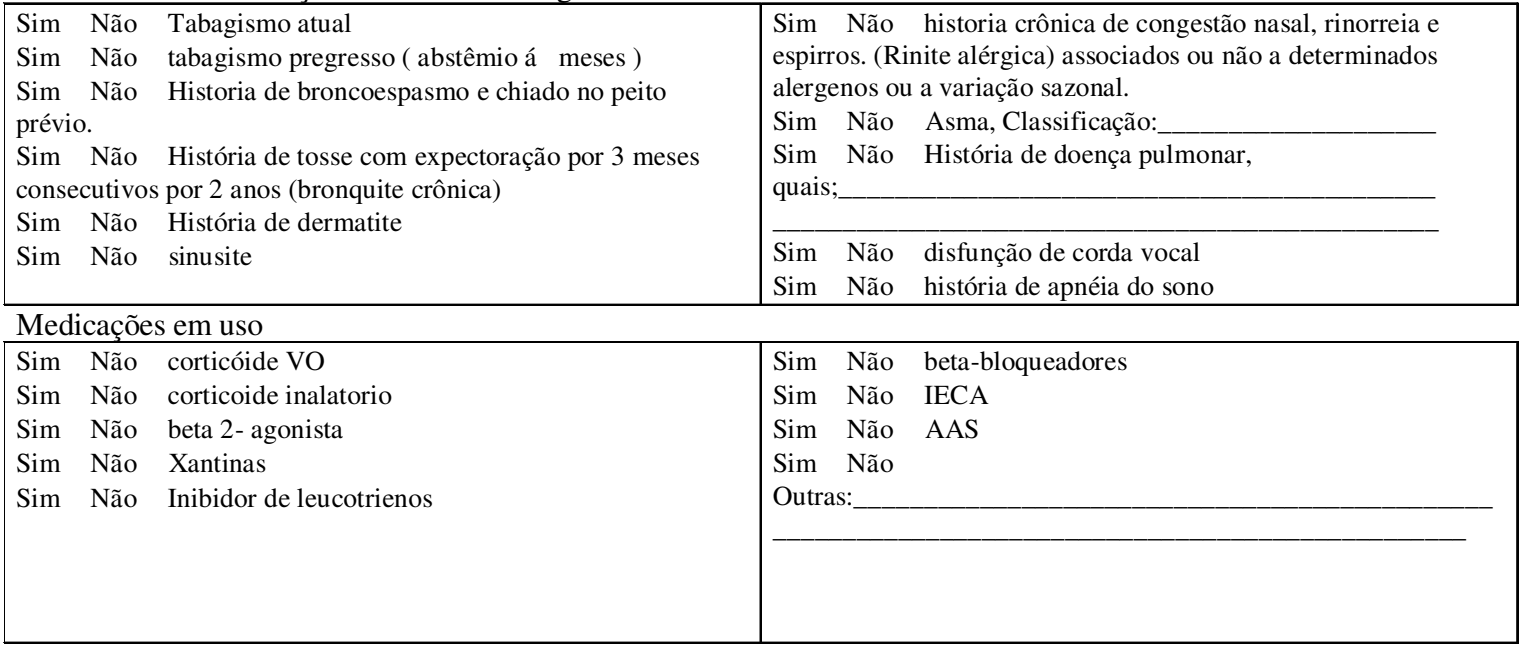

\section{Exame físico}

PA-__ F. cardíaca ____ Peso - ___ Altura: ___ ASC:

Sim Não exame físico pulmonar anormal, qual

Sim Não exame físico cardíaco anormal, qual

Sim Não exame físico de orofaringe anormal, qual

Sim Não exame físico de cabeça e pescoço anormal, qual

Sim Não exame físico abdominal anormal, qual

Laudo do RX de tórax

\section{Laudo do ECG}

Outros laudos importantes ( Teste Ergométrico, ECO, , etc) - Incluir URINA I neste campo caso haja. 
Laboratório

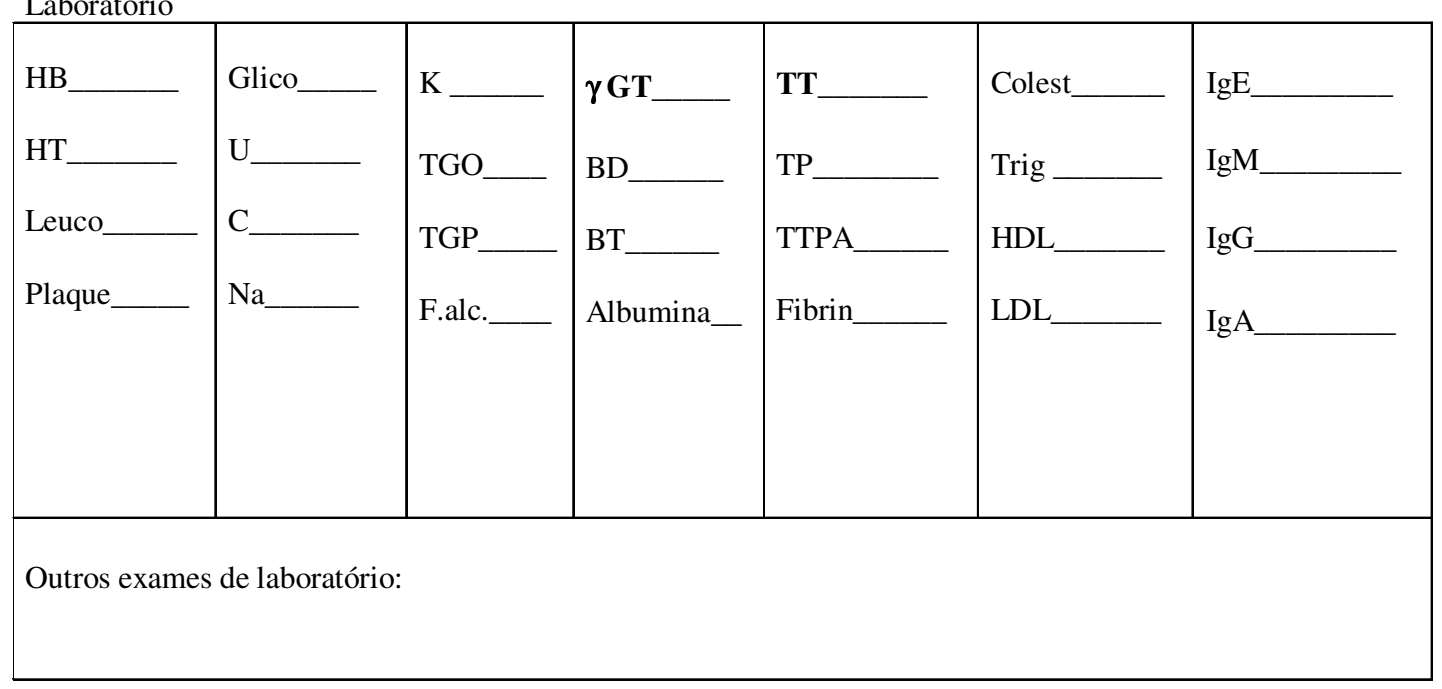

Dados espirométricos:

\begin{tabular}{|c|l|l|l|l|l|l|}
\hline$\underline{\text { Pré }}$ & Absoluto & $\%$ & Pós & absoluto & $\%$ & Resposta \\
\hline $\mathrm{VEF}_{1}$ & & & & & & \\
\hline $\mathrm{VEF}_{1} / \mathrm{CVF}$ & & & & & & \\
\hline $\mathrm{FEF}_{25-75 \%}$ & & & & & & \\
\hline
\end{tabular}

Obs:

\begin{tabular}{|l|l|}
\hline Dados de Óxido Nítrico no ar exalado & Dados do estudo do escarro \\
& $\%$ de Cels. Epiteliais \\
& $\%$ de Eosinófilos \\
$\mathbf{1}^{\text {a }}$ medida & $\%$ de Neutrófilos \\
$\mathbf{2}^{\text {a }}$ medida & $\%$ de Linfócitos \\
& Outras células \\
$\mathbf{3}^{\text {a }}$ medida & \\
\hline Média & \\
\end{tabular}


Teste Alérgico Cutâneo

\begin{tabular}{|c|c|c|c|c|}
\hline \multicolumn{2}{|c|}{ Tipo de Extrato } & Positivo & Negativo & Diâmetro de \\
\hline \multirow{3}{*}{ Acaro } & Tipo 1 & $(\quad)$ & ( & \\
\hline & Tipo 2 & ( & ( & \\
\hline & Tipo 3 & ( & ) & \\
\hline \multirow[t]{2}{*}{ Barata } & Germânica & ( & ( & \\
\hline & Americana & ) & ( & \\
\hline Cachorro & & ) & ) & \\
\hline Gato & & ( & ) & \\
\hline \multirow[t]{2}{*}{ Fungo } & Tipo 1 & ( & ( & \\
\hline & Tipo 2 & ( & ( & \\
\hline Mix de poeira & & ) & ( & \\
\hline Salina & & ( & ( & \\
\hline Histamina & & ( & ( & \\
\hline Látex & & $(\quad)$ & ( & \\
\hline
\end{tabular}


Anexo B. Termo de Consentimento para os Voluntários

\section{HOSPITAL DAS CLÍNICAS}

DA

FACULDADE DE MEDICINA DA UNIVERSIDADE DE SÃO PAULO

TERMO DE CONSENTIMENTO LIVRE E ESCLARECIDO

(Instruções para preenchimento no verso)

\section{I - DADOS DE IDENTIFICAÇÃO DO SUJEITO DA PESQUISA OU RESPONSÁVEL LEGAL}

1. NOME DO PACIENTE

DOCUMENTO DE IDENTIDADE № : SEXO :.$M \square F \square$

DATA NASC

/.......

№

BAIRRO: CIDADE

CEP: TELEFONE: DDD( APTO:....... ..)

2.RESPONSÁVEL LEGAL

NATUREZA (grau de parentesco, tutor, curador etc.)

DOCUMENTO DE IDENTIDADE :

DATA NASCIMENTO.: ....................

ENDEREÇO:

BAIRRO

CEP:. ...TELEFONE:DDD (

SEXO: $M \square F \square$

№. CIDADE: ).

\section{II - DADOS SOBRE A PESQUISA CIENTÍFICA}

\section{TÍTULO DO PROTOCOLO DE PESQUISA}

"Medidas de óxido nítrico no ar exalado de pacientes com história prévia de broncoespasmo no período intra-operatório."

2. PESQUISADOR: Dr.Joaquim Edson Vieira

CARGO/FUNÇÃO: Médico assistente HC-FMUSP INSCRIÇÃO CONSELHO REGIONAL № 62387

UNIDADE DO HCFMUSP: Disciplina de Clínica Geral, Depto de Clínica Médica

3. AVALIAÇÃO DO RISCO DA PESQUISA:

SEM RISCO $\square \quad$ RISCO MÍNIMO $\square \quad$ RISCO MÉDIO
RISCO BAIXO X
RISCO MAIOR $\square$

(probabilidade de que o indivíduo sofra algum dano como conseqüência imediata ou tardia do estudo)

4.DURAÇÃO DA PESQUISA : 18 meses. 


\section{III - REGISTRO DAS EXPLICAÇÕES DO PESQUISADOR AO PACIENTE OU SEU REPRESENTANTE LEGAL SOBRE A PESQUISA, CONSIGNANDO:}

1)Justificativa e os objetivos da pesquisa: Esta pesquisa quer saber quanto um paciente sem asma que teve estreitamento dos pulmões durante anestesia, solta um ar chamado de óxido nítrico quando respira.

2) Procedimentos que serão utilizados e propósitos, incluindo a identificação dos procedimentos que são experimentais: Neste estudo o senhor (senhora) precisa encher o peito e soltar o ar olhando para um relógio com marca no12, até esvaziar o peito, o que demora mais ou menos 10 segundos. O senhor (senhora) vai soprar duas vezes através de um aparelho para encher dois balões de ar, descansando entre cada vez que assopra. A sua respiração será também medida por um teste em que o senhor (a) deve encher o peito e soprar forte em um aparelho, antes e depois de usar uma medicação para os pulmões. $\mathrm{O}$ senhor (a) deverá também fazer algumas inalações com água e sal para facilitar a tosse e expelir catarro que será guardado para exame.

Em um outro dia será feito um exame para saber se o senhor (a) é alérgico e serão feitas dezoito picadas com agulhas na pele dos dois braços para medir se a picada fica vermelha ou não.

3) Desconfortos e riscos esperados: O senhor (senhora) pode sentir dificuldade para soprar durante os exames. O senhor pode não conseguir tossir para soltar catarro. $\mathrm{O}$ senhor (a) pode não querer receber as picadas para ver se tem alergia. O senhor (a ) pode desistir e parar a pesquisa na hora que quiser .

4) Benefícios que poderão ser obtidos: No futuro outros pacientes com asma ou que vão ser operados poderão ser beneficiados em seus tratamentos e cirurgias.

5) Procedimentos alternativos que possam ser vantajosos para o indivíduo: Não existem.

\section{IV - ESCLARECIMENTOS DADOS PELO PESQUISADOR SOBRE GARANTIAS DO SUJEITO DA PESQUISA:}

1. Acesso, a qualquer tempo, às informações sobre procedimentos, riscos e benefícios relacionados à pesquisa, inclusive para dirimir eventuais dúvidas: o senhor(a) pode perguntar qualquer coisa sobre a pesquisa e pode verificar todos os resultados e levar os resultados para outros médicos em quem confia.

2. Liberdade de retirar seu consentimento a qualquer momento e de deixar de participar do estudo, sem que isto traga prejuízo à continuidade da assistência: o senhor(a) pode desistir de colher os exames quaisquer que sejam eles e não terá seu tratamento no Hospital prejudicado.

3. Salvaguarda da confidencialidade, sigilo e privacidade: todas as informações que 0 senhor(a) prestar ou seus exames revelarem só serão de conhecimento do médico que o(a) atende ou de seu médico particular.

4. Disponibilidade de assistência no HCFMUSP, por eventuais danos à saúde, decorrentes da pesquisa: seu atendimento continuará a ser realizado no Hospital durante ou após o fim desta pesquisa.

5. Viabilidade de indenização por eventuais danos à saúde decorrentes da pesquisa: $\underline{\text { os }}$ pesquisadores e o Hospital não possuem meios de indenização material em caso de problemas que possam ocorrer durante a realização destes exames. 


\section{INFORMAÇÕES DE NOMES, ENDEREÇOS E TELEFONES DOS RESPONSÁVEIS PELO ACOMPANHAMENTO DA PESQUISA, PARA CONTATO EM CASO DE INTERCORRÊNCIAS CLÍNICAS E REAÇÕES ADVERSAS.}

Dr. Joaquim Edson Vieira: LIM 20, Faculdade de Medicina, Av. Dr. Arnaldo, 455 sala 1216, fone 3066-7317, 3069-6746

\section{OBSERVAÇÕES COMPLEMENTARES:}

\section{VII - CONSENTIMENTO PÓS-ESCLARECIDO}

Declaro que, após convenientemente esclarecido pelo pesquisador e ter entendido o que me foi explicado, consinto em participar do presente Protocolo de Pesquisa

São Paulo, de de 200

Assinatura do sujeito da pesquisa ou responsável legal

Assinatura do pesquisador (carimbo ou nome legível) 
8-Referências 
Adnot S, Raffestin B. Pulmonary hypertension: NO terapy? Thorax. 1996;51:762-4.

Alving K, Weitzberg E, Lundberg JM. Increased amount of nitric oxide in exhaled air of asthmatics. Eur Respir J. 1993;6:1368-70.

American Thoracic Society. ATS workshop proceedings: exhaled nitric oxide and nitric oxide oxidative metabolism in exhaled breath condensate. $A m \mathrm{~J}$ Respir Crit Care Med. 2006;3:131-45.

American Thoracic Society. Recommendations for standardized procedures for the online and offline measurement of exhaled lower respiratory nitric oxide and nasal nitric oxide in adults and children. Am J Respir Crit Care Med. 1999;160:2104-17.

American Thoracic Society. Standardization of Spirometry. 1994 update. Am J Respir Crit Care Med. 1995;152:1107-36.

Asano K, Chee CB, Gaston B, Lilly CM, Gerard C, Drazen JM, Stamler JS. Constitutive and inducible nitric oxide synthase gene expression, regulation, and activity in human lung epithelial cells. Proc Natl Acad Sci USA. 1994;91:10089-93.

Ashutosh K. Nitric oxide and asthma: review. Curr Opin Pulm Med. 2000;6:21-5. 
Bacuzzi A, Cantone G, Cecchin A, Cuffari S. Intraoperative aspects and complications for the anesthesiologist in the management of patients undergoing thoracic surgery for lung cancer. Rays. 2004;29:461-3.

Baraldi E, Azzolin NM, Zanconato S, Dario C, Zacchello F. Corticosteroids decrease exhaled nitric oxide in children with acute asthma. $J$ Pediatr. 1997;131:381-5.

Barnes PJ, Kharitonov SA. Exhaled nitric oxide: a new lung function test. Thorax. 1996;51:233-7.

Barnes PJ. NO or no NO in asthma? Thorax. 1996;51:218-20.

Berlyne GS, Parameswaran K, Kamada D, Efthimiadis A, Hargreave FE. A comparison of exhaled nitric oxide and induced sputum as markers of airway inflammation. J Allergy Clin Immunol. 2000;106:638-44.

Birrell MA, Battram CH, Woodman P, McCluskie K, Belvisi MG Dissociation by steroids of eosinophilic inflammation from airway hyperresponsiveness in murine airways. Respir Res. 2003;4:3.

Blease K, Lukacs NW, Hogaboan CM, Kunkel SL. Chemokines and their role in airway hyper-reactivy. Respir Res. 2000;1:54-61.

Bluman LG, Mosca L, Newman N, Simon, DG. Preoperative smoking habits and postoperative pulmonary complications. Chest. 1998;113:883-9.

Bredt DS, Snyder SH. Nitric oxide mediates glutamate linked enhancement of cGMP levels in the cerebellum. Proc Natl Acad Sci USA. 1989;86:9030-3.

Brooks-Brunn JA. Predictors of postoperative pulmonary complications following abdominal surgery. Chest. 1997;111:564-71. 
Brown $\mathrm{RH}$, Wagner EM. Mechanisms of bronchoprotection by anesthetic induction agents: propofol versus ketamine. Anesthesiology. 1999;90:822-8.

Brusasco V, Crimi E, Gianiorio P, Lantero S, Rossi GA. Allergen-induced increase in airway responsiveness and inflammation in mild asthma. $J$ Appl Physiol. 1990;69:2209-14.

Burburan SM, Xisto DG, Rocco PRM. Anaesthetic Management in asthma. Minerva Anestesiol. 2007;73:357-65.

Celli BR. The importance of espirometry in COPD and asthma. Effect on approach to management. Chest. 2000;117:15S-9S.

Cerveri I, Locatelli F, Zoia MC, Corsico A, Accordini S, De Marco R. International variations in asthma treatment compliance: the results of the European Community Respiratory Health Study (ECRHS). Eur Respir J. 1999; 14:288-94.

Cheng EY, Mazzeo AJ, Bosnjak ZJ, Coon RL, Kampine JP. Direct Relaxant Effects of Intravenous Anesthetics on airway smooth muscle. Anesth Analg. 1996;83:162-8.

Chiavegato LM, Jardim JR, Faresin SM, Juliano Y. Alterações funcionais respiratórias na colecictectomia por via laparoscópica. J Pneumol. 2000;26:69-6.

Christopherson R, Beattie C, Frank SM, Norris EJ, Meniert, CL. Perioperative morbidity in patients randomized to epidural or general anesthesia for lower extremity vascular surgery. Anesthesiology. 1993;79:422-34. 
Corssen G, Gutierrez J, Reves JC, Huber FC: Ketamine in the anesthetic management of asthmatic patients. Anesth Analg. 1972;51:588-96.

Crimi E, Spanevello A, Neri M, Ind PW, Rossi GA, Brusasco V. Dissociation between airway inflammation and airway hyperresponsiveness in allergic asthma. Am J Respir Crit Care Med. 1998;157:4-9.

Culotta E, Koshland DE. NO news is good news. Science. 1992;258:1862-3.

DeCS. Descritores em Ciência da Saúde [online]. Broncoespasmo. [outubro/2007]. Disponível em: http://decs.bvs.br.

De Gouw HW, Hendriks J, Woltman AM, Twiss IM, Sterk PJ. Exhaled nitric oxide (NO) is reduced shortly after bronchoconstriction to direct and indirect stimuli in asthma. Am J Respir Crit Care Med. 1998;158:315-9.

Del Giudice MM, Brunese FP, Piacentini GL, Pedulla M, Capristo C, Decimo F, Capristo AF. Fractional exhaled nitric oxide (FENO), lung function and airway hyperresponsiveness in naïve atopic asthmatic children. $J$ Asthma. 2004;41:759-65.

Dreborg S. Skin testing. The safety of skin tests and the information obtained from using different methods and concentrations of allergen. Allergy. 1993;48:473-5.

Dupont LJ, Rochette F, Demedts MG, Verleden GM. Exhaled nitric oxide correlates with airway hyperresponsiveness in steroid-naïve patients with mild asthma. Am J Resp Crit Care Med. 1998;157:894-8.

Eschenbacher WL, Boushey HA, Sheppard D. Alteration in osmolarity of inhaled aerosols cause bronchoconstriction and cough, but absence of a permeant anion causes cough alone. Am. Rev. Respir. Dis. 1984;129:211-5. 
Eynott PR, Groneberg DA, Caramori G, Adckok IM, Donelly LE, Kharitonov $\mathrm{S}$, Barnes PL, CHUNG KF. Role of nitric oxide in allergic inflammatio and bronchial hyperresponsiveness. European J Pharmacol. 2002;452:123-33.

Fahy JV, Boushey HA, Lazarus SC, Mauger EA, Cherniack RM, Chinchilli VM, Craig TJ, Drazen JM, Ford JG, Fish JE, Israel E, Kraft M, Lemanske RF, Martin RJ, Mclean D, Peters SP, Sorkness C, Szefler SJ. Safety and Reproducibility of sputum induction in asthmatic subjects in a multicenter study. Am J Respir Crit Care Med. 2001;163:1470-75.

Fernandes CR, Ruiz-Neto PP. The Respiratory System and the Elderly: Anesthetic Implications. Rev Bras Anestesiol. 2002;52:461-70.

Flora-Filho R, Zilberstein B. Artigo de revisão: óxido nítrico: o simples mensageiro percorrendo a complexidade. Metabolismo, síntese e funções. Rev Ass Med Brasil. 2000;46:265-71.

Foresi A, Bertorelli G, Pesci A, Chetta A, Olivieri D. Inflammatory markers in bronchoalveolar lavage and in bronchial biopsy in asthma during remission. Chest. 1990;98:528-35.

Franklin PJ, Taplin R, Stick SM. A community study of exhaled nitric oxide in healthy children. Am J Respir Crit Care Med. 1999;159:69-73.

Fredberg JJ. Bronchospasm and its biophysical basis in airway smooth muscle. Respir Res. 2004;5:2.

Furchgott RF, Zawaszdki JV. The obligatory role of endothelial cells in the relaxation of arterial smooth muscle by acetylcholine. Nature. 1980;288:3736. 
Garibaldi RA, Britt MR, Coleman ML, Reading JC, Pace NL. Risk factors for postoperative pneumonia. Am J Med. 1981;70:677-80.

Gaudino M, Toesca A, Maggiano N, Pragliola C, Possati G. Localization of nitric oxide synthase type III in the internal thoracic and radial arteries and the great saphenous vein: a comparative immunohistochemical study. $J$ Thorac Cardiovasc Surg. 2003;125:1510-5.

Gibson PG, Henry RL, Thomas P. Noninvasive assessment of airway inflammation in children: induced sputum, exhaled nitric oxide, and breath condensate. Eur Respir J. 2000;16:1008-15.

Global Initiative for Asthma. Global strategy for asthma management and Prevention Program. National Heart, Lung, and Blood Institute/World Health Organization. Workshop Report. Washington, U.S. Department of Health, Education, and Welfare. 2002. Publication No. 02-3659.

Global Initiative for Asthma. Global strategy for asthma management and Prevention Program. National Heart, Lung, and Blood Institute/World Health Organization. Workshop Report. Washington, U.S. Department of Health, Education, and Welfare. 2005. Publication No. 02-3659.

Goff MJ, Arain SR, Ficke DJ, Uhrich TD, Ebert TJ. Absence of bronchodilation during desflurane anesthesia: a comparison to sevoflurane and thiopental. Anesthesiology. 2000;93:404-8.

GOLD 2006. Global Initiative for Chronic Obstructive Lung Disease. Executive Summary: Global Strategy for the Diagnosis, Management and Prevention of COPD. Disponível em http://www.goldcopd.com.

Goldman L, Caldera DL, Nusbaum SR, Southwick FS, Krogstad D, Muray B, Burke DS, O'malley TA, Goroll AH, Caplan CH, Nolan J, Carabello B, Slater 
EE. Multifactorial index of cardiac risk in non cardiac surgical procedures. $N$ Engl J Med. 1977;297:845-50.

Guembe L, Villaro AC. Histochemical demonstration of neuronal nitric oxide synthase during development of mouse respiratory tract. Am J Respir Cell Mol Biol. 1999;20:342-51.

Gustafsson LE, Leone AM, Persson MG, Wiklund NP, Moncada S. Endogenous nitric oxide is present in the exhaled air of rabbits, guinea pigs and humans. Biochem Biophys Res Commun. 1991;181:852-7.

Guyton AC, Hall JE. Tratado de Fisiologia Médica. 10 $0^{\mathrm{a}}$ ed. Rio de Janeiro: Editora Guanabara Koogan; 2002. Cap. 37, p.406-16: Ventilação Pulmonar.

Hibbs JB Jr, Taintor RR, Vavrin Z. Macrophage cytotoxicity: role for Larginine deiminase and imino nitrogen oxidation to nitrite. Science. 1987;235:473-6.

Hirshman CA, Downes H, Farbood A, Bergman NA. Ketamine block of bronchospasm in experimental canine asthma. Br J Anaesth. 1979;51:713-8. Hirshman CA, Edelstein G, Peetz S, Wayne R, Downes H. Mechanism of action of inhalational anesthesia on airways. Anesthesiology. 1982;56:10711.

Hunter CJ, Ward R, Woltmann G, Wardlaw AJ, Pavord ID. The safety and success rate of sputum induction using a low output ultrasonic nebuliser. Respir Med. 1999;93:345-8. 
Ichinose M, Takahashi T, Sugiura H, Endoh E, Miura M, Mashito Y, Shirato K. Baseline airway hyperresponsiveness and its reversible component: role of airway inflammation and airway caliber. Eur Respir J. 2000;15:248-53.

Ignarro LJ, Buga GM, Wood KS, Byrns RE, Chaudhuri G. Endotheliumderived relaxing factor produced and released from artery and vein is a nitric oxide. Proc Natl Acad Sci USA. 1987;84:9265-9.

Ignarro LJ. Nitric oxide as a unique signaling molecule in the vascular system: a historical overview. J Physiol Pharmacol. 2002;53:503-14.

Imasaki T, Kobayashi H, Hataishi R, Hayashi I, Tomita T, Majima M. Nitric oxide is generated in smooth muscle layer by neurokinin $A$ and counteracts constriction in guinea pig airway. Nitric oxide. 2001;5:465-74.

Jatakanon A, Lim S, Kharitonov SA, Chung KF, Barnes PJ. Correlation between exhaled nitric oxide, sputum eosinophils, and methacholine responsiveness in patients with mild asthma. Thorax. 1998;53:91-5.

Jilma B, Kastner J, Mensik C, Vondrovec B, Hildebrandt J, Krejcy K, Wagner OF, Eichler HG. Sex differences in concentrations of exhaled nitric oxide and plasma nitrate. Life Sci. 1996;58:469-76.

Joshi MS, Ponthier JL, Lancaster JR Jr. Cellular antioxidant and pro-oxidant actions of nitric oxide. Free Radic Biol Med. 1999;27:1357-66.

Kabalin CS, Yarnold PR, Grammer LC. Low complication rate of corticosteroid-treated asthmatics undergoing surgical procedures. Arch Intern Med. 1995;155:1379-84. 
Kanat F, Golcuk A, Teke T, Golcuk M. Risk factors for postoperative pulmonary complications in upper abdominal surgery. ANZ $J$ Surg. 2007;77:135-41.

Kanazawa H, Shoji S, Yamada M, Fujii T, Kawaguchi T, Kudoh SH, Hirata K, Yoshikawa J. Increased levels of nitric oxide derivatives in induced sputum in patients with asthma. J Allergy Clin Immunol. 1997;99:624-9.

Kharitonov SA, Yates D, Robbins RA, Logan-Sinclair R, Shinebourne EA, Barnes PJ. Increases nitric oxide in exhaled air of asthmatic patients. Lancet. 1994;343:133-5.

Kharitonov SA, Yates D, Barnes PJ. Increased nitric oxide in exhaled air of normal human subjects with upper respiratory tract infections. Eur Respir J. 1995a;8:295-7.

Kharitonov SA, Wells AU, O'Connor BJ, Cole PJ, Hansell DM, Logan-Sinclair $\mathrm{RB}$, Barnes PJ. Elevated levels of exhaled nitric oxide in bronchiectasis. Am J Respir Crit Care Med. 1995b;151:1889-93.

Kharitonov SA, O'Connor BJ, Evans DJ, Barnes PJ. Allergen-induced late asthmatic reactions are associated with elevation of exhaled nitric oxide. Am J Respir Crit Care Med. 1995c;151:1894-9.

Kharitonov SA, Yates DH, Barnes PJ. Inhaled glucocorticoids decrease nitric oxide in exhaled air of asthmatic patients. Am $J$ Respir Crit Care Med. 1996;153:454-7.

kharitonov SA, Alving $\mathrm{K}$, Barnes PJ. Exhaled and nasal nitric oxide measurements: recommendations. Eur Respir J. 1997;10:1683-93. 
Kingston HG, Hirshman CA. Perioperative management of the patient with asthma. Anesth Analg. 1984;63:844-55.

Konturek SK, Konturek PC. Role of nitric oxid in the digestive system. Digestion. 1995;56:1-13.

Kotani N, Hashimoto $H$, Sessler DI, Yoshida $H$, Kimura $N$, Okawa $H$, Muraoka M, Matsuki A. Smoking decreases alveolar macrophage function during anesthesia and surgery. Anesthesiology. 2000;92:1268-77.

Kroenke K, Lawrence VA, Theroux JF, Tuley MR. Operative risk in patients with severe obstructive pulmonary disease. Arch Intern Med. 1992;152:96771.

Lamas S, Marsden PA, Li GK, Tempst P, Michel T. Endothelial nitric oxide synthase: molecular cloning and characterization of a distinct constitutive enzyme isoform. Proc Natl Acad Sci USA. 1992;89:6348-52.

Langley SJ, Goldthorpe S, Custovic A, Woodcock A. Relationship among pulmonary function, bronchial reactivity, and exhaled nitric oxide in a large group of asthmatic patients. Ann Allergy Asthma Immunol. 2003;91:398-404.

Lanz MJ, Leung DYM, McCormick DR, Harbeck R, Szefler SJ, White CW. Comparison of exhaled nitric oxide, serum eosinophilic cationic protein, and soluble interleukin-2 receptor in exacerbations of pediatric asthma. Pediatr Pulmonol. 1997;24:305-11.

Lawrence VA, Hilsenbeck SG, Mulrow CD, Dhanda R, Sapp J, Page CP. Incidence and hospital stay for cardiac and pulmonary complications after abdominal surgery. J Gen Intern Med. 1995;10:671-8. 
Lawrence VA, Dhanda R, Hilsenbeck SG, Page P. Risk of pulmonary complications after elective abdominal surgery. Chest. 1996;110:744-50.

Leick-Maldonado EA, Kay FU, Leonhardt MC, Kasahara DI, Prado CM, Fernandes FT, Martins MA, Tibério IF Comparison of glucocorticoid and cysteinyl leukotriene receptor antagonist treatments in an experimental model of chronic airway inflammation in guinea-pigs. Clin Exp Allergy. 2004;34:145-52.

Leme AS, Kasahara DI, Nunes MP, Martins MA, Vieira JE. Exhaled nitric oxide collected with two different mouthpieces: a study in asthmatic patients. Braz J Med Biol Res. 2002;35:1133-7.

Lim S, Jataknaon A, John M, Gilbey T, O'Connor BJ, Chung K, Barnes PJ. Effect of inhaled budesonide on lung function and airway inflammation: assessment by various inflammatory markers in mild asthma. Am J Respir Crit Care Med. 1999;159:22-30.

Litvan H. Complicaciones respiratorias postoperatorias, en Formación Continuada de Anestesiología y Reanimacíon de Catalunya. Fundaicón Europea de enseñanza en Anestesiología. 1998. 165-79.

Lönnkvist K, Anderson M, Hedlin G, Svartengren M. Exhaled NO and eosinophil markers in blood, nasal lavage and sputum in children with asthma after withdrawal of budesonide. Pediatr Allergy Immunol. 2004;15:351-8.

Maitra A, Kumar V. The lung and the upper respiratory tract. In: Kumar K, Cotran RS, Robbins SL. Basic Pathology. 5a edição. Philadelphia: Saunders; 2003. p.455-508. 
Marletta MA, Yoon PS, lyengar R, Leaf CD, Wishnok JS. Macrophage oxidation of L-arginine to nitrite and nitrate: nitric oxide is an intermediate. Biochemistry. 1988;27:8706-11.

Maziak W, Loukides S, Culpitt S, Sullivan P, Kharitonov SA, Barnes PJ. Exhaled nitric oxide in chronic obstructive pulmonary disease. Am J Respir Crit Care Med. 1998;157:998-1002.

Menezes CC; Vieira JE. Condutas no tratamento do broncoespasmo no perioperatório. Rev Bras Anestesiol. 2002;52:728-38.

Moncada S, Higgs A. The L-arginine-nitric oxide pathway. $N$ Engl $J$ Med. 1993;329:2002-12.

Moulton MJ, Creswell LL, Mackey ME, Cox JL, Rosenbloom, M. Obesity is not a risk factor for significant adverse outcomes after cardiac surgery. Circulation. 1996;94:II87-92.

Nogami H, Shoji S, Nishima S. Exhaled nitric oxide as a simple assessment of airway hyperresponsiveness in bronchial asthma and chronic cough patients. J Asthm. 2003;40:653-9.

Nussler AK, Billiar TR. Inflammation, immunoregulation, and inducible nitric oxide synthase. J Leukoc Biol. 1993;54:171-8.

O'Byrne PM, Inman MD. Airway hyperresponsiveness. Chest. 2003;123:S411-6.

Olsson GL. Bronchospasm during anesthesia. A computer-aided incidence study of 136,929 patients. Acta Anaesthesiol Scand. 1987;31:244-52. 
Pailo AF, Bernardelli IM. Complicações Anestésicas. In: Auler Junior JOC, Miyoshi E, Leilão FBP, Bello CN. Manual Teórico de Anestesilogogia para o aluno de graduação Complicações anestésicas. São Paulo: Editora Atheneu; 2001. p.161-71.

Palmer RMJ, Ferrige AG, Moncada S. Nitric oxide releases accounts for the biological activity of endothelium-derived relaxing factor. Nature. 1987;327:459-60.

Palomino AL, Bussamra MH, Saraiva-Romanholo BM, Martins MA, Nunes MP, Rodrigues JC. Induced sputum in children and adolescents with asthma: safety, clinical applicability and inflammatory cells aspects in stable patients and during exacerbation. J Pediatr (Rio J). 2005;81:216-24.

Paro-Heitor ML, Bussamra MH, Saraiva-Romanholo BM, Martins MA, Okay TS, Rodrigues JC. Exhaled nitric oxide for monitoring childhood asthma inflammation compared to sputum analysis, serum interleukins and pulmonary function. Pediatr Pulmonol. 2008;43:134-41.

Pechkovsky DV, Zissel G, Goldmann T, Einhaus M, Taube C, Magnussen H, Schlaak M, Müller-Quernheim J. Pattern of NOS2 and NOS3 mRNA expression in human A549 cells and primary cultured AEC II. Am J Physiol Lung Cell Mol Physiol. 2002;282:L684-92.

Pereira CAC, Carvalho CRR, Nakatani J. Pneumologia atualização e reciclagem: Sociedade Paulista de Pneumologia e Tisiologia. São Paulo: Atheneu; 1996. Cap. 10, p.193-228: Asma. 
Pereira EDB. Índice prognóstico para complicações pulmonares no pósoperatório de cirurgia abdominal alta. [tese]. São Paulo. Escola Paulista de Medicina; 1994.

Pereira ED, Fernandes AL, da Silva Anção M, de Araúja Pereres C, Atallah AN, Faresin SM. Prospective assessment of the risk of postoperative pulmonary complications in patients submitted to upper abdominal surgery. Sao Paulo Med J. 1999;117:151-160.

Persson MG, Friberg SG, Hedqvist P. Endogenous nitric oxide counteracts antigen-induced bronchoconstriction. Eur J Pharmacol. 1993;249:R7-8.

Phillips EH, Carroll BJ, Fallas MJ, Pearlstein AR. Comparison of laparoscopic cholecystectomy in obese and non-obese patients. Am surg. 1994;60:31621.

Pin I, Gibson PG, Kolendowicz R, Girgis-Gabardo A, Denburg JA, Hargreave FE, Dolovich J. Use of induced sputum cell counts to investigate airway inflammation in asthma. Thorax. 1992;47:25-9.

Telles Filho, PD, Asma Brônquica/Anestesia, Cirurgia e Asma: [julho/2007]. Disponível em:

http://www.asmabronquica.com.br/medical/tratamento_asma_anestesia.html

Pizov R, Brown RH, Weiss YS, Baranov D, Hennes H, Baker S, Hirshman $\mathrm{CA}$. Wheezing during induction of general anesthesia in patients with and without asthma. A randomized, blinded trial. Anesthesiology. 1995;82:11116.

Pizzichini E, Pizzichini MMM, Efthimiadis A, Evans S, Morris MM, Squillace D, Gleich GJ, Dolovich J, Hargreave FE. Indices of airway inflammation in 
induced sputum: reproducibility and validity of cell and fluid phase measurements. Am J Respir Crit Care Med. 1996;154:308-17.

Pizzichini E, Pizzichini MMM, Kideny JC, Efthimiadis A, Hussack P, Popov T, Cox G, Dolovich J, O'byrne P, Hagreave FE. Induced sputum, bronchoalveolar lavage and blood from mild asthmatics: inflammatory cells, lymphocyte subsets and soluble markers compared. Eur Respir J. 1998;11:828-34.

Prado CM, Leick-Maldonado EA, Arata V, Kasahara DI, Martins MA, Tiberio IF. Neurokinins and inflammatory cell iNOS expression in guinea pigs with chronic allergic airway inflammation. Am J Physiol Lung Cell Mol Physiol. 2005;288:L741-8.

Prado CM, Leick-Maldonado EA, Kasahara DI, Capelozzi VL, Martins MA, Tiberio IFLC. Effects of acute and chronic nitric oxide inhibition in an experimental model of chronic pulmonary allergic inflammation in guinea pigs. Am J Physiol Lung Cell Mol Physiol. 2005;289:L677-83.

Prado CM, Leick-Maldonado EA, Miyamoto L, Yano LM, Kasahara DI, Martins MA, Tiberio IF. Capsaicin-sensitive nerves and neurokinins modulate non-neuronal nNOS expression in lung. Respir Physiol Neurobiol. 2008;160:37-44.

Prado CM, Leick-Maldonado EA, Yano L, Leme AS, Capelozzi VL, Martins MA, Tiberio IF. Effects of nitric oxide synthases in chronic allergic airway inflammation and remodeling. Am J Respir Cell Mol Biol. 2006;35:457-65.

Postma DS, Bleecker ER, Amelung PJ, Holroyd KJ, Xu J, Panhuysen CIM, Meyers DA, Levitt RC. Genetic Susceptibility to Asthma - Bronchial Hyperresponsiveness Coinherited with a Major Gene for Atopy. NEJM. 1995; 333:14:894-00. 
Ricciardolo FLM, Sterk PJ, Gaston B, Folkerts G. Nitric oxide in health and disease of the respiratory system. Physiol Rev. 2004;84:731-65.

Robbins RA, Springall DR, Warren JB, Kwon OJ, Buttery LD, Wilson AJ, Adcock IM, Riveros-Moreno V, Moncada S, Polak J. Inducible nitric oxide synthase is increased in murine lung epithelial cells by cytokine stimulation. Biochem Biophys Res Commun. 1994;198:835-43.

Saraiva-Romanholo BM, Barnabé V, Carvalho AL, Martins MA, Saldiva PH, Nunes MP. Comparison of three methods for differential cell count in induced sputum. Chest. 2003;124:1060-6.

Shaul PW, North AJ, Wu LC, Wells LB, Brannon TS, Lau KS, Michel T, Margraf LR, Star RA. Endothelial nitric oxide synthase is expressed in cultured human bronchiolar epithelium. J Clin Invest. 1994;94:2231-6.

Shaul PW. Regulation of endothelial nitric oxide synthase: location, location, location. Annu Rev Physiol. 2002;64:749-74.

Shnider SM, Papper EM . Anesthesia for asthmatic patient. Anesthesiology. $1961 ; 22: 886-92$.

Silkoff PE, McClean PA, Slutsky AS, Caramori M, Chapman KR, Gutierrez C, Zamel N. Exhaled nitric oxide and bronchial reactivity during and after inhaled beclomethasone in mild asthma. J Asthma. 1998;35:473-9.

Smetana GW. Perioperative pulmonary evaluation. N Engl J Med. 1999;340: 937-44. 
Sociedade Brasileira de Pneumologia e Tisiologia, Sociedade Brasileira de Alergia e Imunopatologia, Sociedade Brasileira de Pediatria. Diagnóstico e tratamento da asma brônquica. São Paulo: Associação Médica Brasileira; Brasília: Conselho Federal de Medicina; 2001. [Projeto diretrizes].

Spallarossa D, Battistini E, Silvestri M, Sabatini F, Fregonese L, Brazzola G, Rossi GA. Steroid-naïve adolescents with mild intermittent allergic asthma have airway hyperresponsiveness and exhaled nitric oxide levels. J Asthma. 2003;40:301-10.

Stelmach R, Ribeiro M, Cukier A. Fisiopatologia das doenças pulmonares obstrutivas. In: Carvalho CRR. Fisiologia Respiratória. São Paulo: Editora Atheneu; 2006. p.193-210. (Série Fisiopatologia Clinica v.3).

Tisi GM. Preoperative evaluation of pulmonary function. Am Rev Respir Dis. 1979;119:293-310.

Van Rensen EL, Straathof KC, Veseselic-Charvat MA, Zwinderman AH, Bel $\mathrm{EH}$, Sterk PJ. Effect of inhaled steroids on airway hyperresponsiveness, sputum eosinophils and exhaled nitric oxide levels in patients with asthma. Thorax. 1999;54:403-8.

Van Den Berge M, Meijer RJ, Kerstjens HA, de Reus DM, Koëter GH, Kauffman HF, Postma DS. PC(20) adenosine 5'-monophosphate is more closely associated with airway inflammation in asthma than $P C(20)$ methacholine. Am J Respir Crit Care Med. 2001;163:1546-50.

Van Den Toorn LM, Prins JB, Overbeek SE, Hoogsteden HC, De Jongste JC. Adolescents in clinical remission of atopic asthma have elevated exhaled nitric oxide levels and bronchial hyperresponsivenes. Am J Respir Crit Care Med. 2000;162:953-7. 
Warner DO, Warner MA, Barnes RD, Offord KP, Schroeder DR, Gray DT, Yunginger JW. Perioperative respiratory complications in patients with asthma. Anesthesiology. 1996;85:460-7.

Warner DO, Warner MA, Offord KP, Schroeder DR, Maxson P, Scanlon PD. Airway obstruction and perioperative complications in smokers undergoing abdominal surgery. Anesthesiology. 1999;90:372-9.

Warner DO. Preventing postoperative pulmonary complications: the role of the anesthesiologist. Anesthesiology. 2000;92:1467-72.

Warner MA, Offord KP, Warner ME, Lennon RL, Conover MA, JanssonSchumacher U. Role of preoperative cessation of smoking an other factors in postoperative pulmonary complications: a blinded prospective study of coronary artery bypass patients. Mayo Clin Proc. 1989;64:609-16.

West JB. Fisiologia Respiratória Moderna. 5a ed. Califórnia: Editora Manole; 1996a. Cap. 7, p.83-122: Mecânica da ventilação.

West JB. Fisiologia Respiratória Moderna. 5ª ed. Califórnia: Editora Manole; 1996b. Cap. 10, p.139-52: Testes de função pulmonar como a fisiologia respiratória é aplicada para se medir a função pulmonar.

Westhorpe RN, Ludbrook GL, Helps SC. Crisis management during anaesthesia: bronchospasm. Qual Saf Health Care. 2005;14:e7.

Williams-Russo P, Charlson ME, MacKenzie R, Gold JP, Shires T. Predicting postoperative pulmonary complications. Is it a real problem? Arch Intern Med. 1992;152:1209-13. 
Woerly G, Decot V, Loiseau S, Loyens M, Chihara J, Ono N, Capron M. CD28 and secretory immunoglobulin A-dependent activation of eosinophils: inhibition of mediator release by the anti-allergic drug, suplatast tosilate. Clin Exp Allergy. 2004;34:1379-87.

Wong DH, Weber EC, Schell MJ, Wong AB, Anderson CT, Barker SJ. Factors associated with postoperative pulmonary complications in patients with severe chronic obstructive pulmonary disease. Anesth Analg. 1995;80:276-84.

Wu RSC, Wu KC, Sum DCW, Bishop MJ. Comparative effects of thiopentone and propofol on respiratory resistant after tracheal intubation. $\mathrm{Br} J$ Anaesth. 1996;77:735-8.

Xie QW, Cho HJ, Calaycay J, Mumford RA, Swiderek KM, Lee TD, Ding A, Troso T, Nathan C. Cloning and characterization of inducible nitric oxide synthase from mouse macrophages. Science. 1992;256:225-8.

Zar JH. Biostatistical Analysis. 2 ${ }^{a}$ edição. New Jersey: Prentice-Hall; 1984. Cap.11, p.162-84: Multisample Hypotheses: The analysis of Variance.

Zar JH. Biostatistical Analysis. 2ª edição. New Jersey: Prentice-Hall; 1984. Cap.12, p.185-205: Multiple Comparisons.

Zaugg M, Lucchinetti E. Respiratory function in the elderly. Anesthesiol Clin North America. 2000;18:47-58.

Zitt M. Clinical applications of exhaled nitric oxide for the diagnosis and management of asthma: a consensus report. Clin Ther 2005;27:1238-50. 
APÊNDICE 
Tabela 7. Dados individuais dos pacientes do grupo controle.

\begin{tabular}{|l|c|c|c|c|c|}
\hline $\begin{array}{c}\text { Grupo } \\
\text { Controle }\end{array}$ & Idade & $\begin{array}{c}\text { Neutrófilo } \\
(\%)\end{array}$ & $\begin{array}{c}\text { Eosinófilo } \\
(\%)\end{array}$ & $\begin{array}{c}\text { Macrófago } \\
(\%)\end{array}$ & $\begin{array}{c}\text { Linfócito } \\
(\%)\end{array}$ \\
\hline Contr 13J & 40 & 83,50 & 0,00 & 16,40 & 0,00 \\
Contr 15S & 42 & 51,70 & 0,00 & 48,30 & 0,00 \\
Contr 16R & 41 & 24,40 & 0,00 & 61,00 & 7,30 \\
Contr18MS & 39 & 8,00 & 0,00 & 85,60 & 2,70 \\
Contr 19C & 40 & 68,90 & 0,00 & 30,70 & 0,50 \\
Contr 20C & 41 & 42,30 & 0,00 & 47,80 & 0,00 \\
Contr 21C & 44 & 38,60 & 0,00 & 61,00 & 0,40 \\
Contr 22C & 42 & 1,90 & 0,00 & 97,70 & 0,50 \\
Contr 23C & 51 & 35,00 & 0,00 & 65,00 & 0,00 \\
Contr 24C & 39 & 57,00 & 0,00 & 33,20 & 0,00 \\
\hline
\end{tabular}

Tabela 8. Dados individuais dos pacientes do grupo broncoespasmo.

\begin{tabular}{|l|c|c|c|c|c|}
\hline $\begin{array}{c}\text { Grupo } \\
\text { Broncoespasmo }\end{array}$ & Idade & $\begin{array}{c}\text { Neutrófilo } \\
(\%)\end{array}$ & $\begin{array}{c}\text { Eosinófilo } \\
(\%)\end{array}$ & $\begin{array}{c}\text { Macrófago } \\
(\%)\end{array}$ & $\begin{array}{c}\text { Linfócito } \\
(\%)\end{array}$ \\
\hline Caso 3A & 60 & 72,20 & 1,22 & 24,90 & 1,37 \\
Caso 5M & 35 & 10,16 & 0,55 & 86,26 & 3,02 \\
Caso 6C & 52 & 62,89 & 0,00 & 37,11 & 0,00 \\
Caso 9 & 39 & 65,80 & 0,50 & 20,20 & 1,30 \\
Caso 25z & 54 & 63,30 & 0,00 & 25,10 & 0,00 \\
Caso 34JC & 31 & 8,60 & 1,40 & 86,40 & 3,60 \\
Caso 36DS & 28 & 25,80 & 0,00 & 74,10 & 0,10 \\
Caso 37RM & 19 & 40,00 & 12,00 & 47,20 & 0,70 \\
Caso 38AT & 17 & 55,20 & 1,20 & 38,20 & 5,00 \\
\hline
\end{tabular}

Tabela 9. Dados individuais dos pacientes do grupo asma.

\begin{tabular}{|l|c|c|c|c|c|}
\hline Grupo Asma & Idade & $\begin{array}{c}\text { Neutrófilo } \\
(\%)\end{array}$ & $\begin{array}{c}\text { Eosinófilo } \\
(\%)\end{array}$ & $\begin{array}{c}\text { Macrófago } \\
(\%)\end{array}$ & $\begin{array}{c}\text { Linfócito } \\
(\%)\end{array}$ \\
\hline Caso 1A & 25 & 60,30 & 0,00 & 38,39 & 0,87 \\
Caso 2I & 46 & 52,00 & 0,20 & 41,13 & 6,14 \\
Caso 4C & 30 & 22,45 & 2,62 & 73,75 & 0,00 \\
Caso 7A & 25 & 67,27 & 7,86 & 23,17 & 0,42 \\
Caso 8K & 23 & 9,88 & 84,94 & 5,18 & 0,00 \\
Caso 11S & 30 & 27,67 & 10,91 & 55,35 & 0,00 \\
Caso 26M & 43 & 21,50 & 2,80 & 67,80 & 1,00 \\
Caso 28A & 19 & 85,20 & 2,30 & 12,50 & 0,00 \\
Caso 29M & 20 & 98,00 & 0,00 & 1,30 & 0,80 \\
Caso 30M & 28 & 78,90 & 1,70 & 18,80 & 0,70 \\
Caso 31L & 22 & 77,30 & 5,80 & 16,60 & 0,30 \\
Caso 32C & 53 & 75,40 & 0,70 & 23,90 & 0,00 \\
\hline
\end{tabular}


Tabela 10. Dados individuais dos pacientes do grupo controle.

\begin{tabular}{|l|c|c|c|}
\hline $\begin{array}{c}\text { Grupo } \\
\text { Controle }\end{array}$ & $\begin{array}{c}\text { Contagem Total } \\
\text { Cel/mL10 }\end{array}$ & $\begin{array}{c}\text { IGE } \\
(\mathrm{UI} / \mathrm{mL})\end{array}$ & $\begin{array}{c}\text { NO } \\
(\mathrm{ppb})\end{array}$ \\
\hline Contr 13J & 0,40 & 41,00 & 24,70 \\
Contr 15S & 1,32 & 41,00 & 16,60 \\
Contr 16R & 0,22 & 25,00 & 12,00 \\
Contr18MS & 0,36 & 30,00 & 23,60 \\
Contr 19C & 3,93 & 9,00 & 25,00 \\
Contr 20C & 0,90 & 9,00 & 13,80 \\
Contr 21C & 0,26 & 61,00 & 20,50 \\
Contr 22C & 0,01 & 14,00 & 16,90 \\
Contr 23C & 0,37 & 92,00 & 16,00 \\
Contr 24C & 0,26 & 78,00 & 26,40 \\
\hline
\end{tabular}

Tabela 11. Dados individuais dos pacientes do grupo broncoespasmo.

\begin{tabular}{|l|c|c|c|}
\hline $\begin{array}{c}\text { Grupo } \\
\text { Boncoespasmo }\end{array}$ & $\begin{array}{c}\text { Contagem Total } \\
\text { Cel/mL10 }\end{array}$ & $\begin{array}{c}\text { IGE } \\
(\mathrm{UI} / \mathrm{mL})\end{array}$ & $\begin{array}{c}\mathrm{NO} \\
(\mathrm{ppb})\end{array}$ \\
\hline Caso 3A & 5,60 & 77,40 & 66,20 \\
Caso 5M & 2,16 & 37,70 & 91,40 \\
Caso 6C & 1,30 & 110,00 & 49,60 \\
Caso 9 & 3,80 & 226,00 & 61,40 \\
Caso 25z & 0,16 & 109,00 & 46,20 \\
Caso 34JC & 0,24 & 21,00 & 43,90 \\
Caso 36DS & 1,01 & 233,00 & 37,20 \\
Caso 37RM & 0,21 & 2950,00 & 43,50 \\
Caso 38AT & 2,21 & 883,00 & 37,40 \\
\hline
\end{tabular}

Tabela 12. Dados individuais dos pacientes do grupo asma.

\begin{tabular}{|l|c|c|c|}
\hline Grupo Asma & $\begin{array}{c}\text { Contagem Total } \\
\text { Cel/mL106 }\end{array}$ & $\begin{array}{c}\text { IGE } \\
(\mathrm{UI} / \mathrm{mL})\end{array}$ & $\begin{array}{c}\mathrm{NO} \\
(\mathrm{ppb})\end{array}$ \\
\hline Caso 1A & 0,48 & 2770,00 & 84,00 \\
Caso 2I & 3,15 & 994,00 & 65,70 \\
Caso 4C & 2,70 & 97,40 & 83,60 \\
Caso 7A & 2,20 & - & 79,50 \\
Caso 8K & 1,80 & 1220,00 & 118,20 \\
Caso 11S & 1,30 & 706,00 & 159,00 \\
Caso 26M & 0,26 & 262,00 & 44,10 \\
Caso 28A & 0,68 & 1500,00 & 89,70 \\
Caso 29M & 0,92 & - & 51,00 \\
Caso 30M & 0,85 & 55,00 & 49,60 \\
Caso 31L & 1,24 & 193,00 & 83,90 \\
Caso 32C & 0,54 & 340,00 & 64,20 \\
\hline
\end{tabular}


Tabela 13. Dados individuais dos pacientes do grupo controle.

\begin{tabular}{|c|c|c|c|c|c|c|}
\hline $\begin{array}{c}\text { Grupo } \\
\text { Controle }\end{array}$ & $\begin{array}{l}\text { Prick } \\
\text { teste } \\
\text { Fungo }\end{array}$ & $\begin{array}{l}\text { Prick } \\
\text { teste } \\
\text { Polén }\end{array}$ & $\begin{array}{l}\text { Prick } \\
\text { teste } \\
\text { Ácaro }\end{array}$ & $\begin{array}{l}\text { Prick } \\
\text { teste } \\
\text { Gato }\end{array}$ & $\begin{array}{c}\text { Prick } \\
\text { teste } \\
\text { Cachorro }\end{array}$ & $\begin{array}{l}\text { Prick } \\
\text { teste } \\
\text { Barata }\end{array}$ \\
\hline Contr 13J & Negativo & Negativo & Negativo & Negativo & Negativo & Positivo \\
\hline Contr $15 S$ & Positivo & Negativo & Positivo & Negativo & Negativo & Positivo \\
\hline Contr 16R & Negativo & Negativo & Negativo & Negativo & Negativo & Negativo \\
\hline Contr18MS & Negativo & Negativo & Positivo & Positivo & Positivo & Positivo \\
\hline Contr 19C & Negativo & Negativo & Negativo & Negativo & Negativo & Negativo \\
\hline Contr 20C & Negativo & Negativo & Negativo & Negativo & Negativo & Negativo \\
\hline Contr $21 \mathrm{C}$ & Negativo & Positivo & Positivo & Negativo & Negativo & Positivo \\
\hline Contr 22C & - & 侟 & - & - & - & - \\
\hline & Negativo & Positivo & Positivo & Positivo & Positivo & Positivo \\
\hline Contr 24C & Negativo & Negativo & Negativo & Negativo & Negativo & Negativo \\
\hline
\end{tabular}

Tabela 14. Dados individuais dos pacientes do grupo broncoespasmo.

\begin{tabular}{|l|l|l|l|l|l|l|}
\hline \multicolumn{1}{|c|}{$\begin{array}{c}\text { Grupo } \\
\text { Broncoespamo }\end{array}$} & $\begin{array}{c}\text { Prick } \\
\text { teste } \\
\text { Fungo }\end{array}$ & $\begin{array}{c}\text { Prick } \\
\text { teste } \\
\text { Polén }\end{array}$ & $\begin{array}{c}\text { Prick } \\
\text { teste } \\
\text { Ácaro }\end{array}$ & $\begin{array}{c}\text { Prick } \\
\text { teste } \\
\text { Gato }\end{array}$ & $\begin{array}{c}\text { Prick } \\
\text { teste } \\
\text { Cachorro }\end{array}$ & $\begin{array}{c}\text { Prick } \\
\text { teste } \\
\text { Barata }\end{array}$ \\
\hline Caso 3A & Negativo & Negativo & Negativo & Negativo & Negativo & Negativo \\
Caso 5M & Negativo & Negativo & Positivo & Positivo & Negativo & Negativo \\
Caso 6C & Negativo & Negativo & Positivo & Negativo & Negativo & Negativo \\
Caso 9 & Negativo & Negativo & Negativo & Negativo & Negativo & Negativo \\
Caso 25z & Positivo & Positivo & Positivo & Positivo & Positivo & Positivo \\
Caso 34JC & Negativo & Negativo & Positivo & Negativo & Negativo & Negativo \\
Caso 36DS & Negativo & Negativo & Positivo & Negativo & Negativo & Negativo \\
Caso 37RM & Negativo & Negativo & Positivo & Negativo & Negativo & Negativo \\
Caso 38AT & Negativo & Negativo & Negativo & Negativo & Negativo & Negativo \\
\hline
\end{tabular}

Tabela 15. Dados individuais dos pacientes do grupo asma.

\begin{tabular}{|c|c|c|c|c|c|c|}
\hline $\begin{array}{l}\text { Grupo } \\
\text { Asma }\end{array}$ & $\begin{array}{c}\text { Prick } \\
\text { teste } \\
\text { Fungo }\end{array}$ & $\begin{array}{l}\text { Prick } \\
\text { teste } \\
\text { Polén }\end{array}$ & $\begin{array}{l}\text { Prick } \\
\text { teste } \\
\text { Ácaro }\end{array}$ & $\begin{array}{l}\text { Prick } \\
\text { teste } \\
\text { Gato }\end{array}$ & $\begin{array}{c}\text { Prick } \\
\text { teste } \\
\text { Cachorro }\end{array}$ & $\begin{array}{c}\text { Prick } \\
\text { teste } \\
\text { Barata }\end{array}$ \\
\hline Caso 1A & Neqativo & Neqativo & Positivo & Neqativo & Positivo & Neqativo \\
\hline Caso 21 & Positivo & Positivo & Positivo & Positivo & Neqativo & Positivo \\
\hline Caso 4C & Negativo & Neqativo & Neqativo & Neqativo & Neqativo & Positivo \\
\hline Caso $7 \mathrm{~A}$ & Negativo & Neqativo & Positivo & Neqativo & Neqativo & Negativo \\
\hline Caso 8K & Negativo & Neqativo & Positivo & Neqativo & Neqativo & Negativo \\
\hline Caso $11 \mathrm{~S}$ & Negativo & Negativo & Positivo & Negativo & Negativo & Positivo \\
\hline Caso $26 \mathrm{M}$ & Positivo & Positivo & Negativo & Negativo & Positivo & Positivo \\
\hline Caso 28A & Positivo & Positivo & Positivo & Positivo & Positivo & Negativo \\
\hline Caso 29M & Negativo & Negativo & Positivo & Negativo & Negativo & Negativo \\
\hline Caso 30M & Negativo & Negativo & Positivo & Negativo & Negativo & Negativo \\
\hline Caso 31L & Negativo & Negativo & Positivo & Negativo & Negativo & Negativo \\
\hline Caso 32C & Negativo & Negativo & Positivo & Negativo & Negativo & Negativo \\
\hline
\end{tabular}


Tabela 16. Dados individuais dos pacientes do grupo controle.

\begin{tabular}{|l|c|c|c|c|}
\hline $\begin{array}{c}\text { Grupo } \\
\text { Controle }\end{array}$ & $\begin{array}{c}\text { CVF pré } \\
(\%)\end{array}$ & $\begin{array}{c}\text { CVF pós } \\
(\%)\end{array}$ & $\begin{array}{c}\text { VEF }_{1} \text { pré } \\
(\%)\end{array}$ & $\begin{array}{c}\text { VEF }_{1} \text { pós } \\
(\%)\end{array}$ \\
\hline Contr 13J & 108,00 & 103,00 & 110,00 & 111,00 \\
Contr 15S & 120,00 & 115,00 & 112,00 & 114,00 \\
Contr 16R & 88,00 & 84,00 & 91,00 & 85,00 \\
Contr18MS & 93,00 & 100,00 & 98,00 & 106,00 \\
Contr 19C & 103,00 & 97,00 & 116,00 & 107,00 \\
Contr 20C & 123,00 & 121,00 & 125,00 & 123,00 \\
Contr 21C & 133,00 & 128,00 & 128,00 & 131,00 \\
Contr 22C & 103,00 & 100,00 & 97,00 & 100,00 \\
Contr 23C & 109,00 & 111,00 & 107,00 & 109,00 \\
Contr 24C & 99,00 & 100,00 & 104,00 & 107,00 \\
\hline
\end{tabular}

Tabela 17. Dados individuais dos pacientes do grupo broncoespasmo.

\begin{tabular}{|l|c|c|c|c|}
\hline $\begin{array}{c}\text { Grupo } \\
\text { Broncoespasmo }\end{array}$ & $\begin{array}{c}\text { CVF pré } \\
(\%)\end{array}$ & $\begin{array}{c}\text { CVF pós } \\
(\%)\end{array}$ & $\begin{array}{c}\text { VEF }_{1} \text { pré } \\
(\%)\end{array}$ & $\begin{array}{c}\text { VEF }_{1} \text { pós } \\
(\%)\end{array}$ \\
\hline Caso 3A & 93,00 & 89,00 & 102,00 & 97,00 \\
Caso 5M & 93,00 & 99,00 & 90,00 & 101,00 \\
Caso 6C & 105,00 & 110,00 & 111,00 & 115,00 \\
CASO 9 & 93,00 & 94,00 & 97,00 & 97,00 \\
CASO 25z & 100,00 & 97,00 & 102,00 & 104,00 \\
Caso 34JC & 104,00 & 105,00 & 108,00 & 111,00 \\
Caso 36DS & 104,00 & 104,00 & 101,00 & 106,00 \\
Caso 37RM & 89,00 & 86,00 & 79,00 & 88,00 \\
Caso 38AT & 108,00 & 104,00 & 105,00 & 110,00 \\
\hline
\end{tabular}

Tabela 18. Dados individuais dos pacientes do grupo asma.

\begin{tabular}{|l|c|c|c|c|}
\hline $\begin{array}{r}\text { Grupo } \\
\text { Asma }\end{array}$ & $\begin{array}{c}\text { CVF pré } \\
(\%)\end{array}$ & $\begin{array}{c}\text { CVF pós } \\
(\%)\end{array}$ & $\begin{array}{c}\text { VEF }_{1} \text { pré } \\
(\%)\end{array}$ & $\begin{array}{c}\text { VEF }_{1} \text { pós } \\
(\%)\end{array}$ \\
\hline Caso 1A & 65,00 & 74,00 & 59,00 & 70,00 \\
Caso 2I & 65,00 & 71,00 & 64,00 & 71,00 \\
Caso 4C & 111,00 & 116,00 & 70,00 & 75,00 \\
Caso 7A & 106,00 & 110,00 & 98,00 & 106,00 \\
Caso 8K & 93,00 & 99,00 & 80,00 & 80,00 \\
Caso 11S & 89,00 & 87,00 & 82,00 & 90,00 \\
Caso 26M & 100,00 & 104,00 & 100,00 & 106,00 \\
Caso 28A & 69,00 & 73,00 & 60,00 & 73,00 \\
Caso 29M & 94,00 & 92,00 & 76,00 & 74,00 \\
Caso 30M & 120,00 & 121,00 & 104,00 & 116,00 \\
Caso 31L & 93,00 & 98,00 & 104,00 & 108,00 \\
Caso 32C & 130,00 & 130,00 & 109,00 & 123,00 \\
\hline
\end{tabular}


Tabela 19. Dados individuais dos pacientes do grupo controle.

\begin{tabular}{|l|c|c|c|c|}
\hline $\begin{array}{c}\text { Grupo } \\
\text { Controle }\end{array}$ & $\begin{array}{c}\text { FEF 25-75\% } \\
\text { pré (\%) }\end{array}$ & $\begin{array}{c}\text { FEF 25-75\% } \\
\text { pós }(\%)\end{array}$ & $\begin{array}{c}\mathrm{VEF}_{1} / \mathrm{CVF} \\
\text { pré }(\%)\end{array}$ & $\begin{array}{c}\mathrm{VEF}_{1} / \mathrm{CVF} \\
\text { pós }(\%)\end{array}$ \\
\hline Contr 13J & 90,00 & 114,00 & 103,00 & 107,00 \\
Contr 15S & 86,00 & 103,00 & 94,00 & 99,00 \\
Contr 16R & 91,00 & 82,00 & 104,00 & 100,00 \\
Contr18MS & 92,00 & 103,00 & 106,00 & 106,00 \\
Contr 19C & 157,00 & 135,00 & 113,00 & 111,00 \\
Contr 20C & 122,00 & 125,00 & 101,00 & 101,00 \\
Contr 21C & 104,00 & 137,00 & 97,00 & 103,00 \\
Contr 22C & 75,00 & 85,00 & 93,00 & 99,00 \\
Contr 23C & 94,00 & 98,00 & 98,00 & 98,00 \\
Contr 24C & 129,00 & 143,00 & 105,00 & 108,00 \\
\hline
\end{tabular}

Tabela 20. Dados individuais dos pacientes do grupo broncoespasmo.

\begin{tabular}{|l|c|c|c|c|}
\hline $\begin{array}{c}\text { Grupo } \\
\text { Broncoespasmo }\end{array}$ & $\begin{array}{c}\text { FEF 25-75\% } \\
\text { pré (\%) }\end{array}$ & $\begin{array}{c}\text { FEF 25-75\% } \\
\text { pós }(\%)\end{array}$ & $\begin{array}{c}\mathrm{VEF}_{1} / \mathrm{CVF} \\
\text { pré }(\%)\end{array}$ & $\begin{array}{c}\mathrm{VEF}_{1} / \mathrm{CVF} \\
\text { pós }(\%)\end{array}$ \\
\hline Caso 3A & 69,00 & 67,00 & 110,00 & 110,00 \\
Caso 5M & 65,00 & 84,00 & 97,00 & 102,00 \\
Caso 6C & 118,00 & 113,00 & 106,00 & 104,00 \\
Caso 9 & 96,00 & 94,00 & 105,00 & 102,00 \\
Caso 25z & 105,00 & 129,00 & 102,00 & 108,00 \\
Caso 34JC & 135,00 & 143,00 & 104,00 & 105,00 \\
Caso 36DS & 81,00 & 102,00 & 97,00 & 102,00 \\
Caso 37RM & 64,00 & 89,00 & 90,00 & 102,00 \\
Caso 38AT & 129,00 & 150,00 & 106,00 & 114,00 \\
\hline
\end{tabular}

Tabela 21. Dados individuais dos pacientes do grupo asma.

\begin{tabular}{|l|c|c|c|c|}
\hline $\begin{array}{c}\text { Grupo } \\
\text { Asma }\end{array}$ & $\begin{array}{c}\text { FEF 25-75\% } \\
\text { pré }(\%)\end{array}$ & $\begin{array}{c}\text { FEF 25-75\% } \\
\text { pós }(\%)\end{array}$ & $\begin{array}{c}\mathrm{VEF}_{1} / \mathrm{CVF} \\
\text { pré }(\%)\end{array}$ & $\begin{array}{c}\mathrm{VEF}_{1} / \mathrm{CVF} \\
\text { pós }(\%)\end{array}$ \\
\hline Caso 1A & 52,00 & 69,00 & 91,00 & 97,00 \\
Caso 2I & 51,00 & 59,00 & 97,00 & 100,00 \\
Caso 4C & 27,00 & 31,00 & 63,00 & 65,00 \\
Caso 7A & 86,00 & 96,00 & 92,00 & 96,00 \\
Caso 8K & 47,00 & 37,00 & 85,00 & 81,00 \\
Caso 11S & 56,00 & 75,00 & 91,00 & 104,00 \\
Caso 26M & 90,00 & 103,00 & 100,00 & 102,00 \\
Caso 28A & 48,00 & 71,00 & 88,00 & 100,00 \\
Caso 29M & 43,00 & 40,00 & 80,00 & 80,00 \\
Caso 30M & 63,00 & 90,00 & 86,00 & 97,00 \\
Caso 31L & 118,00 & 136,00 & 111,00 & 110,00 \\
Caso 32C & 61,00 & 87,00 & 84,00 & 94,00 \\
\hline
\end{tabular}

